

\section{DISCLAIMER}

This report was prepared as an account of work sponsored by an agency of the United States Government. Neither the United States Government nor any agency Thereof, nor any of their employees, makes any warranty, express or implied, or assumes any legal liability or responsibility for the accuracy, completeness, or usefulness of any information, apparatus, product, or process disclosed, or represents that its use would not infringe privately owned rights. Reference herein to any specific commercial product, process, or service by trade name, trademark, manufacturer, or otherwise does not necessarily constitute or imply its endorsement, recommendation, or favoring by the United States Government or any agency thereof. The views and opinions of authors expressed herein do not necessarily state or reflect those of the United States Government or any agency thereof. 


\section{DISCLAIMER}

Portions of this document may be illegible in electronic image products. Images are produced from the best available original document. 


\section{NOTICE}

This report is published in the interest of providing information which may prove of value to the reader in his study of effects data derived principally from nuclear weapons tests.

This document is based on information available at the time of preparation which may have subsequently been expanded and re-evaluated. Also, in preparing this report for publication, some classified material may have been removed. Users are cautioned to a void interpretations and conclusions based on unknown or incomplete data.

PRINTED IN USA

Price $\$ 1.50$. Available from the Office of Technical Services, Department of Commerce, Washington 25, D. C. 
Report to the Test Director

\title{
MISSILE STUDIES WITH A BIOLOGICAL TARGET
}

\author{
By \\ V. C. Goldizen, D. R. Richmond, T. L. Chiffelle, \\ I. G. Bowen, and C. S. White
}
Approved by: CLAYTON S. WHITE
Director
Program 33

Approved by: R. L. CORSBIE

Director

Civil Effects Test Group

Lovelace Foundation for Medical

Education and Research

Albuquerque, New Mexico

April 1960 


\begin{abstract}
Fourteen dogs were exposed on the lee side of planted gravel, of a concrete-block wall, and of glass mounted in the open and in houses to the environmental variations associated with full-scale nuclear detonations. Aluminum foil was used to protect the animals from thermal effects. The missile environment was monitored through the use of quantitative missiletrapping techniques. Pressure-time variations in the environment were also recorded. Biologic damage from overpressure and missiles was determined, and the associations between physical environmental factors and biologic response were noted and analyzed. The feasibility of utilizing missile data, along with other available information from the literature, as a means of quantitatively assessing biologic hazard was established by the close correspondence between observed and predicted dangerous wounds. This test provided full-scale validation of procedures and experiments worked out chiefly in the laboratory.
\end{abstract}




\section{ACKNOWLEDGMENTS}

The authors wish to acknowledge the support, encouragement, and aid of the following individuals:

R. L. Corsbie, Director, Civil Effects Test Group, U. S. Atomic Energy Commission

Lt. Col. G. M. McDonnel, Medical Corps, U. S. Army, Department of Defense

Capt. H. A. Claypool, Medical Corps, U. S. Army, Department of Defense

Dr. F. G. Hirsch, Lovelace Foundation for Medical Education and Research

Marian C. Fox, Office of Technical Information Extension, U. S. Atomic Energy

Commission

Appreciation is expressed to the following members of the Staff of the Lovelace Foundation:

R. V. Taborelli for technical assistance and aid with the field installations

R. A. Smith, G. S. Bevil, and R. A. MacMahon for photographic work in the field and preparation of the illustrative material; they were aided after the shot by Edward M. Johnsen and Roy D. Caton

R. W. Albright, E. R. Fletcher, M. A. Osoff, and J. Kleinfeld for analysis of the missile-trap data and statistical aid

M. Loretta Kuhn for assistance in the Pathology Laboratory

V. R. Clare for help with postshot examination of the animals

J. D. Ward, R. T. Sanchez, and M. B. Wetherbe for handling biologic materials and for their support with field activities

Isabell D. Benton, Roberta H. Schlies, Martina B. Smith, and Janet A. Nelson for editorial and secretarial contributions

Gratitude is also expressed for financial aid to the Division of Biology and Medicine of the U. S. Atomic Energy Commission and to the Office of Civil Defense and Mobilization (formerly the Federal Civil Defense Administration). 


\section{CONTENTS}

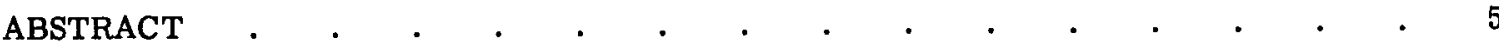

ACKNOWLEDGMENTS $•$ •

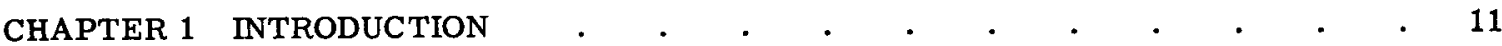

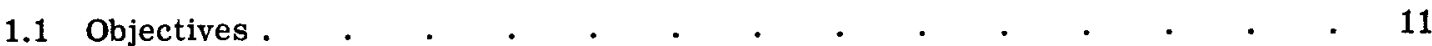

1.2 Background . . . . . . . . . . . . . . . . 11

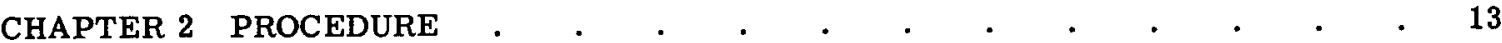

2.1 Techniques 13

2.1.1 Preshot Activities . . . . . . . . . . . . . 13

2.1.2 Recovery . . . . . . . . . . . . . . . 14

2.1.3 Pathological Examination . . . . . . . . . . . . . . 14

2.2 Instrumentation. $. \quad . \quad . \quad . \quad . \quad . \quad . \quad . \quad . \quad . \quad . \quad .15$

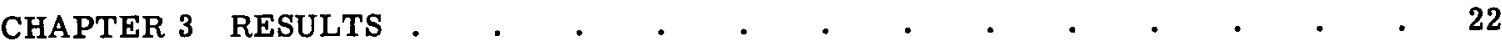

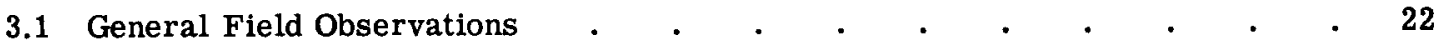

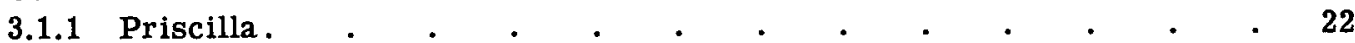

3.1 .2 Galileo . . . . . . . . . . . . . . 22

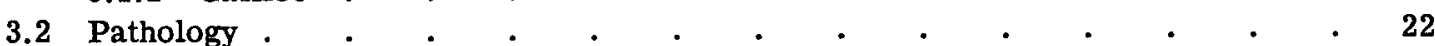

3.2 .1 Priscilla. $. \quad . \quad . \quad . \quad . \quad . \quad . \quad . \quad . \quad . \quad . \quad . \quad 22$

3.2.2 Galileo . . . . . . . . . 23

3.3 Physical Data (Priscilla and Galileo) . . . . . . . . . . . 23

3.3.1 Missile Data . • • • . . . . . . . . 23

3.3.2 Blast Data . . . . . . . . . . . . . . . . 24

3.3.3 Estimation of Presented Area of Biologic Target . . . . . 25

CHAPTER 4 RELATION OF ENVIRONMENTAL DATA TO BIOLOGICAL

DAMAGE • • • • • • • • • • • • • • 37

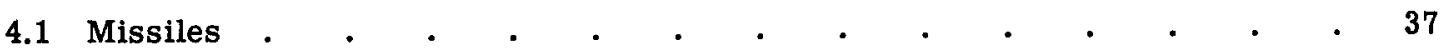

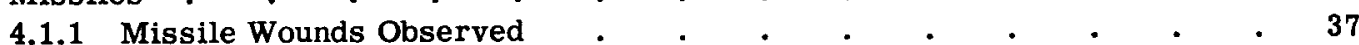

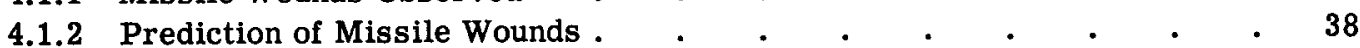

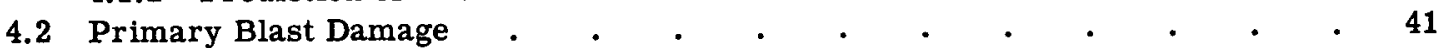

CHAPTER 5 DISCUSSION $\quad$ • $\quad$ •

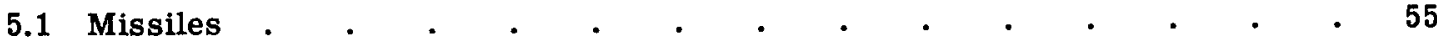

5.2 Biological Factors . $. \quad . \quad . \quad . \quad . \quad . \quad . \quad . \quad . \quad . \quad . \quad 58$

5.2.1 Secondary Blast Effects (Missiles) . . . . . . . . . . 58

5.2.2 Primary Blast Effects (Pressure) . $\quad . \quad$. $\quad . \quad . \quad . \quad . \quad 59$

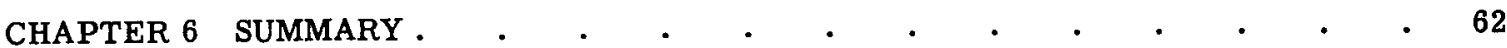




\section{ILLUSTRATIONS}

\section{CHAPTER 2 PROCEDURE}

2.1 Harnessed Dog in Trap with Styrofoam Backing. . . . . . . . . $\quad$ - 16

2.2 Dog in Trap Beneath Styrofoam Missile-Absorbing Trap . . . . . . $\quad$. 16

2.3 Aluminum-Foil Thermal Protector in Front of Animal Trap . . . . . $\quad$. 17

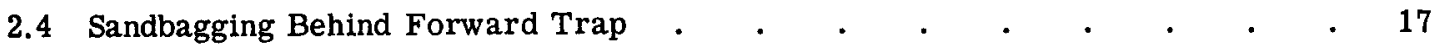

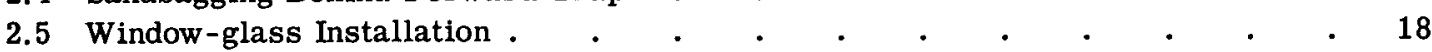

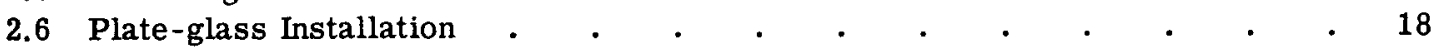

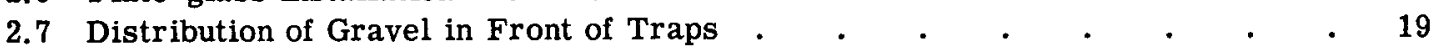

2.8 Over-all View of Typical Trap Line . $\quad . \quad$. $\quad . \quad$. . . . . . . . $\quad . \quad 19$

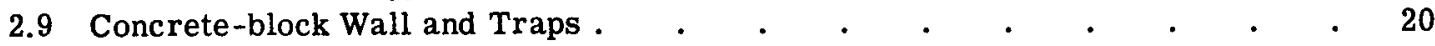

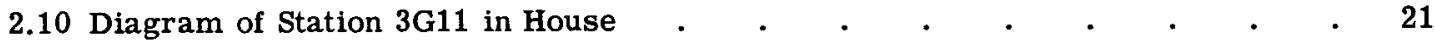

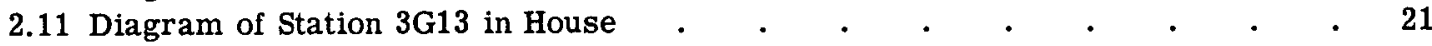

\section{CHAPTER 3 RESULTS}

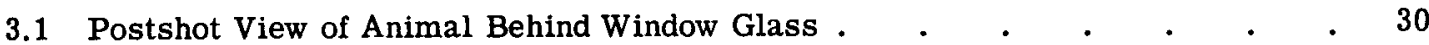

3.2 Same Trap as Fig. 3.1, Showing Missiles Embedded Around

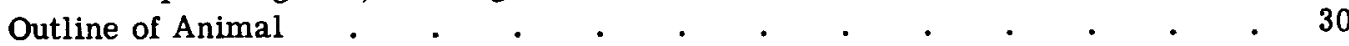

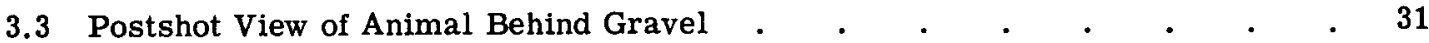

3.4 Postshot View of Animal Behind Concrete-block Wall $\quad$. $\quad$. . . . . $\quad$ - 31

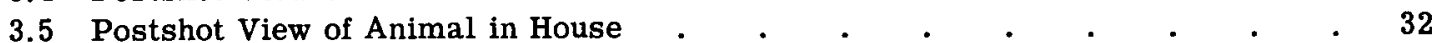

3.6 Postshot View of Station Noted in Fig. 3.5, Showing Marking of Walls and

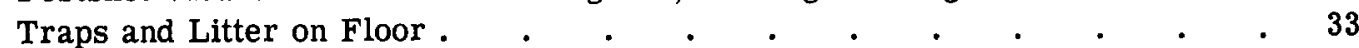

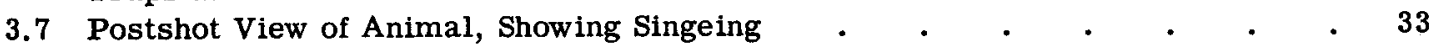

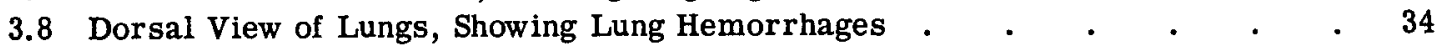

3.9 Dorsal View of Lungs, Showing Multiple Areas of Hemorrhages _ . $\quad$ - $\quad 35$

3.10 Ventral View of Lungs, Showing Multiple Areas of Hemorrhages $\quad$ • $\quad$ • $\quad$ - 36

CHAPTER 4 RELATION OF ENVIRONMENTAL.DATA TO BIOLOGICAL DAMAGE

4.1 Total Wounds Observed as a Function of Nevada Incident Overpressure

4.2 Wounds Observed Per Square Foot of Biologic Target as a Function of Nevada Incident Overpressure

4.3 Wounds Observed Per Square Foot of Biologic Target as a Function of Sea-level-equivalent Incident Overpressure

4.4 Serious Wounds Observed Per Square Foot of Biologic Target as a Function of Sea-level-equivalent Incident Overpressure . .

4.5 Distribution of Glass Missiles for Priscilla and Galileo Explosions Grouped According to Log Mass and Log Velocity as These Relate to Probabilities of Penetrating the Abdominal Wall of Dogs . . .

4.6 Predicted Peritoneal Wounds Per Square Foot of Biologic Target as a

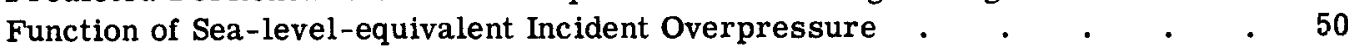

4.7 Comparison of Regression Curves for Observed Serious Wounds and Predicted Peritoneal Wounds

4.8 Total Observed Glass Missiles Per Square Foot of Missile Trap as a Function of Sea-level-equivalent Incident Overpressure •

4.9 Comparison of Regression Curves for Total Missiles Recorded and
Total Observed Wounds

4.10 Predicted Intraperitoneal Wounds Using Series B Missile Data as a

Function of Sea-level-equivalent Incident Overpressure $\cdot$.
4.11 Comparison of Regression Curves for Serious Wounds Observed and Intraperitoneal Wounds Predicted Using Series A and B Missile Data

4.12 Total Observed Incident Glass Missiles for the Series B Missile Data as a Function of Sea-level-equivalent Incident Overpressure 


\section{ILLUSTRATIONS (Continued)}

4.13 Comparison of Regression Curves for Total Wounds Observed and

Total Series A and B Missiles Recorded.

4.14 Comparison of Geometric Mean Velocities and Missiles for Series $A$ and $B$ Missile Data as a Function of Sea-level-equivalent Incident Overpressure

\section{TABLES}

\section{CHAPTER 2 PROCEDURE}

2.1 Placement of Animals

\section{CHAPTER 3 RESULTS}

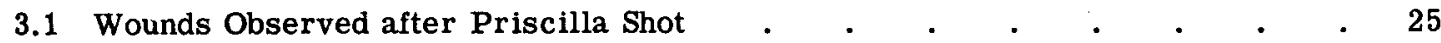

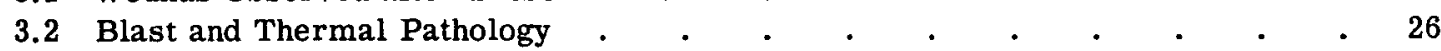

3.3 Wounds Observed after Galileo Shot •

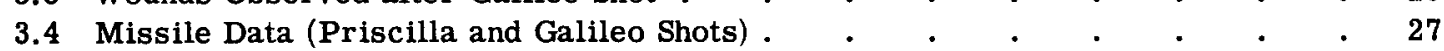

3.5 Glass Missile Data from Traps above Animals (Project 33.4) Compared with Those from Traps Placed at Animal Level (Selected from

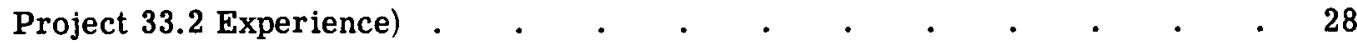

3.6 Blast Data at Animal Stations (Priscilla and Galileo Shots) _ . . . $\quad$ - 29

3.7 Estimated Areas of Animals Presented as Missile Targets $\quad$ • $\quad$ • $\quad$ • $\quad$ - 29

\section{CHAPTER 4 RELATION OF ENVIRONMENTAL DATA TO BIOLOGICAL DAMAGE}

4.1 Observed Total and Serious Wounds and the Total and Serious Wounds

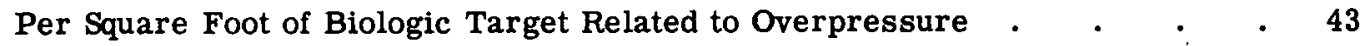

4.2 Prediction of Intraperitoneal Wounds from Observed Missile Data as

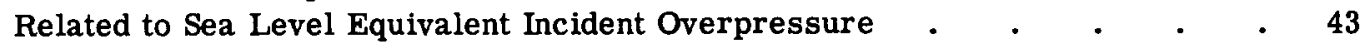

4.3 Observed Serious Wounds and Predicted Intraperitoneal Wounds per Animal

4.4 Comparison of Observed Serious Wounds with Predicted Intraperitoneal Wounds Grouped for the Lower and Higher Overpressures

4.5 Observed Serious and Predicted Intraperitoneal Wounds Using WindowGlass Missile Data Taken from Missile Traps Located at or Very

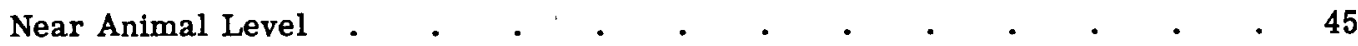

4.6 Summary of Total and Average Data for Observed Total and Serious

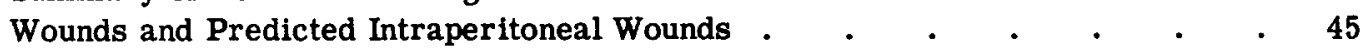

4.7 Comparison of Predicted Intraperitoneal Wounds using Data from Missile Traps Located Above and at the Same Levels as the Animal Targets

4.8 Comparison of Average Geometric Mean Velocities and Masses for the Series A and B Missile Data as a Function of Incident Sea-levelequivalent Overpressure

4.9 Primary Blast Damage (Priscilla and Galileo Shots). 


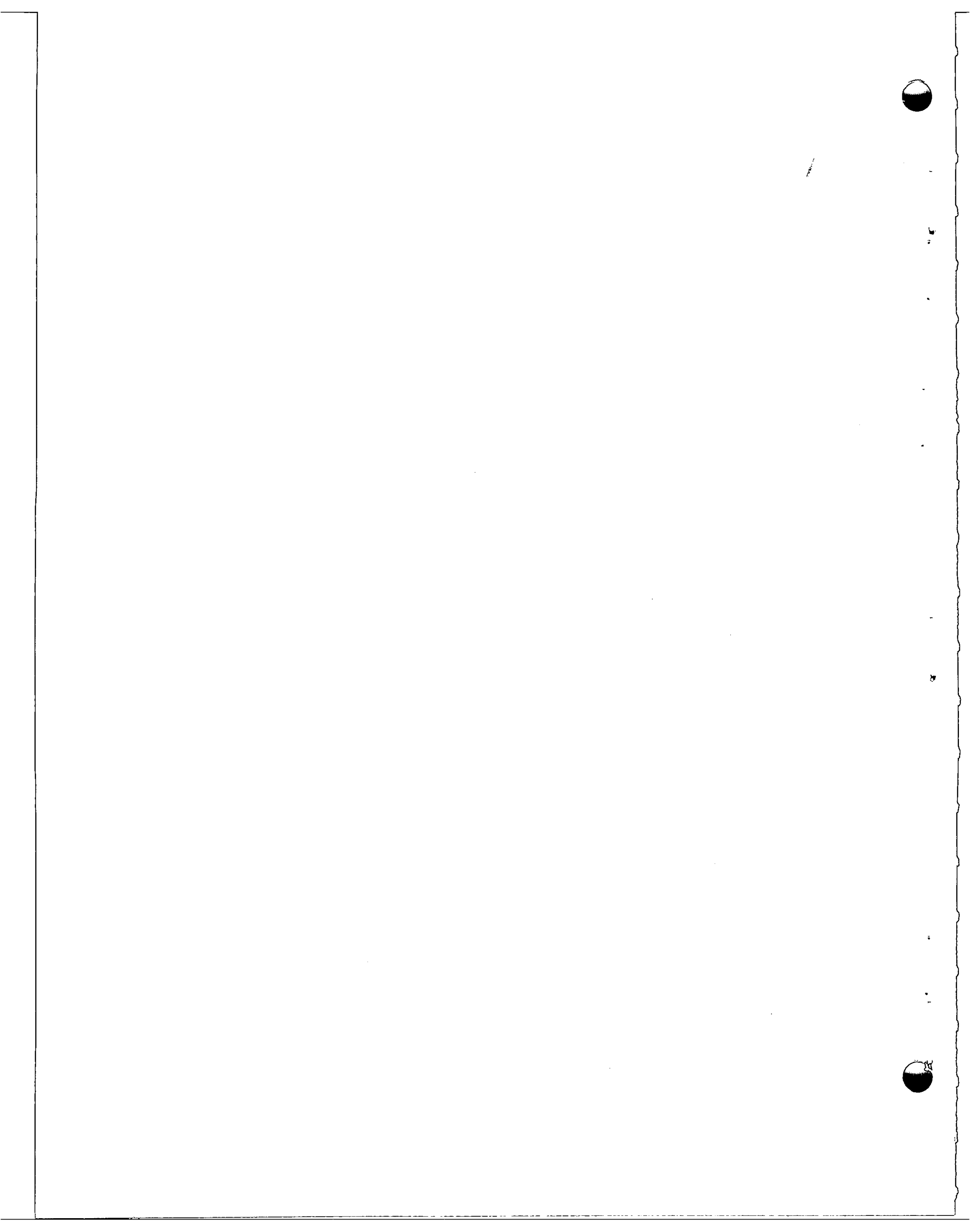




\section{Chapter 1}

\section{INTRODUCTION}

\subsection{OBJECTIVES}

The primary objective of this project was twofold. The first objective was to observe and study the biological damage sustained by dogs exposed to missiles generated by a full-scale nuclear blast in the overpressure regions from approximately 3 to $8 \mathrm{psi}$. Missiles of the following types were studied: (a) glass-fragment missiles occurring in houses and behind window panes mounted in open areas, (b) stone missiles in open areas, and (c) missiles arising from the destruction of a concrete-block wall. The second objective was to explore the feasibility of predicting hazardous conditions by relating biological information to environmental data determined by quantitative missile-trapping techniques.

A secondary objective was to determine biological damage caused by overpressure per se.

\subsection{BACKGROUND}

Experience derived from large-scale explosions, such as the ones that occurred at Texas City, Texas, ${ }^{1,2}$ and Hiroshima and Nagasaki, Japan, ${ }^{3,4}$ has shown that one of the major hazards from an explosion is debris set in motion by the blast wave. The number of casualties attributable to flying debris in the latter two cases has been somewhat obscured by the more dramatic effects of thermal and ionizing radiations which attracted most of the attention of the early investigators. However, 70 per cent of the Japanese survivors exhibited mechanical injuries. At Hiroshima 35 per cent of the injuries were lacerations and 54 per cent were contusions. ${ }^{5}$

During Operation Teapot in 1955 at the Nevada Test Site, a study was made to determine the physical parameters involved in the generation of missiles by nuclear blast. ${ }^{6}$ Later a preliminary attempt ${ }^{7}$ was made to evaluate the biological damage that could have been caused by the glass-fragment missiles whose velocities and masses were determined in the Operation Teapot field study. In the case of missiles arising from window glass in houses exposed to the blast wave from a device having a yield of about $30 \mathrm{kt}$, it was noted that the spacial density of missiles as a function of incident overpressure could be utilized to assess the probabilities of these missiles inflicting dangerous wounds. These estimates were based upon the velocitymass relationships of glass fragments required for these fragments to penetrate the abdominal wall of anesthetized dogs and hence reach the peritoneal cavity, a potentially serious situation.

\section{REFERENCES}

1. George Armistead, Jr., The Ship Explosions at Texas City, Texas, on April 16 and 17, 1947, and Their Results, Engineering Consultants Report to John G. Simonds and Company, Inc., Oil Insurance Underwriters, New York City, June 1, 1947. 
2. Virginia Blocker and T. G. Blocker, The Texas City Disaster-A Survey of 3000 Casualties, Am. J. Surgery, 78: 756-771 (1949).

3. Samuel Glasstone, Ed., "The Effects of Atomic Weapons," Superintendent of Documents, U. S. Government Printing Office, Washington 25, D. C., September 1950.

4. Samuel Glasstone, Ed., "The Effects of Nuclear Weapons," Superintendent of Documents, U. S. Government Printing Office, Washington 25, D. C., June 1957.

5. Samuel Glasstone, Ed., "The Effects of Nuclear Weapons," pp. 457 and 462 , Superintendent of Documents, U. S. Government Printing Office, Washington 25, D. C., June 1957.

6. I. Gerald Bowen, Allen F. Strehler, and Mead B. Wetherbe, Distribution and Density of Missiles from Nuclear Explosions, Operation Teapot Report, WT-1168, December 1956.

7. I. Gerald Bowen et a1., Biological Effects of Blast from Bombs. Glass Fragments as Penetrating Missiles and Some of the Biological Implications of Glass Fragmented by Atomic Explosions, Report AECU-3350, Lovelace Foundation, June 18, 1956. 


\section{Chapter 2}

\section{PROCEDURE}

\subsection{TECHNIQUES}

\subsubsection{Preshot Activities}

(a) Priscilla. Eight Dalmatian dogs trained to individually fitted restraining and supporting harnesses were placed in anchored traps (heavy rectangular boxes open on the side facing Ground Zero) at various distances from GZ (Table 2.1 and Fig. 2.1). The traps were con-

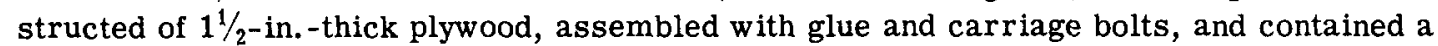
1-in.-thick layer of Styrofoam behind the animal to give protection from impact and to help define the distribution of missiles. Two types of bases were designed to hold the traps in place during the blast, one for the animal only (Fig. 2.1) and the other for an animal and one of the Styrofoam missile-absorber traps of Project 33.2 (Fig. 2.2). Protection from thermal radiation was afforded by a light wooden framework covered with 0.0015 -in.-thick aluminum foil and tied in place over the open side of the trap (Fig. 2.3). The wooden framework extended beyond the open area of the trap to prevent any part of it from striking the animal. Tests conducted prior to Operation Plumbbob proved that the aluminum foil, if caught between a missile and the biological target, would not appreciably alter the velocity of the missile. Those installations at the 8- and 6-psi lines were sandbagged on the lee side to reduce the possibility of displacement of the entire unit (Fig. 2.4).

Three missile sources were employed: double-strength window glass, ${ }^{*}$ plate glass, $\dagger$ and gravel. Both types of glass were glazed into standard steel-frame window installations contained in anchored blast-proof frameworks (Figs. 2.5 and 2.6). The gravel was spread at known distances from the traps on an asphalt-stabilized area (Fig. 2.7). Both the glass and gravel were color-coded to allow a determination of missile source.

Six dogs were placed at the glass-missile stations, and the associated missile trap was located above the dog trap in all instances (see Figs. 2.2 and 2.5). One dog was located at each of the two stations for gravel missiles; no missile trap was attached (see Fig. 2.1). A missile trap for gravel, however, was placed beside and $8 \mathrm{ft}$ away from the dog trap. Piles of gravel were planted nearly the same distances in front of both the dog traps and the missile traps (see Fig. 2.7).

Table 2.1 summarizes the placement of dogs and missile traps for the Priscilla shot and shows the type of missile and the distance of each trap from the missile source.

At each of the four pressure zones chosen for study, personnel of the Department of Defense Project 4.1.4 placed one pig behind standard window glass in an installation similar to the dog and missile traps of this project. A typical line of installations combining the efforts

*Libby-Owens-Ford double-strength window glass, B quality, 0.122 in. thick.

$\dagger$ Franklin Glass Corp., 0.228 in. thick. 
of Projects 4.1.4 and 33.2 with those of Project 33.4 is shown in Fig. 2.8. Placement and recovery procedures were correlated among these projects.*

Placement of animals and button-up activities were completed $6 \mathrm{hr}$ prior to shot time.

(b) Galileo. A procedure similar to that used for Priscilla was carried out for the Galileo shot, but at different pressure levels. Six dogs were used. Gravel was eliminated as a missile source, and a concrete-block wall (Fig. 2.9) was added. (Note that the missile traps are located above the animals). Glass stations also were included in houses as shown diagrammatically in Figs. 2.10 and 2.11. Other appropriate data referable to the Galileo shot are summarized in the last portion of Table 2.1.

\subsubsection{Recovery}

(a) Priscilla. Postshot entry into the area was postponed until radiation levels, as determined by the remote radiological monitoring system of CETG Project 39.9, had fallen below $1 \mathrm{r} / \mathrm{hr}$. Prior to retrieving the animals, a team consisting of a photographer and biologistmonitor entered the area to document damage and anesthetize badly wounded animals. This task required $19 \mathrm{~min}$. All animals were given heavy injections of Nembutal, which proved fatal before they could be transported to base camp. Recovery of animals was accomplished by a trained team of four men in a standard $1 / 2$-ton panel truck $1 \frac{1}{4} \mathrm{hr}$ after the detonation. A second team in a similar vehicle remained outside the area on a stand-by basis, maintaining radio contact with the actual recovery group. All personnel wore full dust-protective outfits and carried tools necessary for the recovery procedure, which required 13 min to perform.

A "clean" team in a "clean" vehicle in the stand-by area accepted the animals and removed them to the Project 4.1 radiological section, where they were completely $X$-rayed in both AP and lateral views. $\dagger$ The animals were then returned to base camp for post-mortem examination.

(b) Galileo. A photographer and biologist-monitor immediately preceded the recovery team. The latter group, in a military $2 \frac{1}{2}$-ton truck, retrieved the animals approximately $2 \mathrm{hr}$ after shot time. Protective clothing and equipment were the same as those used for the Priscilla shot. Since Project 4.1 had been disbanded, no X-rays were taken, and the animals were returned directly to base camp in a clean vehicle.

\subsubsection{Pathological Examination}

(a) Priscilla. A complete autopsy procedure was carried out. The hair from the left (exposed) side of the animal was closely clipped, and all visible surface wounds were mapped. Full-body photographs of the left side were taken; this was repeated after the animals were skinned. Subcutaneous wound tracts were explored using the $\mathrm{X}$-ray pictures as a guide, missiles were recovered where possible, and the depths of their penetrations were probed and recorded. The body and its contained organs were then systematically examined for further missile damage and evidence of blast damage, with a protocol of findings compiled for each animal. Sample sections were obtained for histologic study, and black and white and color photographs were taken of visible damage. The autopsy included examination of the thoracic and abdominal cavities and their contained organs, brain and meninges, eyes, ears, nasal sinuses, pharynx, neck organs, soft tissues, skeletal system, and genitalia. Before the thorax was entered, the trachea was clamped proximal to the larynx. The chest was opened after checking for evidences of pneumothorax, and the heart and inflated lungs were removed. The lungs were superficially examined and photographed, after which each lung was dissected free of surrounding tissues and the tracheal clamp was removed. They were then perfused with 10 per cent buffered formalin and allowed to fix $24 \mathrm{hr}$ prior to sectioning for microscopic examination. All other tissues were fixed in 10 per cent buffered formalin, with the exception of the eyes, which were fixed in Helly's solution after thin slices had been removed from either side

*See WT-1468 (Project 33.2) and WT-1428 (Project 4.1).

†The authors wish to thank Lt. Col. E. A. Langdon and his staff for taking and processing these pictures. 
of the globe with a razor blade. After otoscopic examination the internal auditory apparatus was removed en bloc by sawing through the mastoid bone and including a large portion of the external auditory canal. The medial portion of the tympanic bulla was removed, exposing the entire middle ear cavity to closer examination.

Fixed tissues were sectioned at the NTS using a freezing technique and were stained with Harris' hematoxylin and eosin before microscopic examination.

(b) Galileo. Animals were sacrificed just prior to postshot pathological procedures by intravenous injection of Nembutal followed by exsanguination through the femoral arteries. Examination of these animals paralleled the Priscilla procedure; however, $\mathrm{X}$-rays were not available as dissecting guides, and full-body photographs were not taken.

\subsection{INSTRUMENTATION}

Dynamic pressure vs. time and static pressure vs. time readings for both shots were obtained from the Ballistic Research Laboratories (Project 4.3/33.2). Missile velocities, masses, and distributions were obtained from Project 33.2.*

TABLE 2.1 - PLACEMENT OF ANIMALS

\begin{tabular}{|c|c|c|c|c|c|}
\hline $\begin{array}{l}\text { Animal } \\
\text { trap } \\
\text { No.* }\end{array}$ & $\begin{array}{c}\text { Range from } \\
\text { GZ, ft }\end{array}$ & Missile source $\dagger$ & $\begin{array}{l}\text { Distance } \\
\text { source }(\mathrm{s}) \\
\text { to trap, } \mathrm{ft}\end{array}$ & $\begin{array}{c}\text { Missile } \\
\text { trap } \\
\text { No. }\end{array}$ & $\begin{array}{l}\text { Location of } \\
\text { nearest } \\
\text { missile trap }\end{array}$ \\
\hline 8P2A & 3930 & Window glass & 12.75 & $8 \mathrm{P} 2 \mathrm{~b}$ & Above animal \\
\hline 8P8A & 3930 & Gravel & $\begin{array}{l}6.5 \\
16.75 \\
43.0\end{array}$ & $\begin{array}{l}8 \mathrm{P} 7 \mathrm{a} \\
8 \mathrm{P} 7 \mathrm{~b}\end{array}$ & $\begin{array}{l}\text { Beside but } 8 \mathrm{ft} \\
\text { from animal } \\
\text { trap }\end{array}$ \\
\hline $6 \mathrm{P} 2 \mathrm{~A}$ & 4770 & Window glass & 12.75 & $6 \mathrm{P} 2 \mathrm{~b}$ & Above animal \\
\hline $6 \mathrm{P} 8 \mathrm{~A}$ & 4770 & Gravel & $\begin{array}{r}5.5 \\
14.0 \\
36.0\end{array}$ & $\begin{array}{l}6 \mathrm{P} 7 \mathrm{a} \\
6 \mathrm{P} 7 \mathrm{~b}\end{array}$ & $\begin{array}{l}\text { Beside but } 8 \mathrm{ft} \\
\text { from animal } \\
\text { trap }\end{array}$ \\
\hline 5P2A & 5320 & Window glass & 12.75 & $5 \mathrm{P} 2 \mathrm{~b}$ & Above animal \\
\hline 5P3A & 5320 & Plate glass & 12.75 & $5 \mathrm{P} 3 \mathrm{~b}$ & Above animal \\
\hline $4 \mathrm{P} 2 \mathrm{~A}$ & 6120 & Window glass & 12.75 & $4 \mathrm{P} 2 \mathrm{~b}$ & Above animal \\
\hline 4P3A & 6120 & Plate glass & 12.75 & 4P3b & Above animal \\
\hline $7 \mathrm{G} 3 \mathrm{~A}$ & 2750 & Concrete-block wall & 20.17 & $7 \mathrm{G} 3 \mathrm{~b}$ & Above animal \\
\hline $7 \mathrm{G} 7 \mathrm{~A}$ & 2750 & Plate glass & 11.25 & $7 \mathrm{G} 7 \mathrm{~b}$ & Above animal \\
\hline $7 \mathrm{G} 8 \mathrm{~A}$ & 2750 & Window glass & 11.25 & $7 \mathrm{G} 8 \mathrm{~b}$ & Above animal \\
\hline $3 G 8 A$ & 4700 & Window glass & 10.92 & $3 \mathrm{G} 8 \mathrm{~b}$ & Above animal \\
\hline $3 \mathrm{G} 11 \mathrm{C}$ & 4700 & $\begin{array}{l}\text { Window glass in } \\
\text { house } \ddagger\end{array}$ & 10.0 & $\begin{array}{l}3 G 11 a \\
3 G 11 b \\
\text { 3G11d } \\
\text { 3G11e }\end{array}$ & $\begin{array}{l}\text { Below animal's tail } \\
\text { Below animal's head } \\
\text { Above animal's tail } \\
\text { Above animal's head }\end{array}$ \\
\hline $3 \mathrm{G} 13 \mathrm{C}$ & 4700 & $\begin{array}{l}\text { Window glass in } \\
\text { house } \ddagger\end{array}$ & 10.5 & $\begin{array}{l}3 \mathrm{G} 13 \mathrm{a} \\
3 \mathrm{G} 13 \mathrm{~b} \\
3 \mathrm{G} 13 \mathrm{~d} \\
3 \mathrm{G} 13 \mathrm{e}\end{array}$ & $\begin{array}{l}\text { Below animal's tail } \\
\text { Below animal's head } \\
\text { Above animal's tail } \\
\text { Above animal's head }\end{array}$ \\
\hline
\end{tabular}

* The notation used to designate the traps is as follows: P, Priscilla shot; G, Galileo shot. The number preceding $P$ or $G$ indicates the expected maximum overpressure in pounds per square inch.

$\dagger$ All glass mounted in steel frames in the open except as noted.

\$See Figure 3.5 for arrangement of missile and dog traps in houses.

*See ITR-1468 (to be superseded by WT-1468) for details of the techniques involved. 


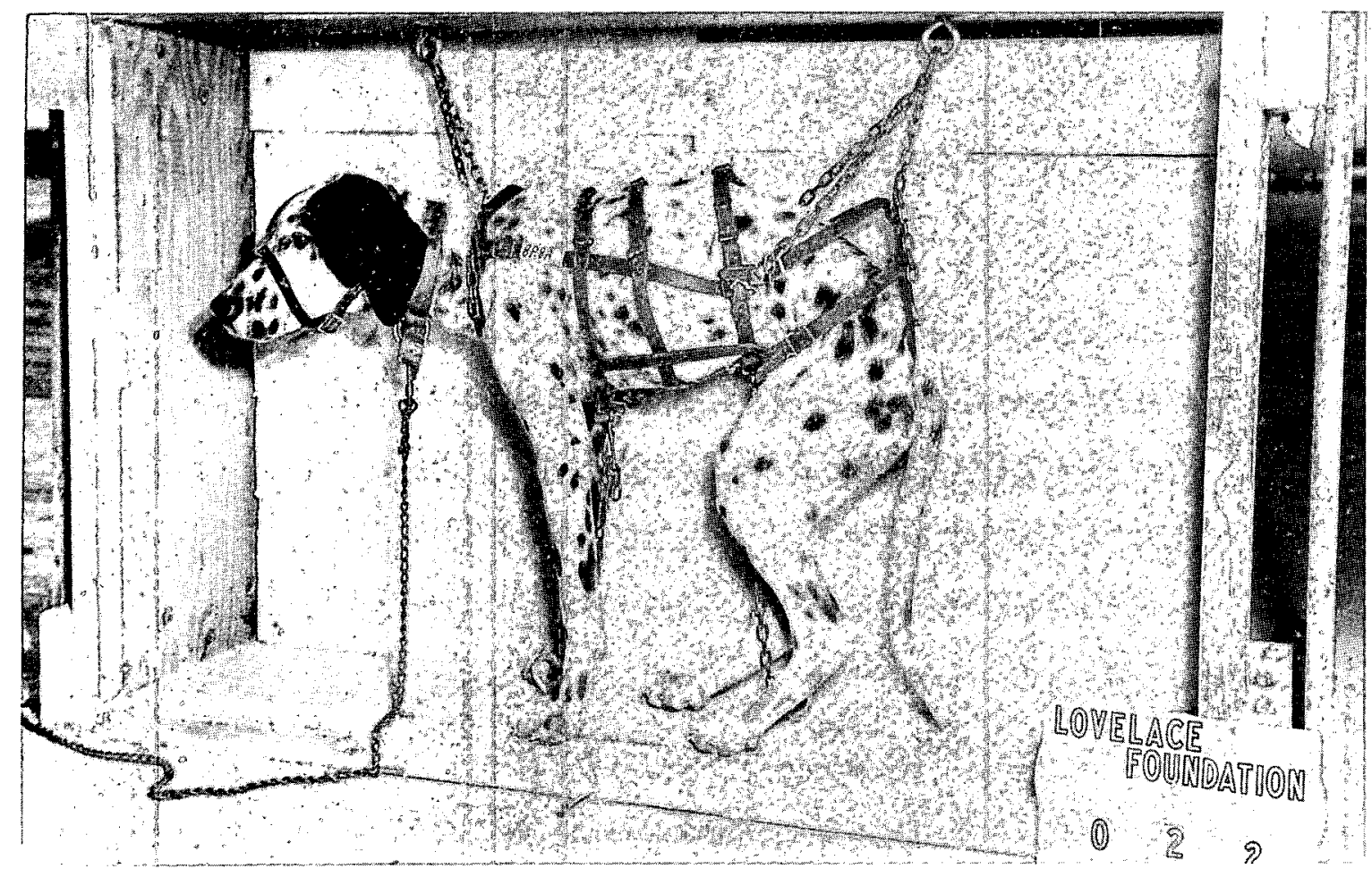

Fig. 2.1 Harnessed dog in trap with styrofoam backing.

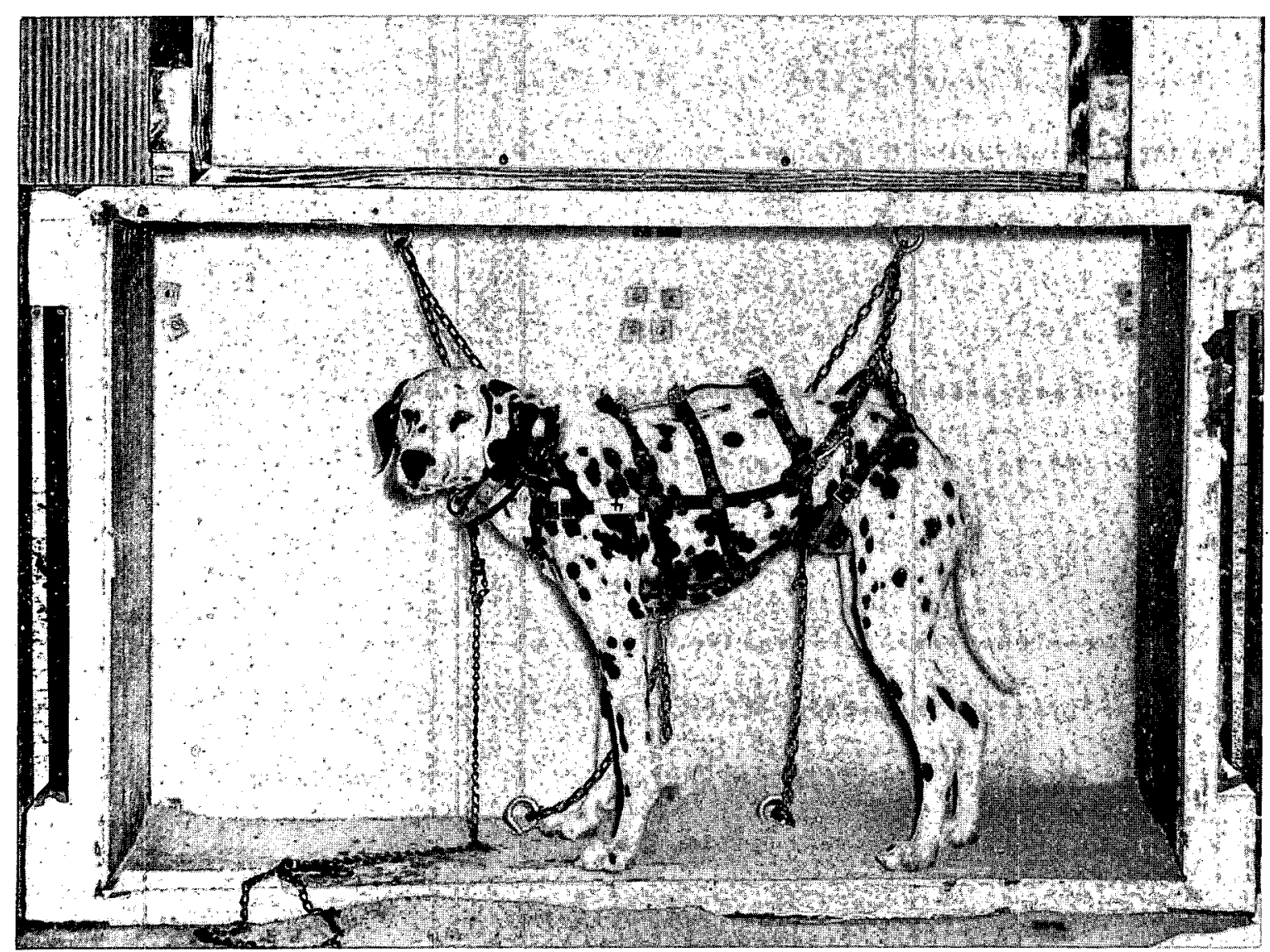

Fig. 2.2 Dog in trap beneath styrofoam missile-absorbing trap. 


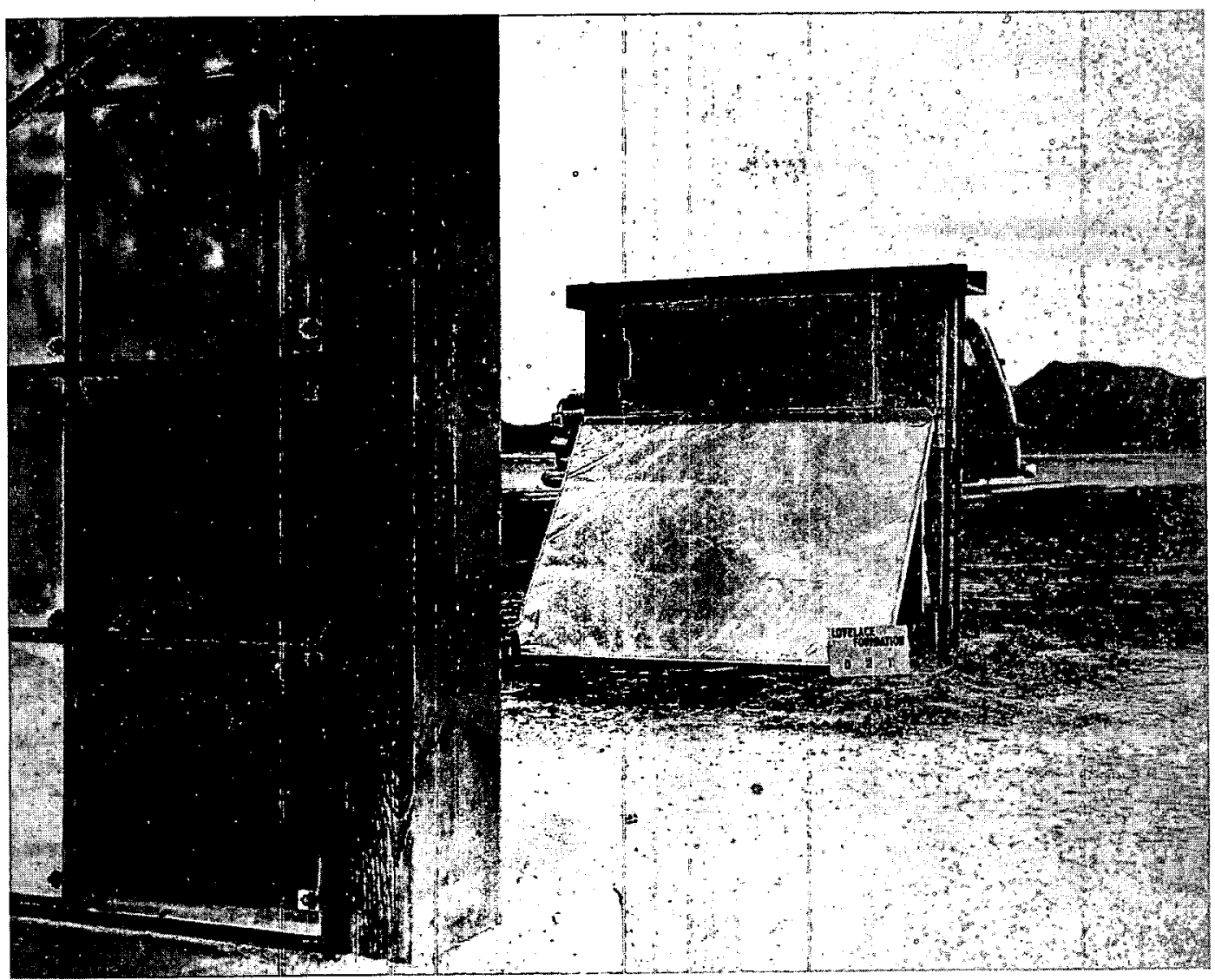

Fig. 2.3 Aluminum-foil thermal protector in front of animal trap.
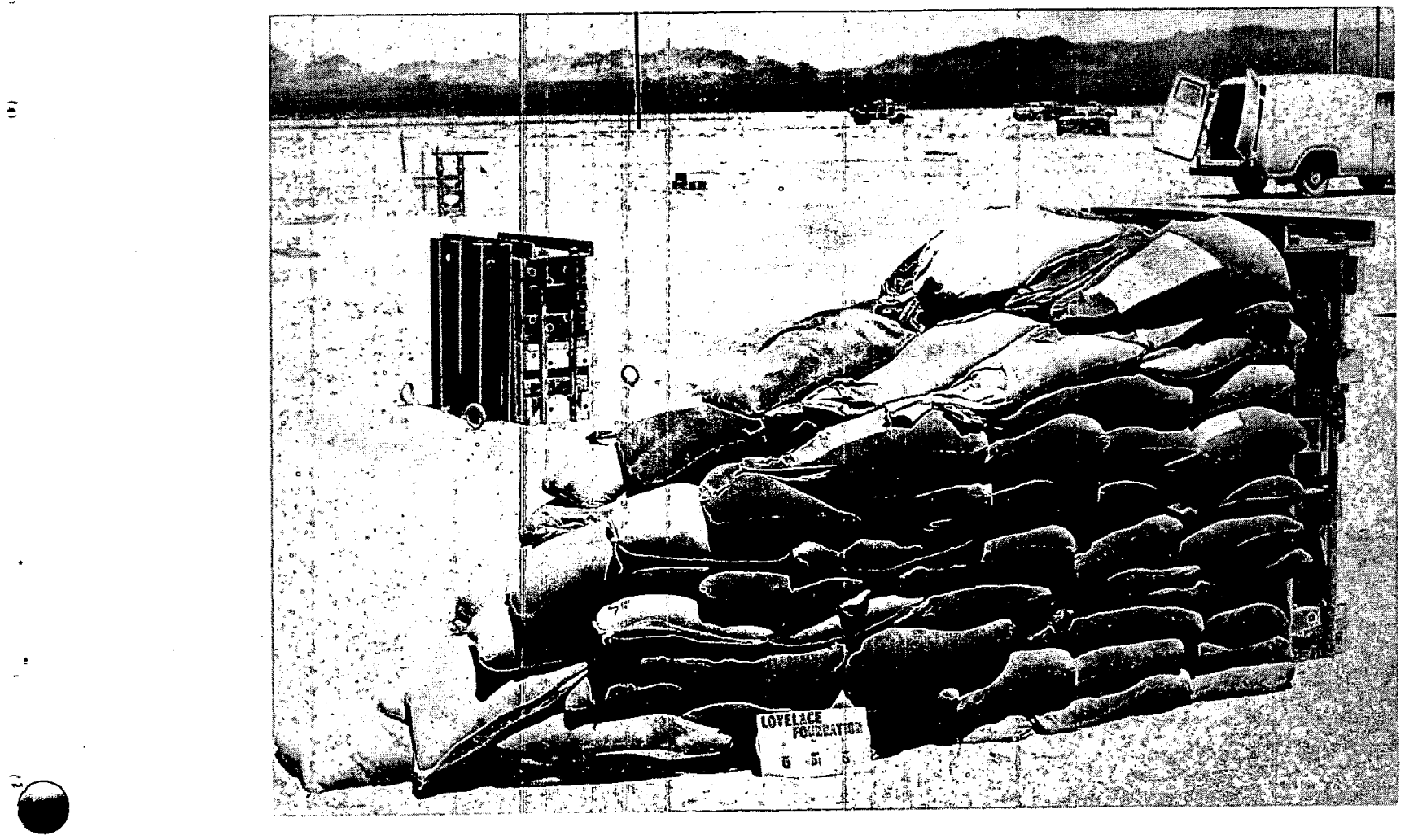

Fig. 2.4 Sandbagging behind forward trap. 


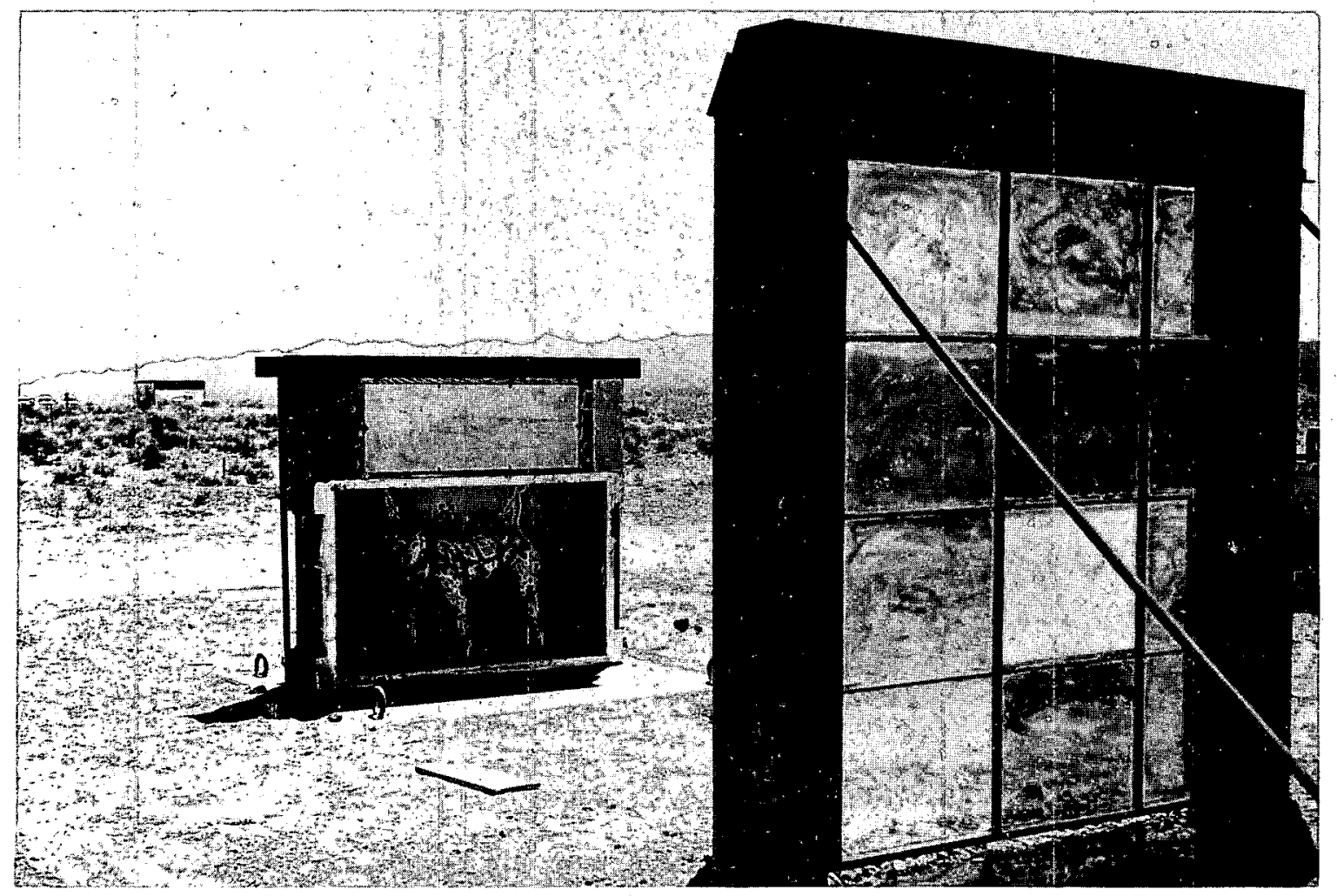

Fig. 2.5 Window-glass installation.

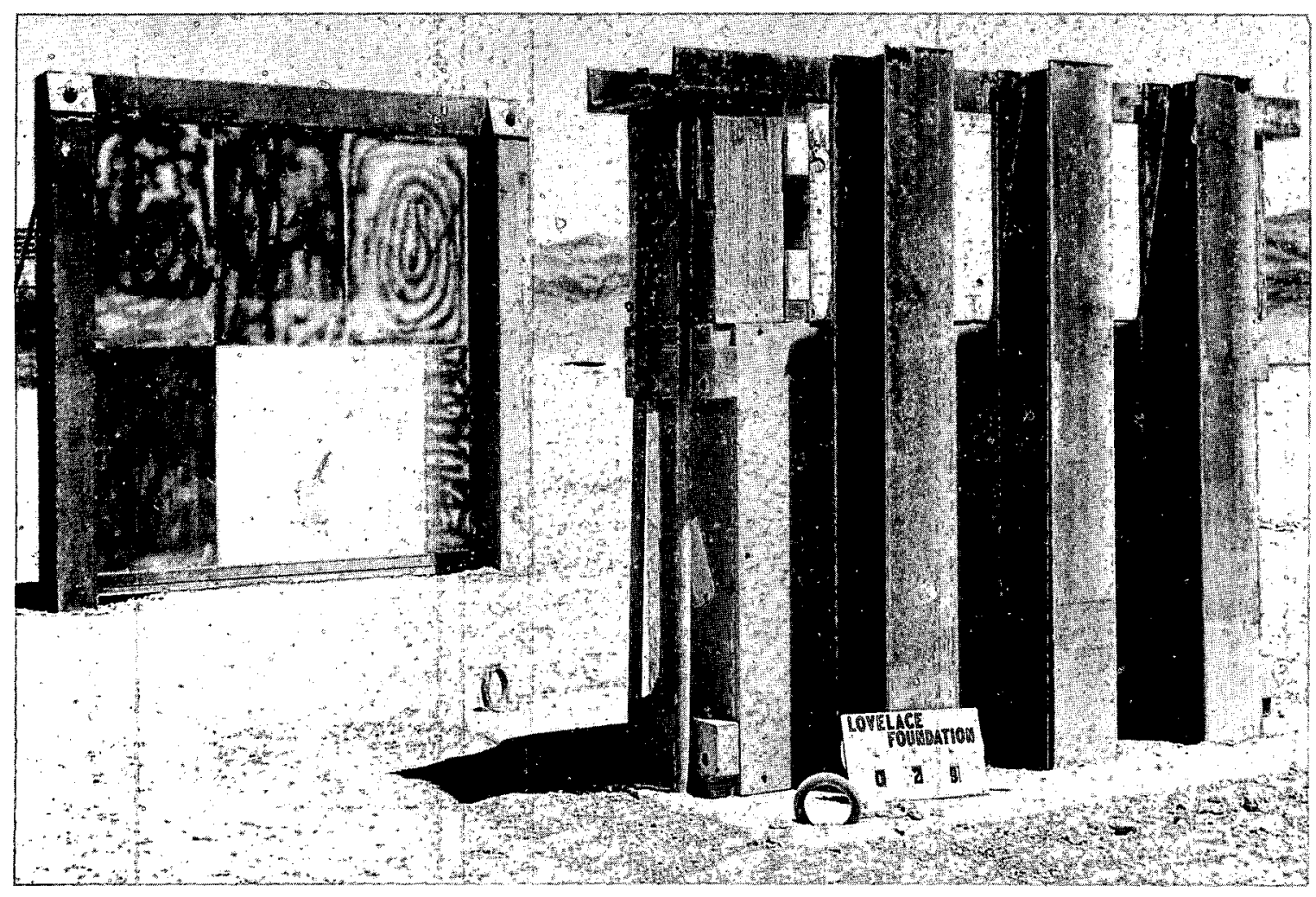

Fig. 2.6 Plate-glass installation. 


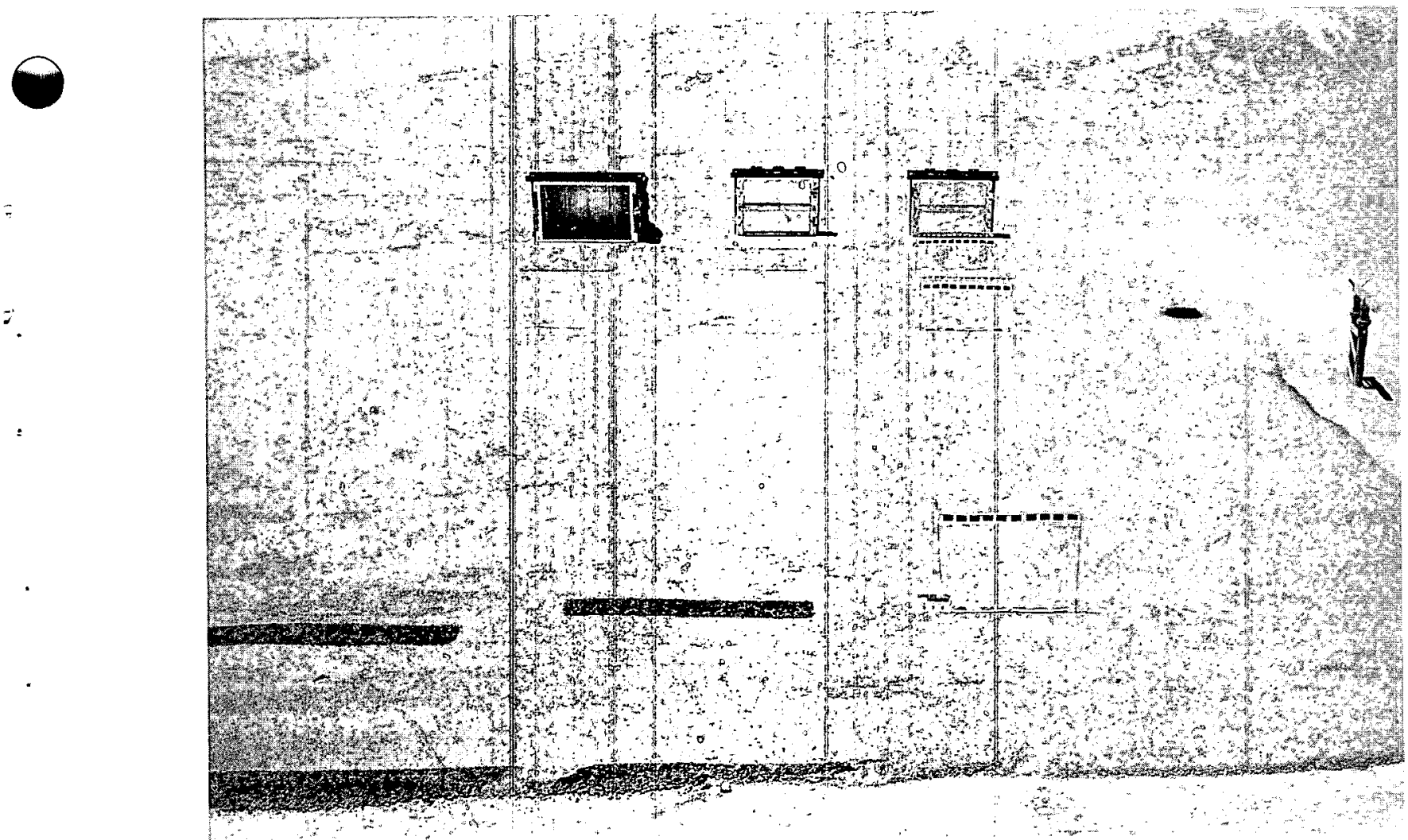

Fig. 2.7 Distribution of gravel in front of traps.

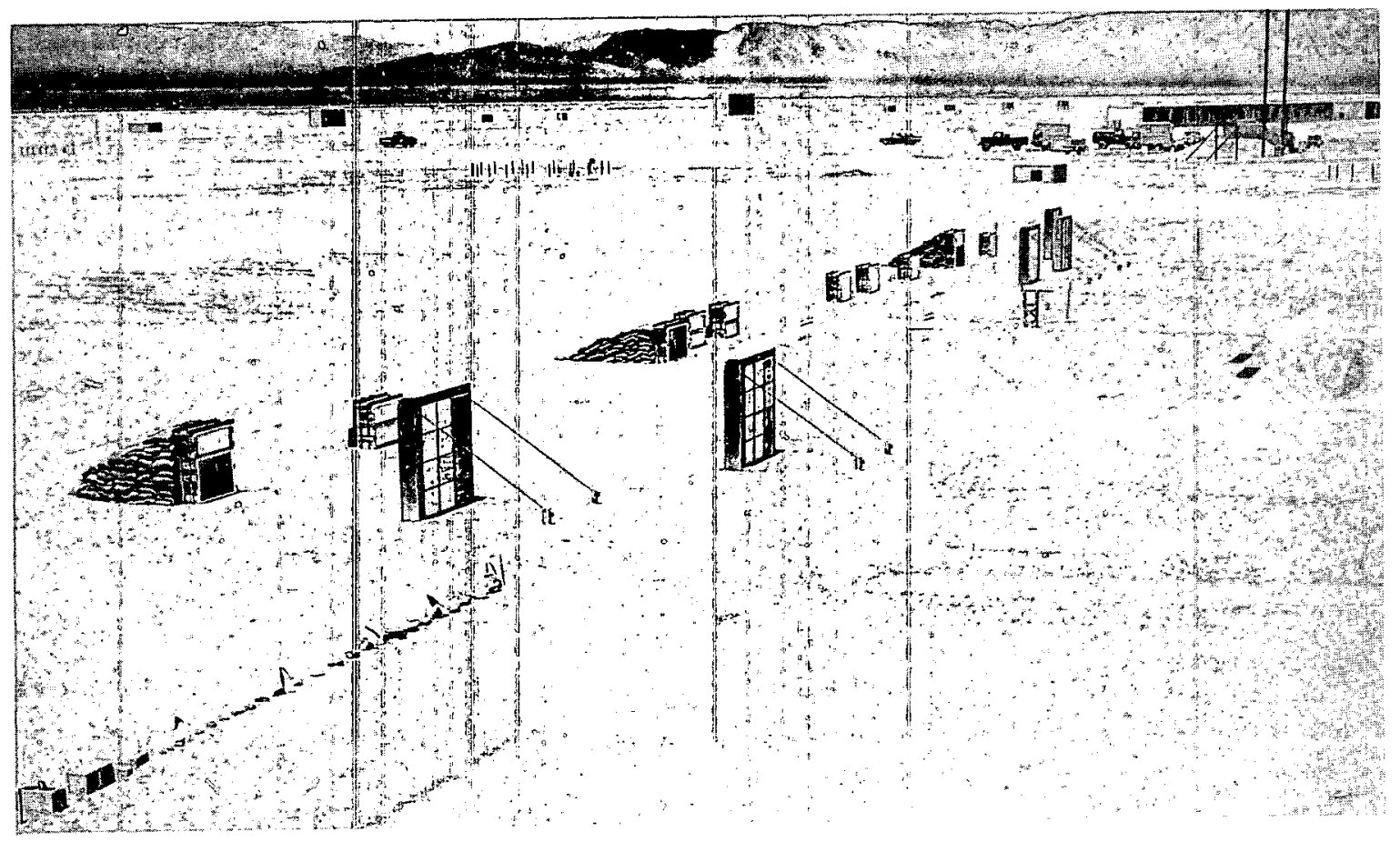

Fig. 2.8 Over-all view of typical trap line. 


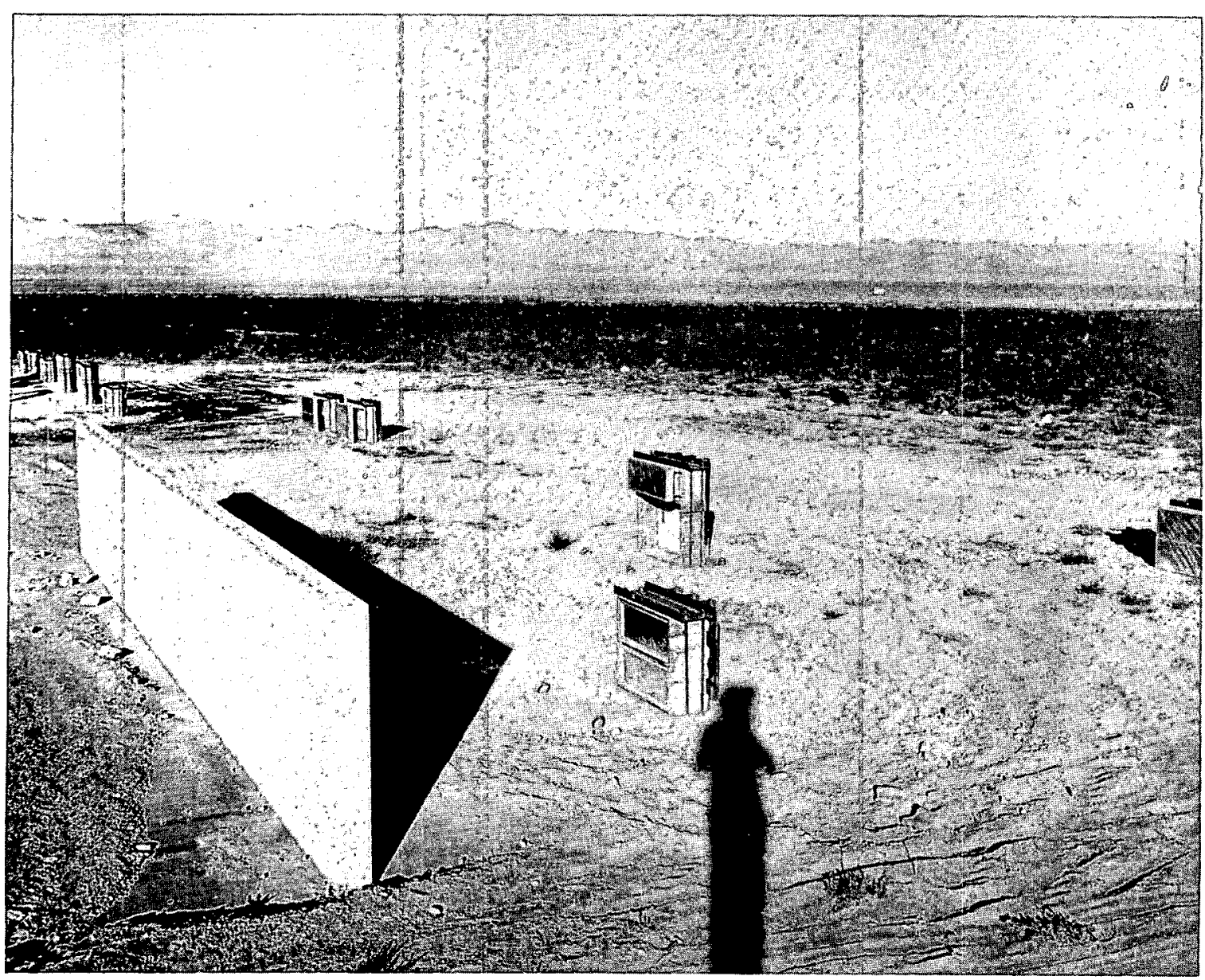

Fig. 2.9 Concrete-block wall and traps. 


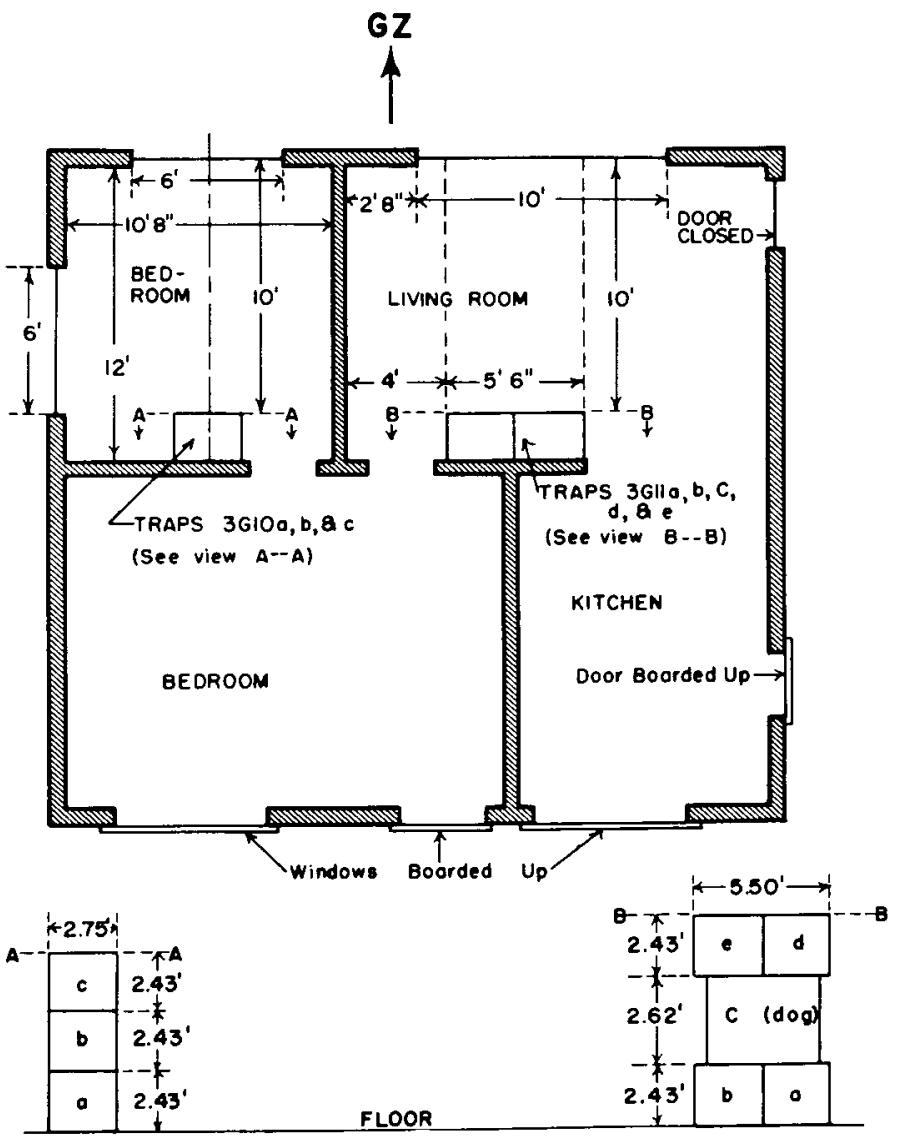

Fig. 2.10 Diagram of station 3G11 in house.

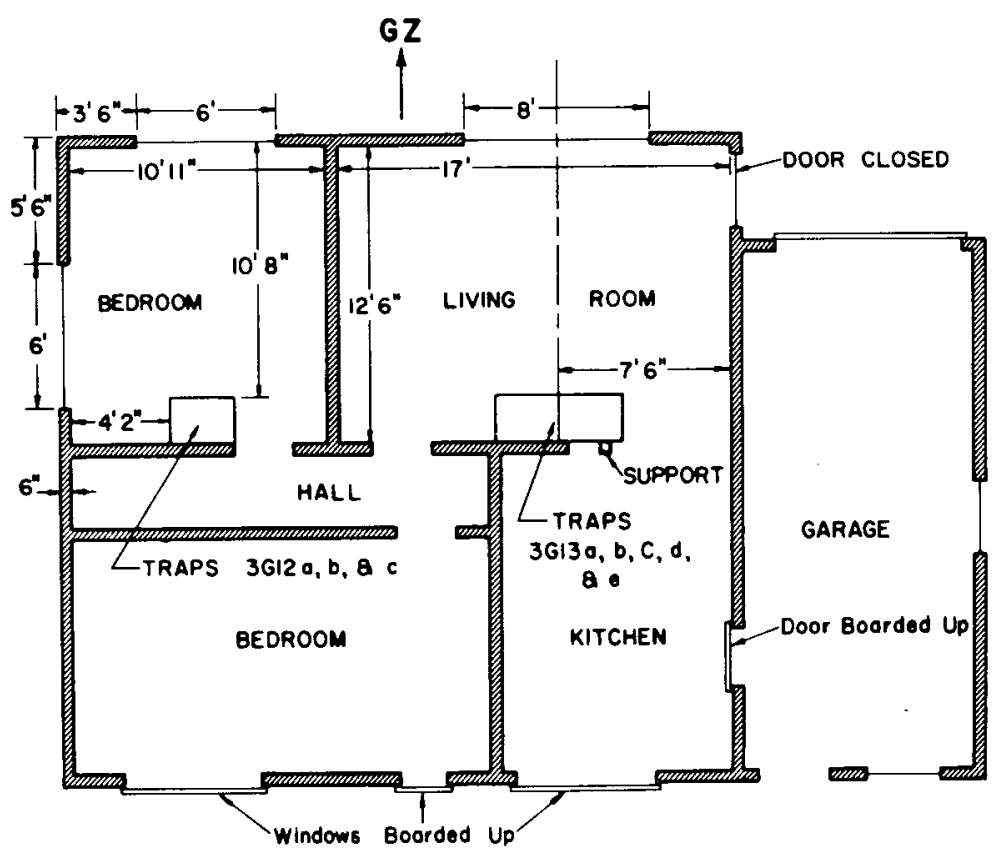

Fig. 2.11 Diagram of station 3G13 in house. 


\section{Chapter 3}

\section{RESULTS}

\subsection{GENERAL FIELD OBSERVATIONS}

\subsubsection{Priscilla}

Glass at all the stations was shattered, and downwind areas were littered with shards of varying sizes. The Styrofoam behind the animals had captured large numbers of these missiles, effectively outlining the dog at the time of arrival of the blast wave (Figs. 3.1 and 3.2). The piles of gravel placed in front of two dogs remained partially intact, but sufficient gravel had moved with a high enough velocity to outline the dogs against the Styrofoam backing of their respective traps (Fig. 3.3). The foil had been blown from all thermal protectors, and the frames were missing at the forward stations. Traps and bases showed no evidence of displacement or physical destruction. Although all the animals were alive, the six behind glass were bleeding from multiple wounds; and those behind gravel were unwounded but singed, the thermal protectors having apparently failed to give complete protection from the flash. Such was the case with one other animal (see Sec. 3.1.2). The six wounded animals were given fatal intraperitoneal doses of Nembutal by the early recovery party; the other two received similar doses when they were brought out of the radioactive area.

\subsubsection{Galileo}

The picture presented in the Galileo shot generally resembled that of Priscilla. The concrete-block wall had been broken into large fragments, which were piled against the animal and spread over the downwind area (Fig. 3.4). The houses remained standing, but the windows were blown in, littering floor areas and impacting against walls, installed traps, and animals (Figs. 3.5 and 3.6). The animals were all alive. One was found with slightly singed fur.

\subsection{PATHOLOGY}

\subsubsection{Priscilla}

A total of 110 wounds involving the skin and usually the underlying tissues was observed among the animals exposed to the Priscilla detonation as detailed in Table 3.1. The table also describes the more severe lacerations and notes the occurrence of 10 serious wounds. The latter were arbitrarily defined as "a laceration penetrating the skin wherein the missile either was stopped by bone or passed into the tissues to a depth of $10 \mathrm{~mm}$ or more."

There were no penetrating wounds that could be attributed to stones or planted gravel. Although most of the damage attributable to glass consisted of small lacerations, missile velocities great enough to chip bone were noted (6P2A, 5P3A and 4P3A). Also, in animal 5P2A the injury to the left foreleg involved a severing of the anterior extensor group of tendons, and two shallow lacerations of the left cornea were noted. The most spectacular laceration, that of 
the scrotum in animal $8 \mathrm{P} 2 \mathrm{~A}$, resulted in complete evisceration of the left testis together with its surrounding tissues and a portion of the spermatic cord.

A rather surprising finding was a laceration in the left groin in animal 8P2A. Apparently the turbulence associated with the geometry of exposure was sufficiently great to cause missiles to approach the biologic target from the side away from GZ.

The upper portion of Table 3.2 contains data from the Priscilla animals and detail findings referable to the lungs, ears, and sinuses due to primary blast effects, along with singeing from the thermal pulse. There was bilateral eardrum rupture in one animal (8P2A). All other intact tympanic membranes were either hemorrhagic or hyperaemic. No sinus pathology was noted. Three animals (8P8A, 6P8A, and 4P2A) were singed from failure of the aluminum foil to give complete protection; the image of the harness was evident in two instances (see Fig. 3.7). Animal 6P8A exhibited numerous small singed areas of the lower legs apparently from contact with hot particles that peppered the extremities.

In one instance (animal 8P2A), there was evidence of blast injury of the lung, grossly and microscopically, consisting of small hemorrhages in the interstitial muscles near the costochondral regions and small scattered areas of hemorrhage visible beneath the pleura in all lobes, but more marked on the right. The largest of the hemorrhagic areas was presented in the right cardiac lobe and measured 3 by $1.5 \mathrm{~cm}$ in area. Microscopically, there were numerous areas of fresh hemorrhages into the alveolar spaces and interstitial tissues, and also typical separations of the connective tissues around large structures, such as the vascular channels and bronchi.

Dust and dirt (observed in the bronchi, bronchioles, and alveoli) were not judged to be hazardous since the particulates were noted only after careful search. Those seen varied from pin-point sizes to flakes having a diameter of about 4 to $5 \mu$.

\subsubsection{Galileo}

Of the 160 lacerating wounds in the six animals exposed to the Galileo explosion, 12 were judged to be potentially serious wounds (see Table 3.3). One missile track passed through the face and into the nasal cavity of animal 3G13C. Another missile perforated the left hind leg. Two nonpenetrating lesions were noted; namely, intraorbital hemorrhage in animal 7G7A and a large hematoma on the left leg of animal 7G3A, which was exposed behind the concrete-block wall. The most unusual injury found was a circular laceration completely around the rectum of animal 3G13C which exposed but did not injure the rectal sphincter. This lesion apparently again demonstrates the significance of severe turbulence resulting from the geometry of exposure which may more generally point to an increase in missile hazard in situations in which the biologic target is located near a wall downstream from a missile source.

The lower portion of Table 3.2 shows that three animals suffered lung hemorrhages due to blast (see Figs. 3.8, 3.9, and 3.10). These were bilateral and consisted of local areas of hyperaemia; however, microscopic signs of alveolar and interstitial hemorrhage were minimal.

There were five eardrum ruptures noted; in two instances these ruptures were bilateral. Bilateral hemorrhages of the frontal sinuses were seen in only one animal (7G7A). Thermal effects, limited to singeing of black hair, were likewise found in only one instance (3G11C).

\subsection{PhySiCAl DATA (PRISCILla AND GALILEO)*}

\subsubsection{Missile Data}

(a) Project 33.4 Missile Traps. Data from the 22 missile traps located near the 14 animals exposed to both the Priscilla and Galileo shots, as noted in Table 2.1, are detailed in Table 3.4. The geometric mean velocities and masses of missiles for each trap are set forth, along with the extremes in mass and velocity. Also, the average number of missiles per square foot of missile trap is detailed, along with the total number and type of missiles re-

*The authors are indebted to Project 33.2 personnel for making the missile data collected during the Plumbbob Operation in 1957 available prior to the publication of WT-1468, which will contain data on over 20,000 missiles collected during the 1957 field operations at NTS. ${ }^{1}$ 
covered and evaluated. The reader will note from Table 3.4 that the over-all number of missiles totalled 2898, of which 2576, 117, and 205 were glass fragments, gravel, and natural stones, respectively.

(b) Selected Project 33.2 Missile Traps. Except for the glass-missile and animal stations placed in houses, the missile traps were all located above the animals at the distances from the missile source noted in Table 2.1. It is of interest to compare data from other glassmissile stations in which the traps were placed near ground level (as were the animals) but at the same ranges from GZ. Data selected from Project 33.2 experience for six window-glass stations are detailed in Table 3.5. These data show missile findings for the Project 33.4 traps placed above the animals and for two Project 33.2 traps for each of the six stations located on the ground at the same range, but at different distances from the missile sources. Facts regarding the latter point are shown in the last column of Table 3.5.

Although these Project 33.4 and 33.2 data are not strictly comparable because of the difference in distance of missile travel among other things, it is nevertheless true that the Project 33.2 traps bracket the conditions existing for the Project 33.4 stations. Thus significant generalities can be drawn from Table 3.5. First, there was a tendency for the traps at animal level to "see" a lesser number of missiles than those above the animals at the closer ranges; the opposite was true at the farther ranges. Second, the average geometric mean velocities for the lower traps were generally higher than for the traps above the animals. Third, the average geometric mean masses for the lower traps tended to be less than those for the traps located above the animals, particularly at the farther ranges (lower overpressures).

Such facts as the above reflect the adequacy with which the missile traps located above the animals sampled the missile environment of each animal. Since this matter will be dealt with more fully in Chap. 4, it will not be discussed further here.

\subsubsection{Blast Data*}

Table 3.6 shows the pressure-time data obtained by personnel of BRL with instruments placed near the animal stations in the Priscilla shot and at the same. range, but with a different azmuth, as for the Galileo shot. Overpressures were measured with ground-baffle mechanical pressure gauges located in the open in all instances. The overpressure behind the concreteblock wall where animal trap 7G3A was situated and the overpressures inside and on the forward face of the houses containing animal traps $3 \mathrm{G} 11 \mathrm{C}$ and $3 \mathrm{G} 13 \mathrm{C}$ were not measured. How ever, it is useful to state that the free-field overpressure of $3.8 \mathrm{psi}$ measured at the same range as the houses could be expected to reflect ${ }^{2}$ at the wall surface facing GZ to about 8.5 psi. It was this latter overpressure and the accompanying winds that were the blast parameters more nearly concerned with energizing the glass missiles arising from the windows in the houses rather than the lower incident overpressure of $3.8 \mathrm{psi}$ and its associated winds.

In column 6 , Table 3.6, the overpressures referable to the glass-missile stations measured at NTS altitude were converted to their sea-level equivalents ${ }^{2,3}$ for the convenience of those who would prefer thinking in terms of sea-level conditions. By way of further explanation, the sea-level equivalent overpressures represent those local static overpressures at sea level having nearly the same durations as those noted at NTS which, if incident upon a house by an increase in pressure due to reflection, would have produced glass-missile behavior similar to that observed in the present study.

The approximate yield figures computed from the blast data, as computed from data by Glasstone $^{2}$ and noted for the Priscilla and Galileo detonations in the last column of Table 3.6, may also be taken to represent the ylelds at sea level referable to the equivalent sea-level overpressures noted above because the error involved is small and concerns differences in the overpressure durations. Also of interest is the fact that at the NTS altitude a given yield produces higher wind velocities at a given overpressure than at sea level, but the range at which the overpressure occurs is less at NTS than at sea level. Thus, for a given yield, this apparent loss of range associated with the higher overpressures required to obtain higher winds at

*The authors are indebted to personnel of the Ballistic Research Laboratories for making blast data available prior to publication of their final report. 
sea level is partially compensated for by the gain in range at which the higher overpressure occurs at sea level.

\subsubsection{Estimation of Presented Area of Biologic Target}

An attempt was made postshot in the laboratory, using available field photographs of the dogs in place in the traps, to estimate the presented area of the Project 33.4 animals. This was done by cutting the animal-trap outline from an enlarged print and weighing the cutout. Then the silhouette of the animal was cut out and weighed. Since the area of the animal trap was known, the area of the dog could be computed from the ratio of the two weights obtained. The results for 11 animals are shown in the second column of Table 3.7. These averaged $2.09 \pm 0.13 \mathrm{sq} \mathrm{ft}$ with low and high figures of 1.77 and $2.25 \mathrm{sq} \mathrm{ft}$, respectively.

Because the custom-fit harness used on the animals was made of 1-in.-wide thick cotton webbing and the several straps over the left side of the dog could act as a shield from missiles, it was necessary to correct the figures for the presented area; the harness areas on two animals were snipped from a photo, the cutouts were weighed, and their areas were determined as explained above. The correction averaged -16.3 per cent of the total presented areas, and the figures in the third column of Table 3.7 give a reasonably close estimate of the actual area of each animal available as a "soft" target for missiles.

\section{REFERENCES}

1. I. G. Bowen et al., Secondary Missiles Generated by Nuclear-produced Blast Waves, Project 33.2, Operation Plumbbob Report, WT-1468 (in preparation).

2. Samuel Glasstone, Ed., "The Effects of Nuclear Weapons," Superintendent of Documents, U. S. Government Printing Office, Washington 25, D. C., June 1957.

3. I. G. Bowen et al., A Model Designed to Predict the Motion of Objects Translated by Classical Blast Waves, Report CEX-58.9 (in preparation).

TABLE 3.1 - WOUNDS OBSERVED AFTER PRISCILLA SHOT

\begin{tabular}{|c|c|c|c|}
\hline \multirow{2}{*}{$\begin{array}{l}\text { Dog } \\
\text { No. }\end{array}$} & \multicolumn{2}{|c|}{ Number wounds } & \multirow[b]{2}{*}{ Remarks } \\
\hline & Total & Serious* & \\
\hline 8P2A & 49 & 2 & $\begin{array}{l}\text { Groin, left, } 20 \mathrm{~mm} \text { deep. Foreleg, right medially, } 19 \mathrm{~mm} \\
\text { deep exposing a major artery and vein of cubital } \\
\text { fossa. Scrotum, 3-cm laceration with evisceration of } \\
\text { left testicle. }\end{array}$ \\
\hline $8 \mathrm{P} 8 \mathrm{~A}$ & None & None & \\
\hline 6P2A & 20 & 2 & $\begin{array}{l}\text { Face, left, } 14 \mathrm{~mm} \text { deep, } 45 \mathrm{~mm} \text { long, with fracture left } \\
\text { canine tooth. Knee, left rear, } 26 \mathrm{~mm} \text { long, } 6 \mathrm{~mm} \text { deep } \\
\text { to bone. }\end{array}$ \\
\hline $6 \mathrm{P8A}$ & None & None & \\
\hline 5P2A & 14 & 4 & $\begin{array}{l}\text { Foreleg, left lateral, } 13 \mathrm{~mm} \text { long, } 6 \mathrm{~mm} \text { deep to proxi- } \\
\text { mal epiphysis ulna. Leg, rear, left lateral, } 22 \mathrm{~mm} \\
\text { deep, } 5 \mathrm{~mm} \text { in diameter. Neck, left, glass embeeded } \\
\text { to depth of } 18 \mathrm{~mm} \text {. Thorax, left lateral, } 15 \mathrm{~mm} \text { deep } \\
\text { to, and with slight laceration of, pleura. Eye, left, } \\
\text { two shallow lacerations of the cornea. }\end{array}$ \\
\hline 5P3A & 15 & 1 & $\begin{array}{l}\text { Foreleg, left lateral, } 22 \mathrm{~mm} \text { long, } 6 \mathrm{~mm} \text { deep to articu- } \\
\text { lating surface of bone with small fracture epicondyle } \\
\text { ulna. }\end{array}$ \\
\hline 4P2A & 8 & None & Ear, left, laceration severed a peripheral blood vessel. \\
\hline 4P3A & 4 & 1 & $\begin{array}{l}\text { Shoulder, left, } 14 \mathrm{~mm} \text { deep to scapular spine with } \\
\text { small "nick" fracture. }\end{array}$ \\
\hline Totals & 110 & 10 & \\
\hline
\end{tabular}

*A serious injury is arbitrarily defined as a wound penetrating the skin to bone or to a depth of $10 \mathrm{~mm}$ or more in tissue. 
TABLE $3.2-$ BLAST AND THERMAL PATHOLOGY

\begin{tabular}{|c|c|c|c|c|c|}
\hline \multirow{2}{*}{$\begin{array}{l}\text { Animal } \\
\text { No. }\end{array}$} & \multirow{2}{*}{$\begin{array}{c}\text { Lung } \\
\text { hemorrhage }\end{array}$} & \multicolumn{2}{|c|}{ Ears* } & \multirow{2}{*}{$\begin{array}{c}\text { Sinus* } \\
\text { hemorrhage }\end{array}$} & \multirow[b]{2}{*}{ Thermal effects } \\
\hline & & Right & Left & & \\
\hline $8 \mathrm{P} 2 \mathrm{~A}$ & $\begin{array}{l}\text { Bilateral, greater } \\
\text { right, Grade I }\end{array}$ & $+\mathrm{H}$ & $+\mathrm{H}$ & & \\
\hline $8 \mathrm{P8A}$ & Negative & $\mathrm{H}$ & $\mathrm{H}$ & & $\begin{array}{l}\text { Singeing of hair, outline of } \\
\text { harness prominent }\end{array}$ \\
\hline $6 \mathrm{P} 2 \mathrm{~A}$ & Negative & $\mathrm{H}$ & $\mathrm{h}$ & & \\
\hline $6 \mathrm{P} 8 \mathrm{~A}$ & Negative & $\mathrm{H}$ & $\mathrm{H}$ & & $\begin{array}{l}\text { Singeing of hair with harness } \\
\text { pattern; lower legs peppered } \\
\text { with small singed areas }\end{array}$ \\
\hline $5 \mathrm{P} 2 \mathrm{~A}$ & Negative & $h$ & $\mathbf{h}$ & & \\
\hline 5P3A & Negative & $\mathrm{H}$ & $\mathrm{H}$ & & \\
\hline $4 \mathrm{P} 2 \mathrm{~A}$ & Negative & $\mathrm{H}$ & $\mathrm{h}$ & & Slight singeing \\
\hline 4P3A & Negative & $\mathrm{H}$ & $\mathrm{H}$ & & \\
\hline $7 \mathrm{G} 3 \mathrm{~A}$ & $\begin{array}{l}\text { Bilateral, greater } \\
\text { right, Grade II }\end{array}$ & $+\mathrm{H}$ & $\mathrm{H}$ & & \\
\hline $7 \mathrm{G} 7 \mathrm{~A}$ & $\begin{array}{l}\text { Bilateral, greater } \\
\text { right, Grade I }\end{array}$ & $+\mathrm{H}$ & $+\mathrm{H}$ & + & \\
\hline $7 \mathrm{G} 8 \mathrm{~A}$ & $\begin{array}{l}\text { Bilateral, greater } \\
\text { right, Grade I }\end{array}$ & $+\mathrm{H}$ & $+\mathrm{H}$ & & \\
\hline $3 \mathrm{G} 8 \mathrm{~A}$ & Negative & $\mathrm{H}$ & $\mathrm{H}$ & & \\
\hline $3 \mathrm{G} 11 \mathrm{C}$ & Negative & & & & $\begin{array}{l}\text { Slight singeing limited to } \\
\text { black spots }\end{array}$ \\
\hline $3 \mathrm{G} 13 \mathrm{C}$ & Negative & & & & \\
\hline
\end{tabular}

*The following symbolism has been used: $+\mathrm{H}$, rupture; H, hemorrhage; h, hyperemia; and +, positive finding.

TABLE 3.3-WOUNDS OBSERVED AFTER GALILEO SHOT

\begin{tabular}{|c|c|c|c|}
\hline \multirow{2}{*}{$\begin{array}{c}\text { Dog } \\
\text { No. }\end{array}$} & \multicolumn{2}{|c|}{ Number wounds } & \multirow[b]{2}{*}{ Remarks } \\
\hline & Total & Serious* & \\
\hline 7G $3 \mathrm{~A}$ & 10 & None & $\begin{array}{l}\text { Foot, lateral left rear, } 50 \mathrm{~mm} \text { long. Foot, medial } \\
\text { right rear, } 24 \mathrm{~mm} \text { long. Hematoma extending } \\
\text { from distal half of left tibia to area over foot. }\end{array}$ \\
\hline $7 \mathrm{G} 7 \mathrm{~A}$ & 48 & 2 & $\begin{array}{l}\text { Hip, left, } 25 \mathrm{~mm} \text { deep, } 50 \mathrm{~mm} \text { long. Hip, left, } 20 \\
\text { mm deep, } 35 \mathrm{~mm} \text { long. Eye, left, intraorbital } \\
\text { hemorrhage. }\end{array}$ \\
\hline 7G8A & 15 & 2 & $\begin{array}{l}\text { Face, left, } 30 \mathrm{~mm} \text { deep, } 10 \mathrm{~mm} \text { long. Foreleg, } \\
\text { left, penetrating to bone. }\end{array}$ \\
\hline $3 G 8 A$ & 14 & None & All wounds tiny nicks. \\
\hline 3G11C & 36 & 2 & $\begin{array}{l}\text { Shoulder, left, } 49 \mathrm{~mm} \text { deep, } 20 \mathrm{~mm} \text { long. Leg, } \\
\text { left rear, } 22 \mathrm{~mm} \text { long, passed through leg a } \\
\text { distance of } 38 \mathrm{~mm} \text {. Hip, left, subcutaneous } \\
\text { ecchymotic area. }\end{array}$ \\
\hline $3 \mathrm{G} 13 \mathrm{C}$ & 37 & 6 & $\begin{array}{l}\text { Foreleg, left lateral, } 40 \mathrm{~mm} \text { long to bone. Fore- } \\
\text { leg, left upper lateral, } 20 \mathrm{~mm} \text { deep, } 10 \mathrm{~mm} \\
\text { long. Foreleg, left upper lateral, } 20 \mathrm{~mm} \text { deep. } \\
\text { Face, left, penetrated } 12 \mathrm{~mm} \text { into nasal cavity. } \\
\text { Thorax, left lateral, } 30 \mathrm{~mm} \text { deep. Rectum, cir- } \\
\text { cular incision about rectum exposing, but not } \\
\text { injuring, rectal sphincter. }\end{array}$ \\
\hline Totals & 160 & 12 & \\
\hline
\end{tabular}

*A serious injury is defined arbitrarily as a wound penetrating the skin to bone or to a depth of $10 \mathrm{~mm}$ or more in tissue. 
TABLE 3.4-MISSILE DATA (PRISCILLA AND GALILEO SHOTS)

\begin{tabular}{|c|c|c|c|c|c|c|c|c|c|}
\hline $\begin{array}{c}\text { Missile } \\
\text { trap } \\
\text { No.* }\end{array}$ & $\begin{array}{l}\text { Type of } \\
\text { missile }\end{array}$ & $\begin{array}{c}\text { Total } \\
\text { number } \\
\text { missiles }\end{array}$ & $\begin{array}{l}\text { Average } \\
\text { missiles } \\
\text { per sq } \mathrm{ft}\end{array}$ & Miss & le velo & $\begin{array}{l}\text { city, ft/sec } \\
\text { Geometric } \\
\text { mean } \dagger\end{array}$ & Min. & issile ma & $\begin{array}{l}\text { ss, g } \\
\text { Geometric } \\
\text { mean } \dagger\end{array}$ \\
\hline \multirow[t]{2}{*}{$8 \mathrm{P} 2 \mathrm{~b}$} & W glass & 497 & 180.5 & 84 & 237 & 145 & 0.041 & 35.48 & 0.229 \\
\hline & Stones & 25 & 9.1 & 104 & 212 & 168 & 0.013 & 2.63 & 0.044 \\
\hline $8 P 7 a$ & Gravel & 11 & 4.0 & 124 & 196 & 164 & 0.152 & 0.745 & 0.306 \\
\hline $8 P 7 b$ & Gravel & 78 & 28.3 & 103 & 215 & 154 & 0.611 & 1.305 & 0.264 \\
\hline \multirow[t]{2}{*}{$6 \mathrm{P} 2 \mathrm{~b}$} & W glass & 105 & 38.1 & 67 & 168 & 108 & 0.045 & 14.13 & 0.651 \\
\hline & Stones & 20 & 7.3 & 107 & 204 & 144 & 0.014 & 1.62 & 0.069 \\
\hline $6 \mathrm{P} 7 \mathrm{a}$ & Gravel & 3 & 1.1 & 80 & 180 & 124 & 0.018 & 0.789 & 0.121 \\
\hline $6 P 7 b$ & Gravel & 25 & 9.1 & 111 & 200 & 145 & 0.022 & 0.842 & 0.087 \\
\hline $5 \mathrm{P} 2 \mathrm{~b}$ & W glass & 88 & 32.0 & 60 & 168 & 104 & 0.028 & 17.8 & 1.0 \\
\hline $5 \mathrm{P} 3 \mathrm{~b}$ & $P$ glass & 9 & 3.3 & 94 & 150 & 121 & 0.140 & 5.15 & 0.877 \\
\hline $4 \mathrm{P} 2 \mathrm{~b}$ & $\mathrm{~W}$ glass & 48 & 17.4 & 75 & 188 & 107 & 0.028 & 28.2 & 1.47 \\
\hline $4 \mathrm{P} 3 \mathrm{~b}$ & $P$ glass & 1 & & & & 47 & & & 0.60 \\
\hline \multirow[t]{2}{*}{ 7G3b } & $\begin{array}{c}\text { Concrete } \\
\text { wall }\end{array}$ & & & & & & & & \\
\hline & Stones & 30 & 10.9 & 143 & 274 & 194 & 0.011 & 0.171 & 0.035 \\
\hline \multirow[t]{3}{*}{$7 \mathrm{G} 7 \mathrm{~b}$} & $\begin{array}{c}P \text { glass } \\
\text { (flat) }\end{array}$ & 4 & 1.5 & 142 & 150 & 147 & 24.8 & 596.0 & 151.0 \\
\hline & $\begin{array}{l}\text { P glass } \\
\text { (edge) }\end{array}$ & 28 & 10.2 & 75 & 188 & 118 & 0.112 & 28.18 & 1.19 \\
\hline & Stones & 101 & 36.7 & 88 & 293 & 197 & 0.010 & 0.764 & 0.036 \\
\hline \multirow[t]{2}{*}{$7 \mathrm{G} 8 \mathrm{~b}$} & $\mathrm{~W}$ glass & 127 & 46.1 & 75 & 237 & 142 & 0.045 & 44.7 & 0.604 \\
\hline & Stones & 29 & 10.5 & 117 & 236 & 180 & 0.011 & 0.575 & 0.067 \\
\hline $3 G 8 b$ & W glass & 15 & 5.4 & 53 & 150 & 96 & 0.563 & 7.32 & 2.62 \\
\hline 3G11a & $\mathrm{W}$ glass & 164 & 59.5 & 84 & 237 & 141 & 0.018 & 8.91 & 0.303 \\
\hline $3 \mathrm{G} 11 \mathrm{~b}$ & W glass & 336 & 91.5 & 84 & 237 & 131 & 0.011 & 8.91 & 0.236 \\
\hline 3G11d & W glass & 278 & 75.7 & 84 & 211 & 141 & 0.022 & 5.62 & 0.355 \\
\hline 3G11e & $\mathrm{W}$ glass & 169 & 61.4 & 84 & 237 & 134 & 0.011 & 4.47 & 0.316 \\
\hline 3G13a & $W$ glass & 196 & 53.4 & 45 & 237 & 133 & 0.018 & 8.91 & 0.281 \\
\hline $3 G 13 b$ & W glass & 150 & 40.8 & 84 & 211 & 134 & 0.018 & 8.91 & 0.252 \\
\hline 3G13d & $\mathrm{W}$ glass & 207 & 56.4 & 94 & 237 & 142 & 0.018 & 7.08 & 0.328 \\
\hline $3 G 13 e$ & $W$ glass & 154 & 41.9 & 94 & 237 & 144 & 0.045 & 7.08 & 0.557 \\
\hline \multirow[t]{4}{*}{ Totals } & All & 2898 & & & & & & & \\
\hline & Glass & 2576 & & & & & & & \\
\hline & Gravel & 117 & & & & & & & \\
\hline & Stones & 205 & & & & & & & \\
\hline
\end{tabular}

${ }^{*} \mathbf{P}=$ Priscilla traps; $\mathrm{G}=$ Galileo traps.

†The geometric mean is the antilog of the mean of the logarithms of the missile velocities or their masses, as the case may be. 
TABLE 3.5-GLASS MISSILE DATA FROM TRAPS ABOVE ANIMALS (PROJECT 33.4) COMPARED WITH THOSE FROM TRAPS PLACED AT ANIMAL LEVEL (SELECTED FROM PROJECT 33.2 EXPERIENCE)

\begin{tabular}{|c|c|c|c|c|c|c|c|c|c|}
\hline $\begin{array}{c}\text { Missile } \\
\text { trap } \\
\text { No.* }\end{array}$ & $\begin{array}{c}\text { Total } \\
\text { number } \\
\text { missiles }\end{array}$ & $\begin{array}{l}\text { Average } \\
\text { missiles } \\
\text { per sq ft }\end{array}$ & Miss & le velo & $\begin{array}{l}\text { ity, ft/sec } \\
\text { Geometric } \\
\text { mean }\end{array}$ & Min. & issile $\mathrm{m}$ & $\begin{array}{l}\text { Gss, } g \\
\text { Geometric } \\
\text { mean }\end{array}$ & $\begin{array}{c}\text { Distance of } \\
\text { missile } \\
\text { travel, ft }\end{array}$ \\
\hline 8P1a $\dagger$ & 103 & 37.40 & 67 & 266 & 141 & 0.018 & 45.000 & 0.245 & 7.75 \\
\hline 8P9a & 180 & 65.36 & 75 & 237 & 154 & 0.035 & 11.000 & 0.318 & 22.75 \\
\hline $8 \mathrm{P} 2 \mathrm{~b}$ & 497 & 180.5 & 84 & 237 & 145 & 0.0414 & 35.48 & 0.229 & 12.75 \\
\hline $6 \mathrm{P} 1 \mathrm{a} \dagger$ & 67 & 24.33 & 94 & 188 & 129 & 0.028 & 7.080 & 0.594 & 7.75 \\
\hline 6P9a $†$ & 178 & 64.63 & 53 & 188 & 123 & 0.056 & 11.000 & 0.419 & 22.75 \\
\hline 6P2b & 105 & 38.12 & 67 & 168 & 108 & 0.045 & 14.130 & 0.651 & 12.75 \\
\hline 5P1a $\dagger$ & 48 & 17.43 & 75 & 188 & 114 & 0.089 & 11.000 & 1.301 & 7.75 \\
\hline 5P8a† & 40 & 14.52 & 53 & 211 & 120 & 0.112 & 8.913 & 1.011 & 17.75 \\
\hline $5 \mathrm{P} 2 \mathrm{~b} \ddagger$ & 88 & 32.00 & 60 & 168 & 104 & 0.028 & 17.800 & 1.000 & 12.75 \\
\hline 4P1a $\dagger$ & 68 & 24.69 & 60 & 168 & 106 & 0.035 & 14.130 & 1.230 & 7.75 \\
\hline 4P8a† & 41 & 14.89 & 53 & 168 & 114 & 0.089 & 8.913 & 0.677 & 17.75 \\
\hline 4P2bł & 48 & 17.43 & 75 & 188 & 107 & 0.028 & 28.200 & 1.470 & 12.75 \\
\hline 7G9a† & 192 & 69.72 & 75 & 211 & 134 & 0.045 & 28.180 & 0.442 & 6.2 \\
\hline 7G6at & 221 & 80.25 & 84 & 211 & 141 & 0.028 & 8.913 & 0.323 & 21.2 \\
\hline $7 \mathrm{G} 8 \mathrm{~b} \ddagger$ & 127 & 46.11 & 75 & 237 & 142 & 0.045 & 44.700 & 0.604 & 11.25 \\
\hline $3 \mathrm{G} 6 \dagger$ & 42 & 11.95 & 84 & 168 & 122 & 0.178 & 8.913 & 1.440 & 4.6 \\
\hline $3 G 9 \dagger$ & 16 & 4.55 & 67 & 150 & 104 & 0.604 & 16.530 & 3.692 & 19.5 \\
\hline $3 \mathrm{G} 8 \mathrm{~b} \ddagger$ & 15 & 5.4 & 53 & 150 & 96 & 0.563 & 7.320 & 2.620 & 10.9 \\
\hline
\end{tabular}

* $\mathbf{P}=$ Priscilla traps; $\mathbf{G}=$ Galileo traps.

†Selected traps from Project 33.2.

$\$$ Project 33.4 data taken from Table 3.4. 
TABLE 3.6 - BLAST DATA AT ANIMAL STATIONS (PRISCILLA AND GALILEO SHOTS)

\begin{tabular}{|c|c|c|c|c|c|c|}
\hline \multirow{2}{*}{$\begin{array}{l}\text { Animal } \\
\text { trap } \\
\text { No.* }\end{array}$} & \multirow{2}{*}{$\begin{array}{c}\text { Missile } \\
\text { trap } \\
\text { No. }\end{array}$} & \multicolumn{2}{|c|}{$\begin{array}{c}\text { Maximum } \\
\text { overpressure }\end{array}$} & \multirow{2}{*}{$\begin{array}{l}\text { Overpressure } \\
\text { duration, } \\
\text { msec }\end{array}$} & \multirow{2}{*}{$\begin{array}{c}\text { Equivalent } \\
\text { sea-level } \\
\text { incident } \\
\text { overpressure, } \neq \\
\text { psi }\end{array}$} & \multirow{2}{*}{$\begin{array}{c}\text { Approximate } \\
\text { yield computed, } 8 \\
\text { kt }\end{array}$} \\
\hline & & $\begin{array}{l}\text { Expected, } \\
\text { psi }\end{array}$ & $\begin{array}{c}\text { Measured, } \dagger \\
\text { psi }\end{array}$ & & & \\
\hline $8 P 2 A$ & $8 \mathrm{P} 2 \mathrm{~b}$ & 8 & 8.6 & 823 & 4.25 & 38 \\
\hline \multirow[t]{2}{*}{ 8P8A } & $8 \mathrm{P} 7 \mathrm{a}$ & 8 & 8.6 & 823 & & \\
\hline & $8 P 7 b$ & 8 & 8.6 & 823 & & \\
\hline 6P2A & $6 \mathrm{P} 2 \mathrm{~b}$ & 6 & 6.4 & 920 & 3.23 & \\
\hline \multirow[t]{2}{*}{$6 \mathrm{P} 8 \mathrm{~A}$} & $6 \mathrm{P} 2 \mathrm{a}$ & 6 & 6.4 & 920 & & \\
\hline & $6 \mathrm{P} 2 \mathrm{~b}$ & 6 & 6.4 & 920 & & \\
\hline 5P2A & $5 \mathrm{P} 2 \mathrm{~b}$ & 5 & 5.6 (est.) & 964 (est.) & 2.87 & \\
\hline 5P3A & $5 \mathrm{P} 3 \mathrm{~b}$ & 5 & 5.6 (est.) & 964 (est.) & 2.87 & \\
\hline 4P2A & $4 \mathrm{P} 2 \mathrm{~b}$ & 4 & 4.6 (est.) & 1027 (est.) & 2.41 & \\
\hline 4P3A & $4 \mathrm{P} 3 \mathrm{~b}$ & 4 & 4.6 (est.) & 1027 (est.) & 2.41 & \\
\hline $7 \mathrm{G} 3 \mathrm{~A}$ & $7 \mathrm{G3b}$ & 7 & 8.4 & 576 & 4.32 & 11 \\
\hline $7 \mathrm{G} 7 \mathrm{~A}$ & $7 \mathrm{G} 7 \mathrm{~b}$ & 7 & 8.4 & 576 & 4.32 & \\
\hline 7G8A & $7 \mathrm{G} 8 \mathrm{~b}$ & 7 & 8.4 & 576 & 4.32 & \\
\hline 3G8A & 3G8b & 3 & 3.8 & 756 & 2.12 & \\
\hline \multirow[t]{4}{*}{$3 \mathrm{G} 11 \mathrm{C}$} & 3G11a & 3 & $3.8(8.5)$ & 756 & 4.45 & \\
\hline & $3 \mathrm{G} 11 \mathrm{~b}$ & 3 & $3.8(8.5)$ & 756 & 4.45 & \\
\hline & 3G11d & 3 & $3.8(8.5)$ & 756 & 4.45 & \\
\hline & $3 \mathrm{G} 11 \mathrm{e}$ & 3 & $3.8(8.5)$ & 756 & 4.45 & \\
\hline \multirow[t]{4}{*}{$3 \mathrm{G} 13 \mathrm{C}$} & 3G13a & 3 & $3.8(8.5)$ & 756 & 4.45 & \\
\hline & $3 G 13 b$ & 3 & $3.8(8.5)$ & 756 & 4.45 & \\
\hline & 3G13d & 3 & $3.8(8.5)$ & 756 & 4.45 & \\
\hline & $3 \mathrm{G} 13 \mathrm{e}$ & 3 & $3.8(8.5)$ & 756 & 4.45 & \\
\hline 14 & 22 & & & & & \\
\hline
\end{tabular}

$* \mathbf{P}=$ Priscilla; $\mathrm{G}=$ Galileo.

$\dagger$ Measurements taken with ground-baffle gauges in the open. No pressure gauges were located behind the concrete-block wall or inside houses where animals $3 \mathrm{G} 11 \mathrm{C}$ and $3 \mathrm{G} 13 \mathrm{C}$ were actually located. Nevada pressure altitude: Priscilla, $13.3 \mathrm{psi}$; Galileo, $12.7 \mathrm{psi}$. Ambient temperature: Priscilla, $17^{\circ} \mathrm{C}$; $\mathrm{Galileo}$ $18.8^{\circ} \mathrm{C}$. Figures inside parentheses are computed reflected overpressures following the procedure of Glasstone. ${ }^{2}$

¥Computed after Bowen et al. ${ }^{3}$ to give the incident maximal pressure which if reflected from a window-containing house will give nearly the same missile velocities as were measured in Nevada.

$\$$ Computed after Bowen et al. ${ }^{1}$ using the measurements at the 6 and $8 \mathrm{P}$ and the 3 and $8 \mathrm{G}$ stations, following Glasstone. 2

TABLE 3.7 - ESTIMATED AREAS OF ANIMALS PRESENTED AS MISSILE TARGETS

\begin{tabular}{lccc} 
& \multicolumn{3}{c}{ Estimated presented area, sq ft } \\
Dog No. & Initial estimate & $\begin{array}{c}\text { Corrected for } \\
\text { harness shielding }\end{array}$ & Comment \\
\hline 8P2A & 2.16 & 1.81 & Photo unsuitable \\
8P8A & & & \\
6P2A & 2.08 & 1.74 & \\
6P8A & 2.20 & 1.84 & \\
5P2A & 1.98 & 1.66 & Photo unsuitable \\
5P3A & 2.13 & 1.78 & Photo unsuitable \\
4P2A & & & \\
4P3A & 1.77 & 1.48 & \\
7G3A & & & \\
7G7A & 2.06 & 1.72 & \\
7G8A & 2.09 & 1.75 & \\
3G8A & 2.17 & 1.82 & \\
3G11A & 2.25 & 1.88 & \\
3G13C & 2.07 & 1.73 & $1.75 \pm 0.11$ \\
Average & $2.09 \pm 0.13$ & &
\end{tabular}




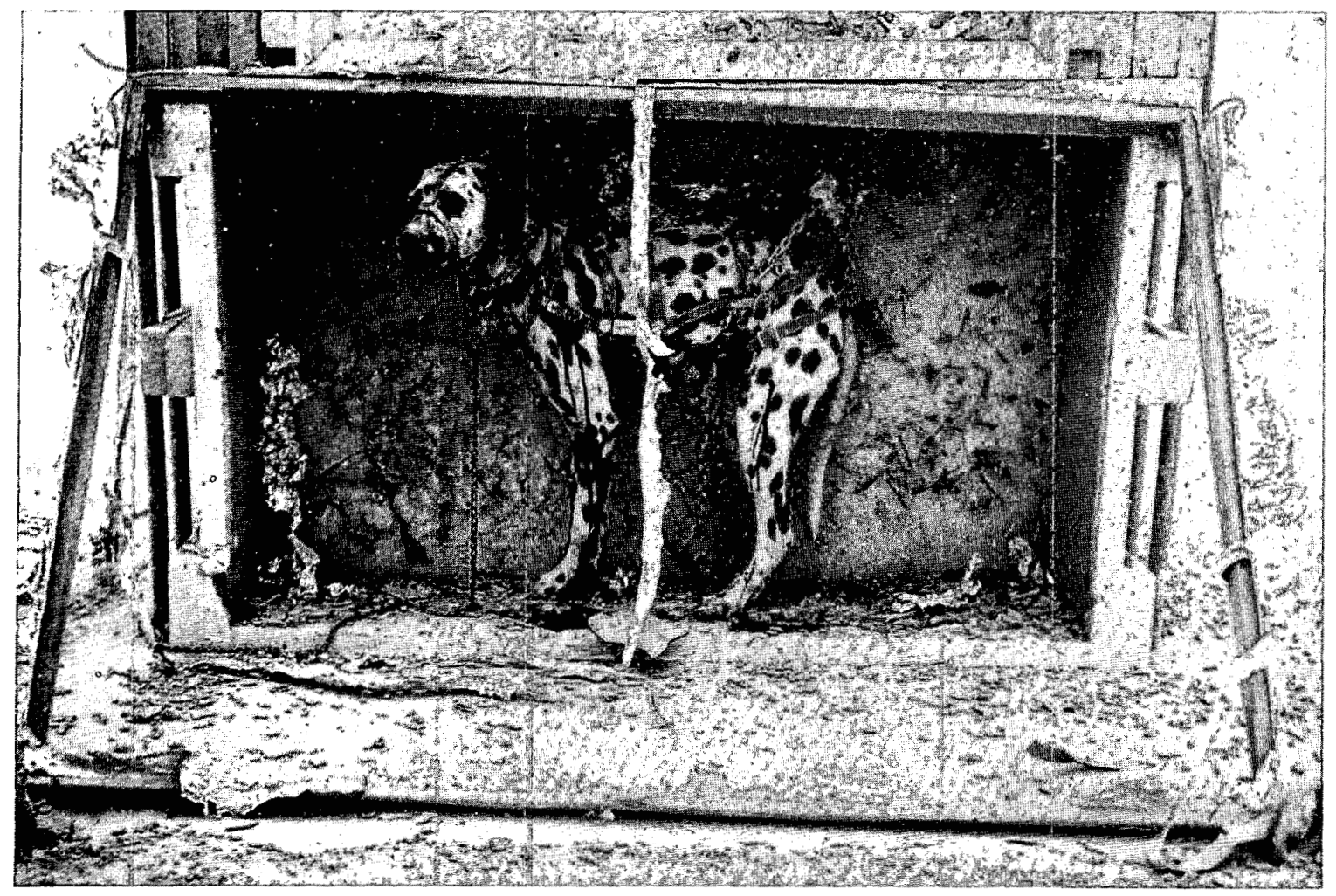

Fig. 3.1 Postshot view of animal behind window glass.

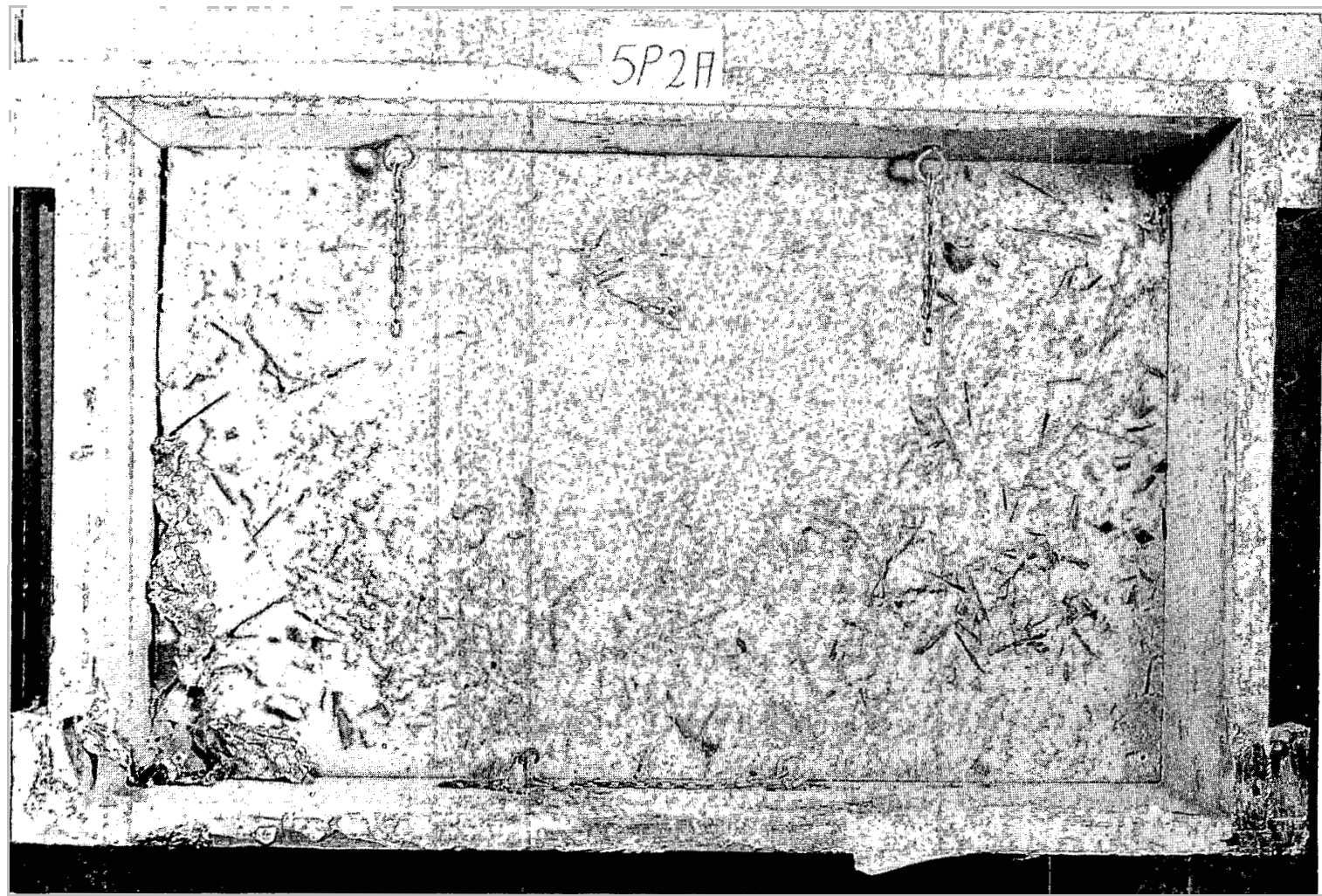

Fig. 3.2 Same trap as Fig. 3.1, showing missiles embedded around outline of animal 


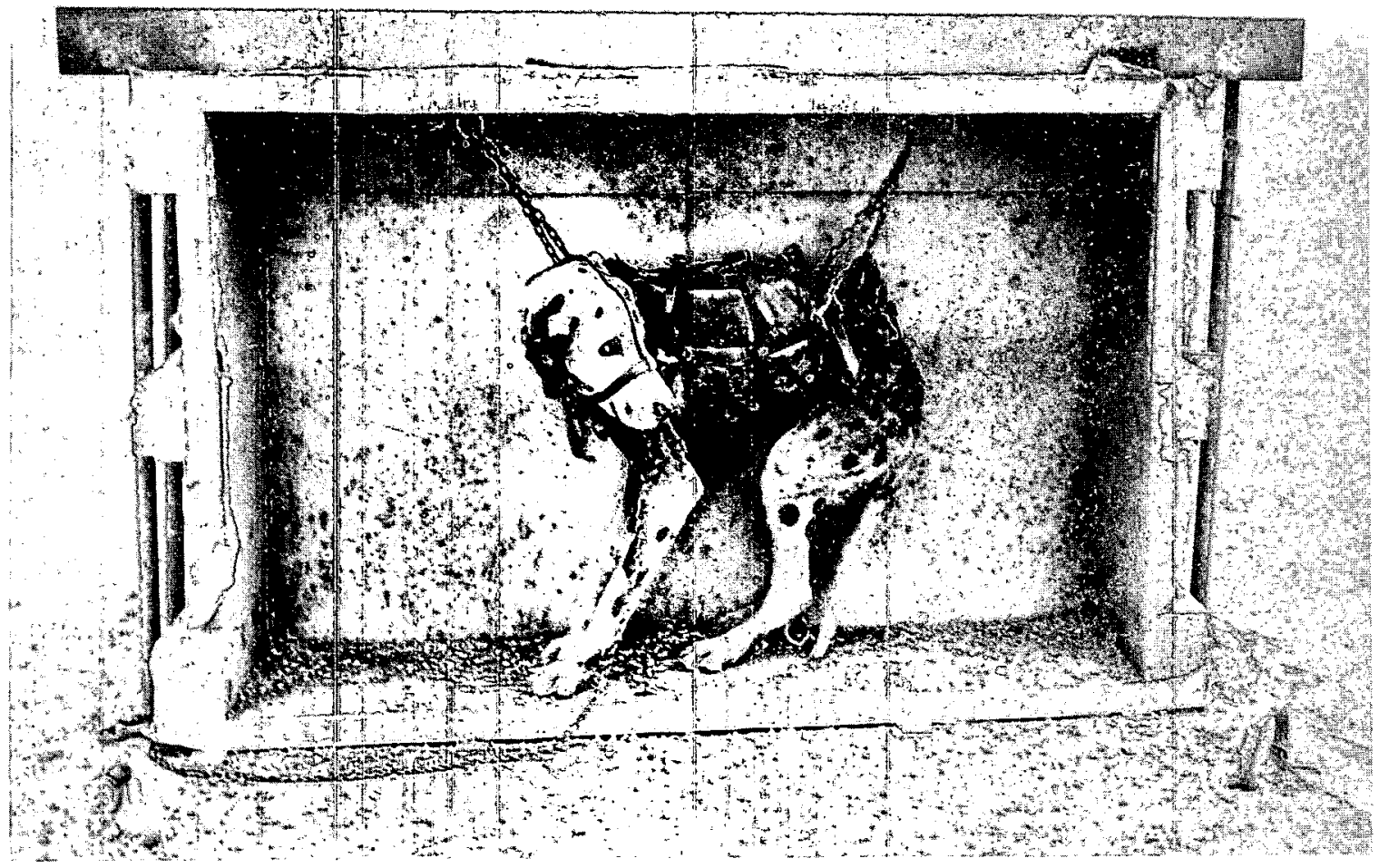

Fig. 3.3 Postshot view of animal behind gravel.

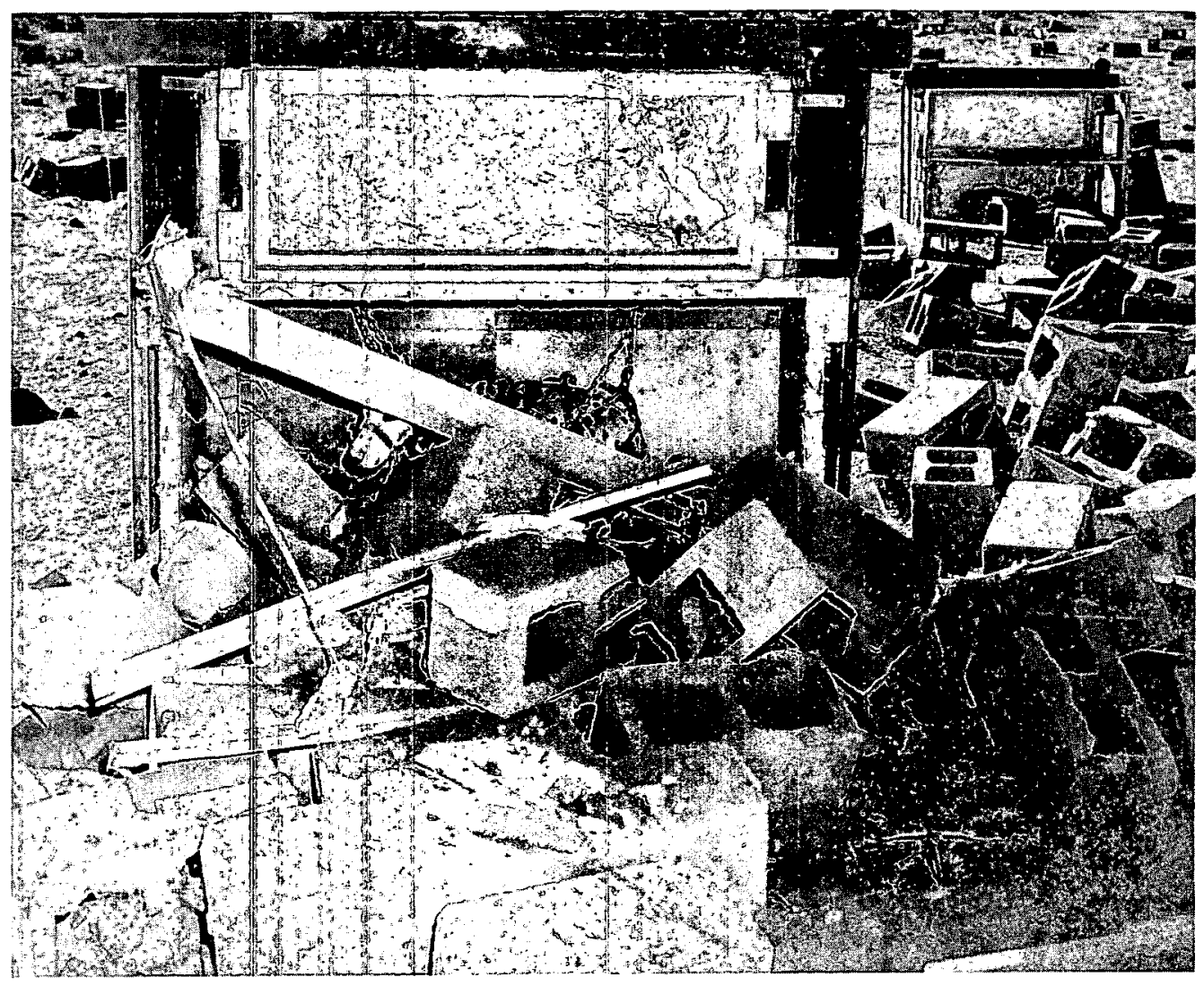

Fig. 3.4 Postshot view of animal behind concrete-block wall. 


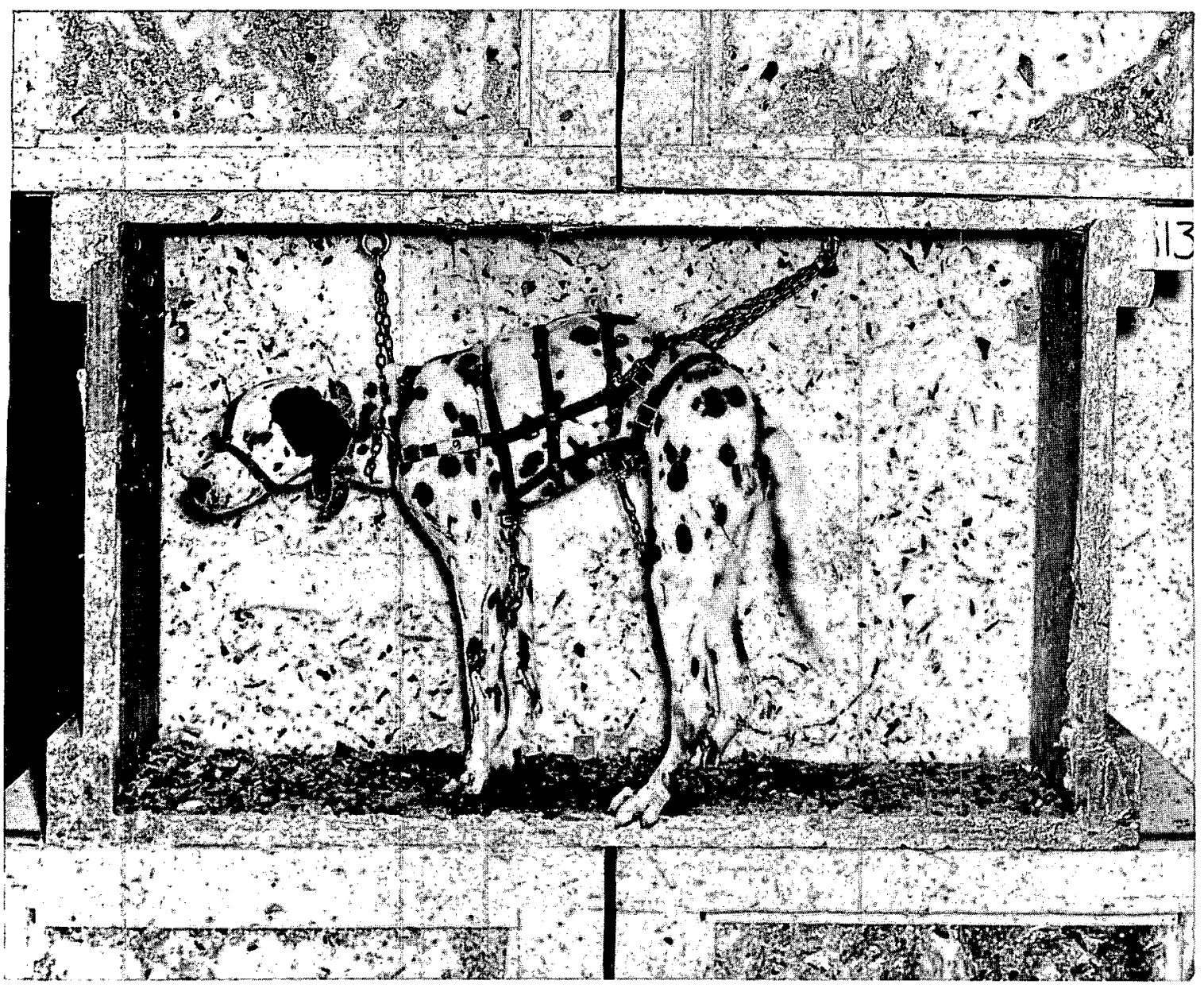

Fig. 3.5 Postshot view of animal in house. 


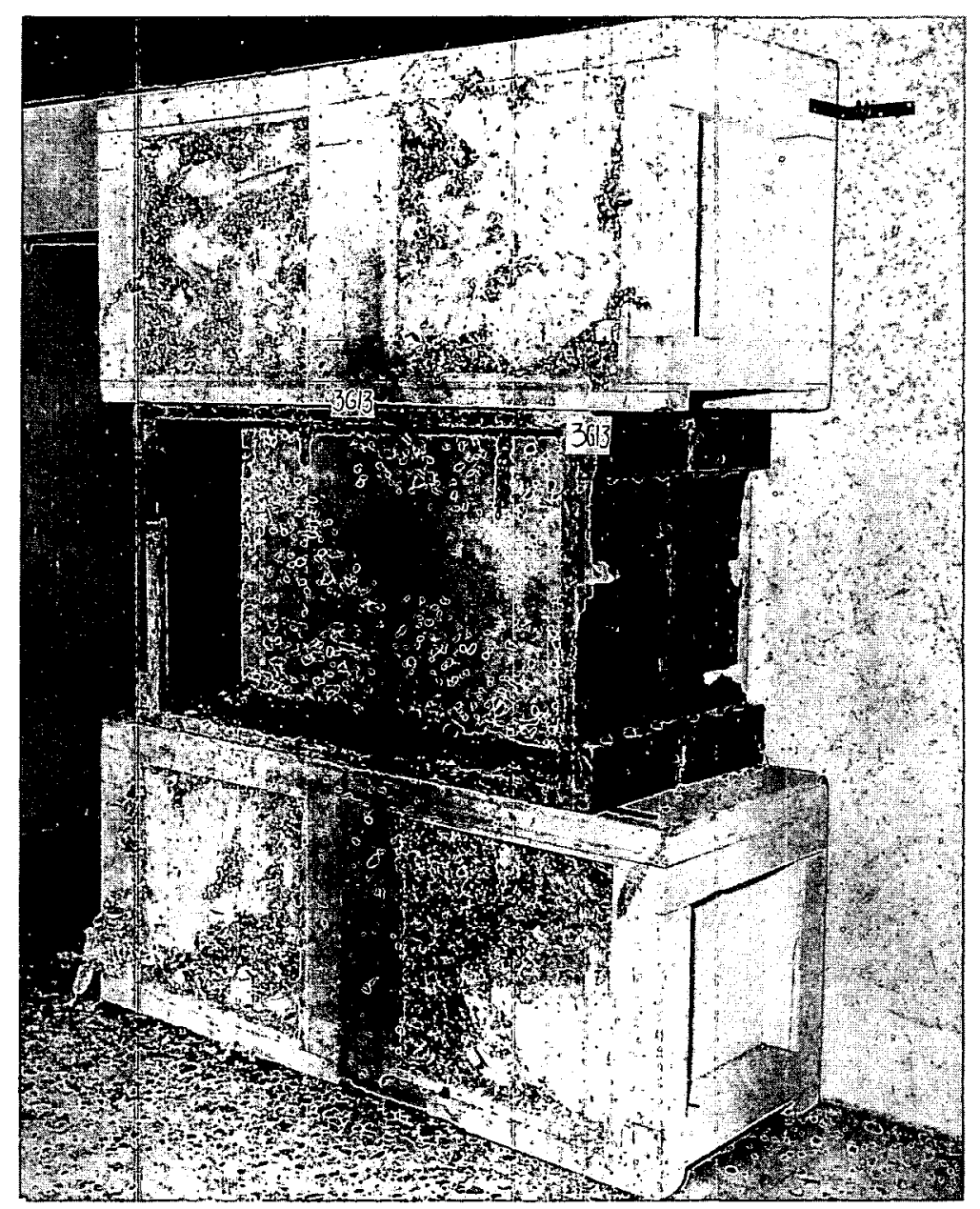

Fig. 3.6 Postshot view of station noted in Fig. 3.5, showing marking of walls and traps and litter on floor.

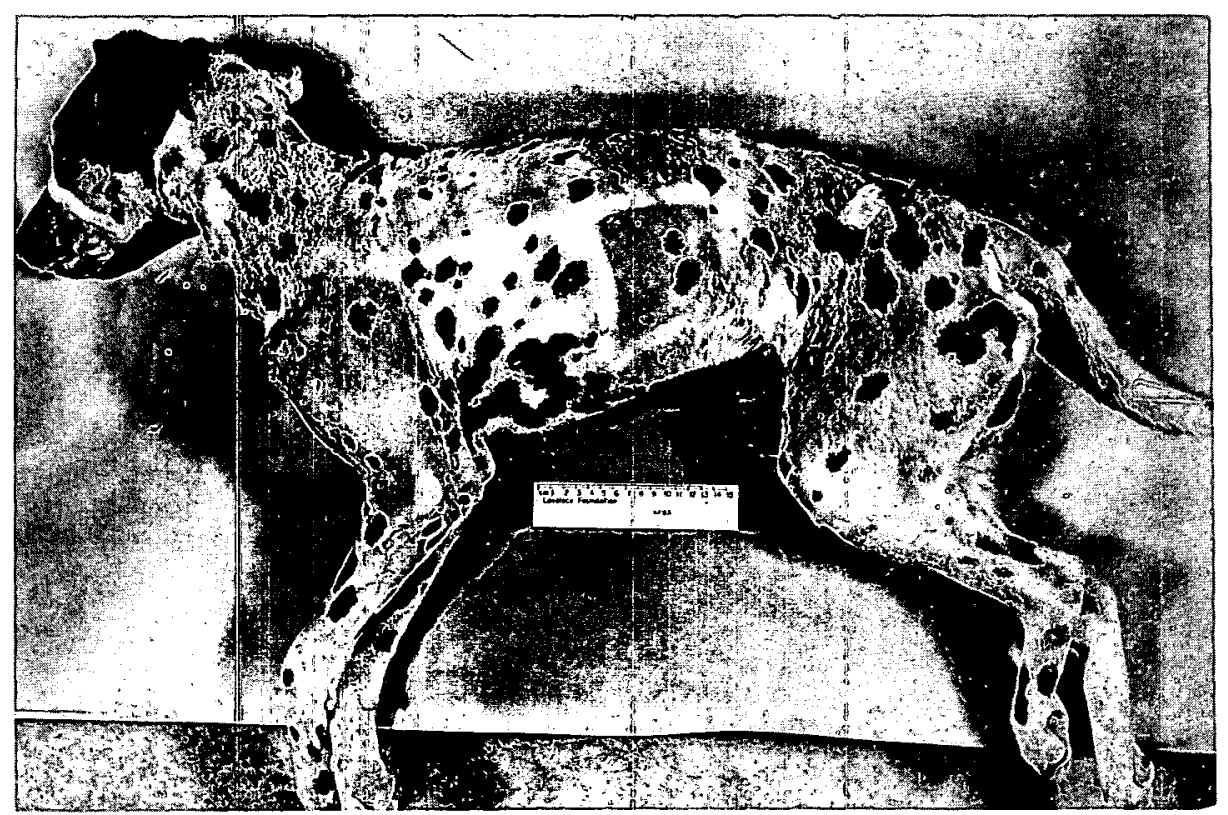

Fig. 3.7 Postshot view of animal, showing singeing. 


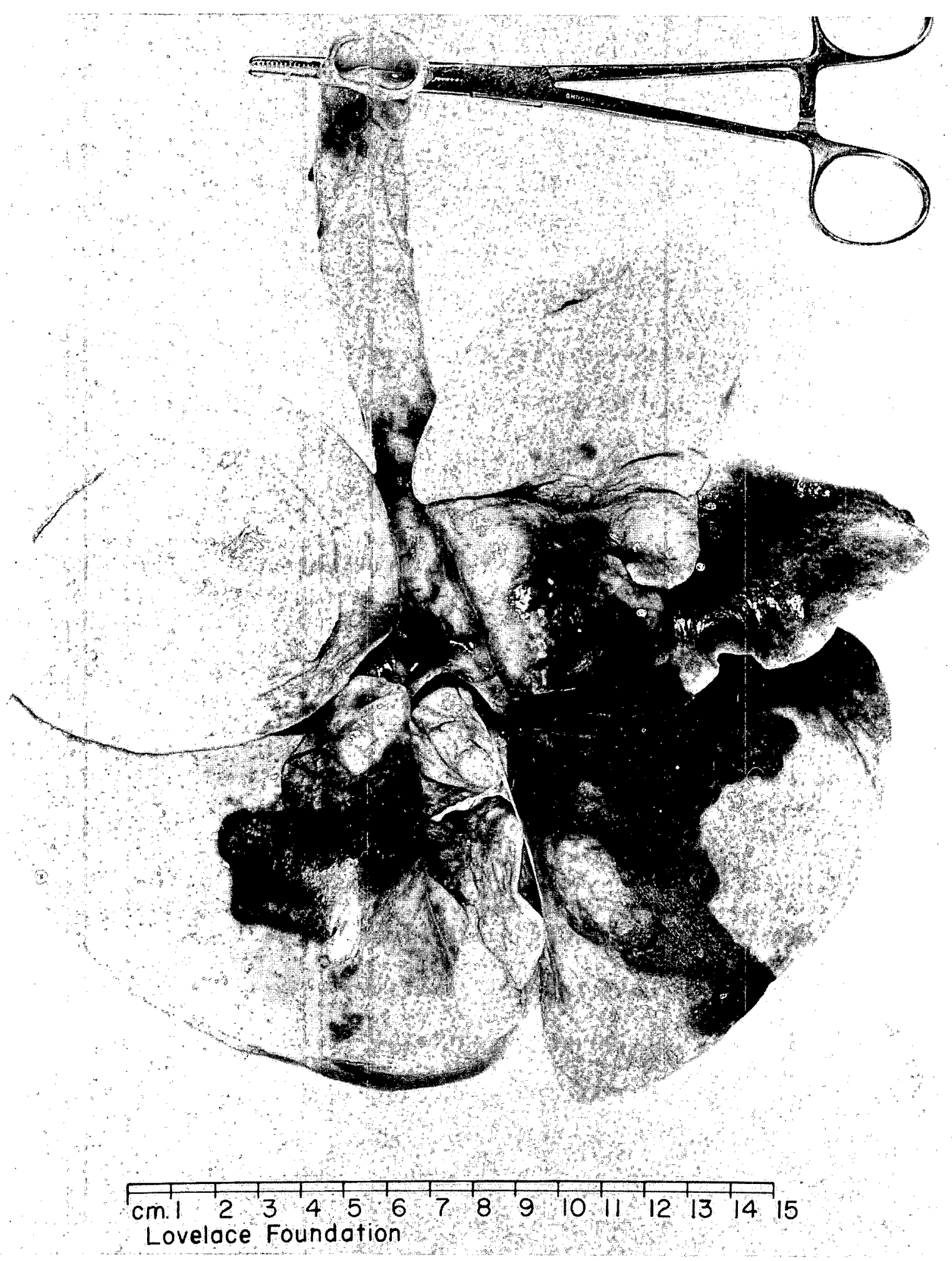

Fig. 3.8 Dorsal view of lungs, showing lung hemorrhages. 


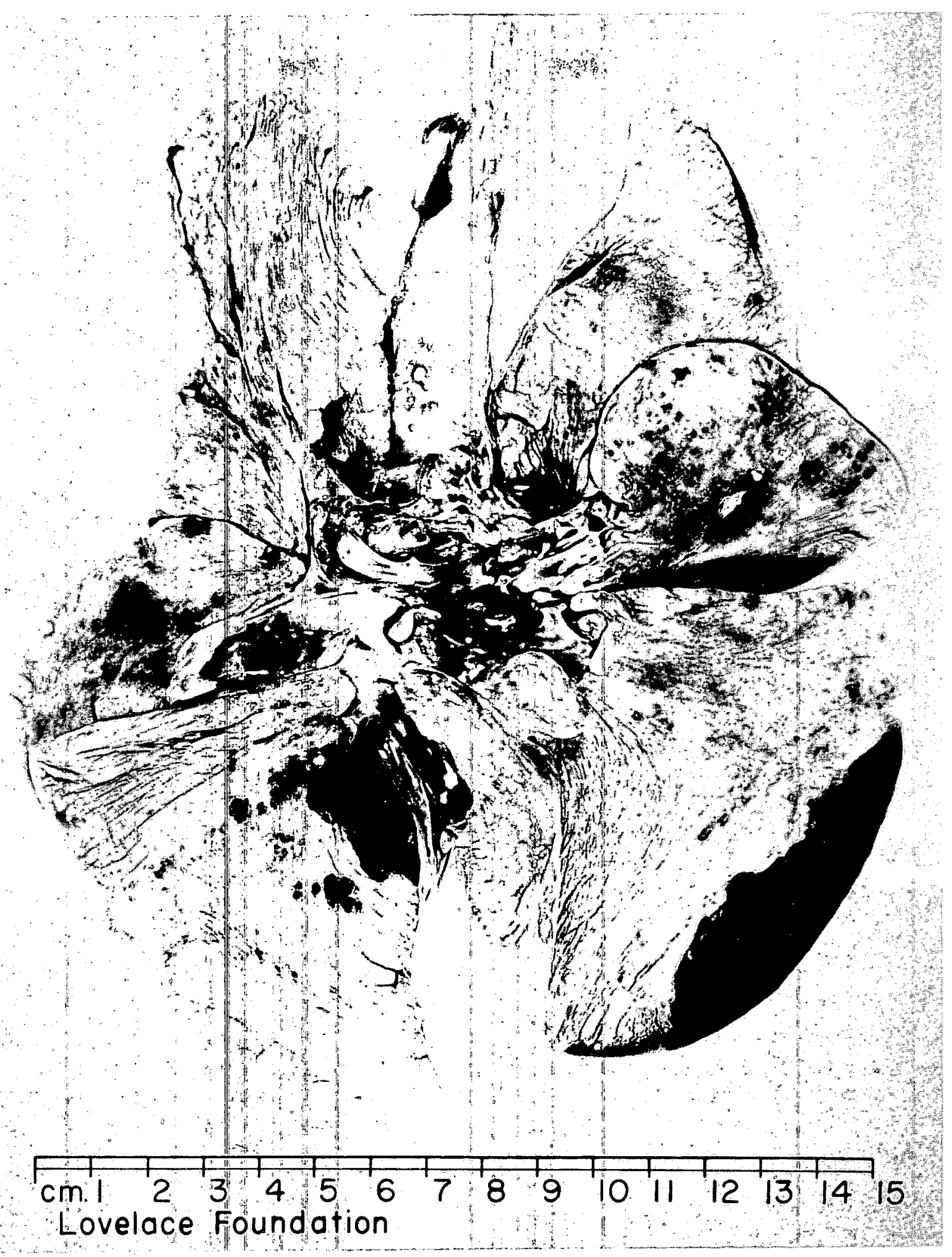

Fig. 3.9 Dorsal view of lungs, showing multiple areas of hemorrhages. 


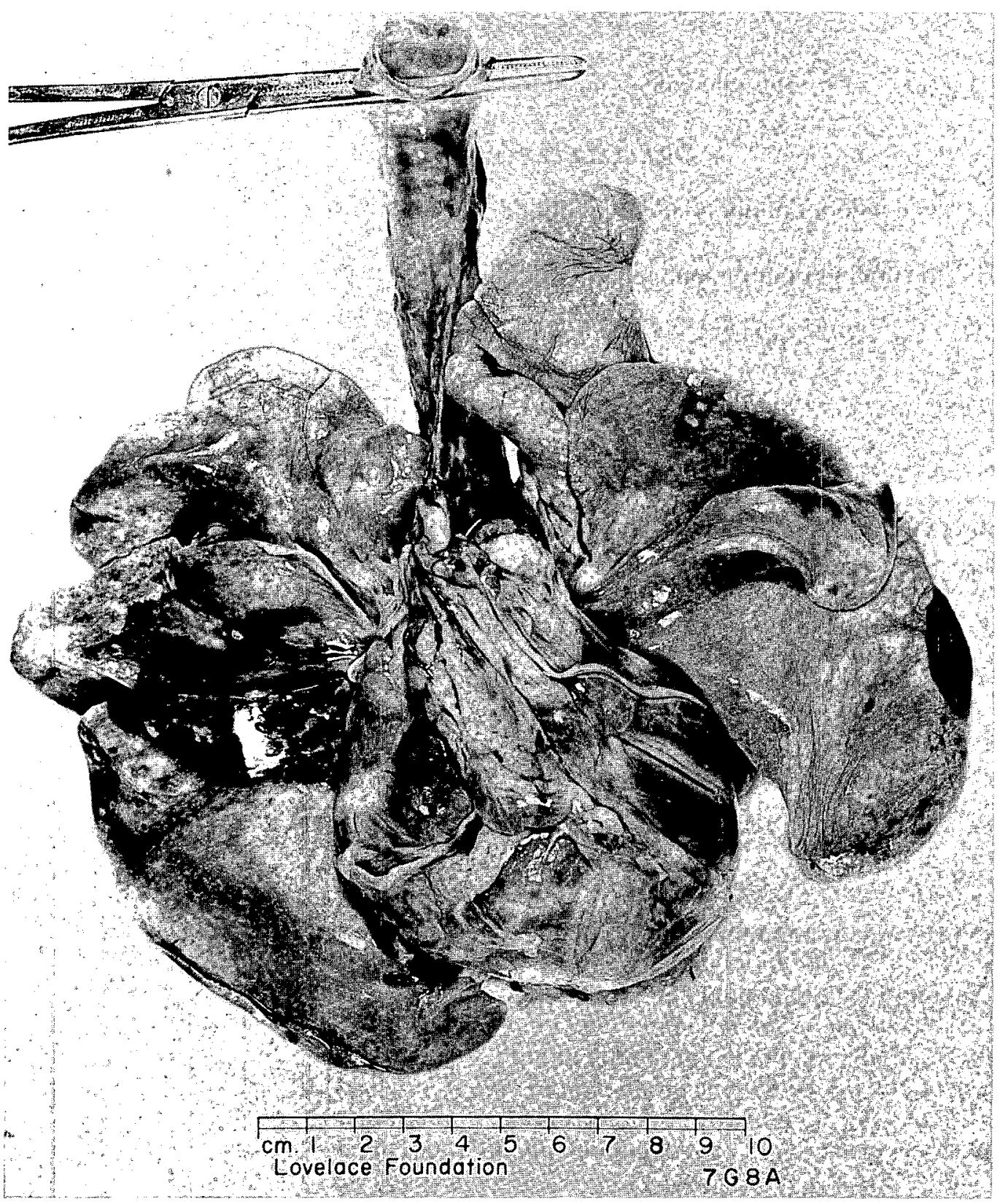

Fig. 3.10 Ventral view of lungs, showing multiple areas of hemorrhages. 


\section{Chapter 4}

\section{RELATION OF ENVIRONMENTAL DATA TO BIOLOGICAL DAMAGE}

\subsection{MISSILES}

\subsubsection{Missile Wounds Observed}

From the material presented thus far it is apparent that the missile wounds observed in the present study were due almost entirely to fragmented glass. Table 4.1 , which includes data from the glass-missile stations at which animals were exposed, was prepared to summarize information referable to total wounds, serious wounds, the wounds per square foot of biologic target, and their relation to overpressure and yield. Incident overpressures measured at the several stations are shown, along with the sea-level equivalent overpressures explained earlier.

A few significant points can be made from the Table 4.1 data. First, consider the average figures at the bottom of the table; there was a total of 260 wounds, an average of 23.6 per animal. Of these, 22 were judged to be serious wounds, a mean of 2 per animal. Thus, on the average, for every 12 wounds suffered by an animal there was one potentially serious insult. Second, in terms of area of the biologic target, there were averages of 13.4 total injuries per square foot; the serious injuries numbered about 1.2 per square foot of presented surface area. Assuming a presented area, face-on, for a 160-lb lightly clothed human to be near $6 \mathrm{sq} f t$ in a similar exposure, the above figures might represent a hazard from window glass involving 80 total wounds, of which 7 could be potentially dangerous to life without early surgical care.

From the data shown in Table 4.1, Fig. 4.1 was prepared to show the relationship between the total number of wounds observed and the incident overpressures measured at NTS altitude. Attention is called to the points marked $3 \mathrm{G} 11$ and $3 \mathrm{G13}$, which refer to the two stations inside houses on the Galileo shot and which were plotted at two overpressures, namely, at 3.8 psi near the left side of the figure (the overpressure incident on the houses) and at 8.5 psi (the computed reflected overpressure) near the right side of the figure. It is obvious that the wounds observed inside the houses can best be compared with those observed at stations in the open on the basis of the reflected pressure that occurred as the incident pressure pulse impinged against the walls of the houses.

Figure 4.2 somewhat similarly shows the relationship between the NTS incident overpressures and the number of wounds observed per square foot of biologic target. Again the data referable to stations 3 G13 and 3 G11 located inside the houses best fit those observed at the open stations on the basis of the reflected rather than the incident overpressure.

Because the Priscilla and Galileo shots involved detonations at different ambient pressures, a somewhat more equitable comparison of results can be realized by normalizing all data to sea-level conditions. Figures 4.3 and 4.4 show the observed total and serious wounds per square foot of biologic target as a function of the incident sea-level equivalent overpressure, assuming that the targets were in houses and that the forces energizing the missiles 
were the reflected pressures and the associated winds. The scatter resulting from the small number of animals and the random nature of the sampling error is readily apparent, particularly with relation to the serious wound data noted in Fig. 4.4.

Also readily apparent is the variation in the intercepts of the regression lines with the pressure axis for Figs. 4.3 and 4.2 , both of which refer to the observed total wounds per square foot of biologic target. In Fig. 4.2, NTS incident overpressure was used, and the meager data at hand indicate that in 50 per cent of the cases the total wounds per square foot approaches zero at about 3.1 psi incident overpressure for animals exposed in the open at NTS altitude. On the other hand, solving the regression equation given in Fig. 4.3 for $\mathrm{W}=0$ shows that the intercept occurs at about $1.7 \mathrm{psi}$. This means that for animals exposed in houses at sea level there will be a 50 per cent chance of wounding at an incident overpressure of only 1.7 psi.

The reader should realize that the data apply only to conditions in which the target is between about 10 and $13 \mathrm{ft}$ from the missile source and to yields in the range from approximately 10 to $40 \mathrm{kt}$. For higher yields it is doubtful, however, that glass missiles at a given overpressure will be travelling much faster than those for the lower yields, but it is certain that the distance over which the missiles maintain near maximum velocity will be greater for the higher than the lower explosive yields. Matters such as these have been discussed elsewhere in more detail. ${ }^{2}$

\subsubsection{Prediction of Missile Wounds}

(a) Project 33.4 Data. Because it is known that the wounding power of a glass fragment, among other things, is a function of its mass and impact velocity and because data are available 3 showing the probability of glass missiles passing through the abdominal wall of dogs to reach the peritoneal cavity as a function of missile mass and velocity, Fig. 4.5 was prepared. The illustration summarizes the 2576 glass missiles recovered from the Priscilla and Galileo missile traps in terms of mass-velocity categories. The numerals in the body of the figure refer to the number of missiles fitting the indicated mass-velocity groupings. The curves marked $P=0, P=0.5$, and $P=1.0$ were taken from Bowen et al. ${ }^{3}$ and, in terms of the velocity and mass scales, express the zero, 50 per cent, and 100 per cent probabilities that missiles would pass into the peritoneal cavity of dogs. The reader will note that 471 missiles lie above the zero probability line, but only 19 are above the 50 per cent probability curve.

The glass-missile data were more precisely analyzed in terms of the probability of penetration of the dog's abdominal wall as follows: all missiles in the sample of 2576 were assessed in relation to the probability curves, and a probability was assigned to each according to its mass-velocity relationship. Following this, the probabilities were summed for each glass-missile station; the results are set forth in columns 5 through 7 of Table 4.2, which also notes the total missiles recovered, the total area of the missile traps at each station, the number of missiles per square foot of missile trap, and the sea-level equivalent overpressures. The fifth column of Table 4.2 shows that, over-all, 76.8 missiles of the total of 2576 could be expected to produce an intraperitoneal lesion in dogs based on the statistical assessment of probabilities. On the average, this comes to 1.1 missiles per square foot of trap area, an interesting average value because the average number of serious wounds observed per square foot of biological target was 1.2 (column 6 of Table 4.1).

Column 7 of Table 4.2 sets forth the predicted data on the basis of intraperitoneal wounds expected per animal using the data for presented area of animals from Table 3.7. Over-all, 22 wounds serious enough to have reached the peritoneal cavity had the abdominal area been struck were expected, an average of 2 per animal. This corresponds exactly to the total serious wounds observed; namely, 22, or 2 per animal, as shown in the third column of Table 4.1.

Although the average correspondence is remarkably close, it is necessary to look critically at the predicted and observed data in the case of each individual dog. These data are summarized in Table 4.3. Application of a simple chi-square $\left(\chi^{2}\right)$ test to the data in Table 4.3 indicated there was, over-all, no statistically significant difference between the number of predicted intraperitoneal wounds and the number of observed serious wounds. However, the table shows considerable variation in the individual case between observed serious wounds and predicted intraperitoneal injuries. The facts are further elucidated and quantitated in Fig. 4.6, 
which shows the distribution of predicted peritoneal wounds per square foot of target area as a function of sea-level equivalent incident overpressure. The spread in data is readily apparent.

A useful comparison of the observed serious wounds and the predicted peritoneal wounds per square foot of target area can be made by using the regression curves from Figs. 4.6 and 4.4 which, for convenience, are shown in Fig. 4.7. A study of the two curves shows that at the higher overpressures the "average" predicted wounds exceeded the "average" observed wounds; i.e., the biological target was not "seeing" the penetrating missiles in the number recorded by the missile traps. Conversely, at the lower overpressures the observed wounds exceeded the predicted values; i.e., the biologic target was receiving penetrating missiles not "seen" by the missile traps. Also, the regression curve for predicted wounds indicates a 50 per cent threshold for intraperitoneal wounds at about 2.4 psi incident overpressure (sea level), but the animal targets received serious wounds below this overpressure.

Another comparison in tabular form is shown in Table 4.4 in which the observed and predicted data are grouped for the higher and lower sea-level equivalent incident overpressures. At the higher incident overpressures, about 20 intraperitoneal wounds were predicted and 14 serious wounds were observed. Thus the prediction was 42.8 per cent above the observed data. At the lower overpressures approximately 2 intraperitoneal wounds were predicted and 8 serious wounds were observed. Thus the prediction was 78.1 per cent too low. Application of a simple $\chi^{2}$ test ${ }^{4}$ to the totals data in Table 4.4 revealed a significant difference between the predicted and observed figures when comparing the higher with the lower overpressure regions. However, because of the small sample and the great variability in the figures, a simple $\chi^{2}$ test ${ }^{4}$ of the data for predicted and observed wounds at the five higher-overpressure regions revealed no significant difference; i.e., the variation observed might well have been due to chance. Such was also the case with lower overpressures.

A more sophisticated application of the $\chi^{2}$ function, ${ }^{5}$ however, revealed that the figures for the lower regions of overpressure for observed and predicted wounds showed a difference that was significant $(P=<0.001)$, a difference greater than that which would be expected from chance alone. A similar analysis of the higher overpressure region revealed a probability of 0.10 , indicating no essential difference in the observed and predicted wounds.

Such observations suggest that the missile traps at the several stations were not providing a very accurate sample of the missile environment that actually existed where each individual animal was located, although, on the over-all average, the correspondence between observed and predicted figures was quite good. This was true because the overprediction at higher overpressures compensated somewhat for the underprediction at the lower overpressures. This matter and the problem of assuming any similarity between the arbitrary criteria utilized to define the serious observed wounds and the data employed to predict intraperitoneal wounds will be considered in another section.

Another group of analytical observations concerns the square-foot distribution of total missiles captured by the missile traps as a function of overpressure, shown in Fig. 4.8, compared with the square-foot distribution of total wounds received by the biologic target, shown in Fig. 4.3. Figure 4.9 makes such a comparison. The fact that so many more missiles were trapped at the higher overpressure than there were wounds observed is surprising even in view of the fact that many more glass missiles of smaller masses are known to be formed at higher overpressures than at lower overpressures. ${ }^{3,6}$

An observation equally significant concerns the fact that the regression curve for the total observed missiles goes to zero at a little over 2 psi even though the regression curve for the total wounds does not reach zero until the overpressure is near $1.7 \mathrm{psi}$. These observations strengthen the conclusion that the missile traps were not adequately sampling the missile environment of each of the animals.

(b) Comparison with Selected Data from Project 33.2. The difficulties just mentioned, wherein the missile traps located above the animals apparently gave less than a desirable assessment of the missile environment to which each was exposed, stimulated an analysis similar to that described in Sec. 4.1.2a using data from missile traps placed at ground level, previously detailed in Sec. 3.3.1b. The results are summarized in Table 4.5, which was compiled from figures presented in Tables 3.4, 3.5, 4.1, and 4.2 and which also contains data from the two missile-trap stations in the houses. The latter were included because the missile traps were placed both above and below the animal locations. 
In the material that follows, information in Table 4.5 referable to missiles and prediction of intraperitoneal wounds will be spoken of as the "Series B data" in contrast with Project 33.4 figures used thus far in this chapter which will be termed "Series A data."

A study of Table 4.5 reveals a number of interesting facts, which, for convenience, are summarized in Table 4.6. First, there were 193 wounds observed, of which 18 were serious, giving an average ratio of total to serious wounds of 10.7. The ratio was 11.4 and 9.3 for the higher and lower overpressures, respectively.

Second, a total of 16.7 intraperitoneal wounds was predicted from the Series B missile data; this compares favorably with the empirical finding of 18 serious wounds, the predicted figure being only 7.2 per cent below the observed. $\mathrm{A} \chi^{2}$ test $^{5}$ indicated that there was no significant difference between the empirical and predicted figures, there being a 71 per cent probability that chance alone could explain the variations in the data.

Third, at the higher overpressures 12 serious wounds were documented and 13.4 intraperitoneal wounds were predicted, making the predicted wounds 11.7 per cent above the observed serious wounds. At the lower overpressures 3.4 intraperitoneal wounds were predicted and 6 were observed. In neither case were there statistically significant differences between the empirical and predicted figures, although at the lower overpressures the prediction was 44.2 per cent below the observed wounds, with only 6 chances in a 100 that the variations were caused by spurious factors alone. For the higher overpressures a more clear-cut statistical indication that chance variations explained the difference noted was obtained, as shown by the probability figure of 0.65 noted at the bottom of Table 4.5.

Fourth, in the Series B data an average of 41.5 missiles per square foot of missile trap was recorded with which was associated an average figure of about 13.6 wounds per square foot of biologic target, nearly 1.3 of which were serious. Thus, for every square foot of target, 1 in 3 of the trapped and recorded missiles produced a wound; whereas, 1 in 32 trapped missiles produced a serious wound. At the higher overpressures an average of 60.87 glass missiles was recorded per square foot of trap associated with 19.1 and 1.7 total and serious wounds per square foot of target, respectively. These data show that for each square foot of target, 5 of every 16 missiles ( 1 in every 3.2) produced a wound and 1 in every 36 caused an injury judged serious. At the lower overpressures there was an average of 22.1 missiles per square foot of trap associated with 8.1 and 0.9 total and serious wounds, respectively. Of every 11 missiles per square foot, 4 caused a wound ( 1 in 2.75 ); whereas, only 1 in 25 per square foot produced a serious wound.

Although the data are meager, it is instructive to delete the missile-trap stations in houses from the Series A figures and compare only the results for missile traps located above the animals with those for missile traps placed at animal level. Such a comparison appears in Table 4.7, which details information from Tables 4.4 and 4.5. It is clear that the Project $33.4 \mathrm{mis}-$ sile traps (those above the animals) gave a predicted result 39 per cent above the observed figures; whereas, the Project 33.2 traps (those located at animal level) gave a predicted figure only 2 per cent below the observed number. Such a result strengthens the supposition that missile-trap data can indeed be utilized to sample the physical environment in a way that is reliable and biologically significant, provided sufficient attention is given to experimental design.

A number of graphic presentations are helpful to further illustrate the improvement in the prediction technique. For example, Fig. 4.10 shows the Series B predictions for intraperitoneal wounds per square foot of target as a function of the sea-level-equivalent overpressure. Comparisor with the Series A data in Fig. 4.6 shows much less spread in the results and a more horizontal slope of the regression level. The meaning of this is further elucidated by studying Fig. 4.11, which compares the regression lines for the Series A and B predictions of intraperitoneal wounds with that for the observed serious wounds, the parameters being sea-levelequivalent incident overpressure and wounds per square foot of target area. It is obvious the Series B prediction is much nearer the observed data, although the curve for the observed data has an intercept with the $x$ axis 1.4 psi (the 50 per cent threshold of serious wounds for animals in houses would occur at a sea-level-equivalent incident overpressure of 1.4 psi); whereas, the curve for the predicted data has an intercept at 1.93 psi (50 per cent of the predicted intraperitoneal wounds would occur at sea-level incident overpressure as low as 1.9 psi). 
Whether or not this apparent error of $0.5 \mathrm{psi}$ is real or not depends, among other things, upon whether the criteria arbitrarily adopted for serious wounds is indeed similar to that associated with intraperitoneal wounds. This point will be discussed later; however, it can be said now that even if the criteria were identical, the correspondence between the predicted and observed data would be remarkably close, particularly in view of the small number of serious wounds associated with using so few animals to sample the wounding potential of window-glass missiles.

Figure 4.12, which gives the observed total number of incident glass missiles per square foot of missile trap for the Series B data as a function of sea-level-equivalent overpressure, also shows a much narrower spread in the data than was the case with the Series A figures presented in Fig. 4.8. Also, the slope of the regression line for Series B data was less steep, as illustrated in Fig. 4.13, which compares the Series A and B regression curves with one which shows the total wounds observed as functions of missiles or wounds per square foot of target and overpressure. That the intercept for the total observed wounds and the Series $B$ missile data proved to be $1.67 \mathrm{psi}$ and $1.71 \mathrm{psi}$, respectively, provides a satisfying result which greatly strengthens the confidence which may be placed in the Styrofoam missile-trapping technique as an indicator of biologic hazard.

Since it was mentioned earlier that the possibility of wounding from glass missiles is a function of, among other things, the mass and impact velocity of a given missile, Table 4.8 was prepared from the data in Tables 3.4, 3.5, and 3.6 to show how missile mass and velocity generally behave as a function of overpressure. Series A and B data for window glass were used. Figure 4.14 graphically shows the average trend in the results. Generally, missile velocity increases with increasing overpressure in a near linear manner, but missile mass decreases exponentially with increasing overpressure.

The biological significance of such relationships can be emphasized by pointing out that such data can be employed to assess the "average" probabilities of a glass fragment entering the peritoneal cavity of a dog as a function of overpressure. It is only necessary to read the geometric mean velocities and masses for a given overpressure from Fig. 4.14, which gives the median arithmetic values for these parameters since the distributions are skewed, and to utilize the empirical equation of Bowen et $a .^{3}$ to compute the required probabilities. The equation is:

$$
P=\frac{\log V-2.5172+\log (\log m+2.3054)}{0.4842}
$$

where $\mathbf{P}=$ probability

$\mathrm{V}=$ velocity in feet per second

$\mathbf{m}=$ mass in grams

\subsection{PRIMARY BLAST DAMAGE}

Table 4.9 summarizes the relations between the incident and reflected overpressures and the observed gross pathology associated with variations in environmental pressure. The duration of the reflected overpressures at each station is also shown. Grade I lung hemorrhage (meaning minimal to slight damage) was observed in three dogs. In Each case the hemorrhage was bilateral but was more marked on the right, the side of the animal which was away from GZ and against or near the Styrofoam pad forming the anterior portion of the rear wall of the animal trap. It is, of course, possible that displacement of the animal against the rear wall of the missile trap might have been a factor in producing the lung lesions. However, this seems unlikely since in no instance was the light Styrofoam 22 deformed by the animal's body. It is well to point out here that, with the possible exception of the animals located in the houses (3G11C and 3G13C), the maximal overpressures to which animals were exposed was not the free-field incident overpressures that were measured or estimated, but were approximately those which were reflected from the rear wall of the animal traps. Figures for these were computed and are shown in Table 4.9.

Grade II lung hemor rhage was observed in dog 7G3A, which was exposed behind the wall on the Galileo detonation. Again, lung damage was greater on the right side. This was the side 
that was adjacent to the wall of the missile trap. Although the lung damage noted was probably due to the sharply rising overpressure and its reflection, the possible contribution of nonpenetrating missile impact cannot be excluded since it is known to produce contusions of the lung. ${ }^{7-9}$

Seven of 28 eardrums were ruptured. All of these were ruptured at incident and reflected overpressures above 8.4 and 21.2 psi, respectively. Of the remaining 21 eardrums, 13 were hemorrhagic, 4 were hyperaemic, and 4 showed no pathology. The latter were from animals located inside the houses at an incident pressure of $3.8 \mathrm{psi}$, where significant reflection of the pressure would hardly occur, although high reflected pressures could be expected outside on the wall facing the blast. In contrast animal 3G8A, which was also exposed to a 3.8-psi incident pressure, but was located in the open in an animal trap where pressure reflection could be expected, exhibited bilaterally hemor rhagic tympanic membranes.

Only one case of hemorrhage into the paranasal sinuses was noted. This was in animal 7G7A, which was exposed to an incident overpressure of 8.4 psi (21.2 psi reflected).

\section{REFERENCES}

1. Samuel Glasstone, Ed., "The Effects of Nuclear Weapons," U. S. Government Printing Office, Washington 25, D. C., June 1957.

2. I. G. Bowen et al., A Model Designed to Predict the Motion of Objects Translated by Classical Blast Waves, Report CEX-58.9 (in preparation).

3. I. G. Bowen et al., Biological Effects of Blast from Bombs. Glass Fragments as Penetrating Missiles and Some of the Biological Implications of Glass Fragmented by Atomic Explosions, Report AECU-3350, Lovelace Foundation, June 18, 1956.

4. R. A. Fisher, "Statistical Methods for Research Workers," 10th ed., Oliver \& Boyd Ltd., Edinburgh, 1946.

5. R. S. Burington and D. C. May, "Handbook of Probability and Statistics with Tables," pp. 178-180, Handbook Publishers, Inc., Sandusky, Ohio, 1958.

6. I. G. Bowen, A. F. Strehler, and M. B. Wetherbe, Distribution and Density of Missiles from Nuclear Explosions, Operation Teapot Report, WT-1168, December 1956.

7. C. S. White and D. R. Richmond, Blast Biology, Report TID-5764, September 1959.

8. C. S. White and I. G. Bowen, Comparative Nuclear Effects of Biomedical Interest, Report CEX-58.8 (in preparation).

9. Külbs, Lunge and Trauma, Arch. exp. Pathol. Pharmakol. Naunyn-Schmiedeberg's, 62: 3946 (1909). 
TABLE 4.1 - OBSERVED TOTAL AND SERIOUS WOUNDS AND THE TOTAL AND SERIOUS WOUNDS PER SQUARE FOOT OF BIOLOGIC TARGET

RELATED TO OVERPRESSURE

\begin{tabular}{|c|c|c|c|c|c|c|c|c|}
\hline \multirow{2}{*}{$\begin{array}{l}\text { Station } \\
\text { No. }\end{array}$} & \multicolumn{2}{|c|}{$\begin{array}{c}\text { Wounds } \\
\text { per animal }\end{array}$} & \multirow{2}{*}{$\begin{array}{l}\text { Animal } \\
\text { target } \\
\text { area, } \\
\text { sq ft }\end{array}$} & \multicolumn{2}{|c|}{$\begin{array}{l}\text { Wounds per sq } \mathrm{ft} \\
\text { of animal }\end{array}$} & \multicolumn{2}{|c|}{$\begin{array}{l}\text { Incident pressure, } \\
\text { psi }\end{array}$} & \multirow{2}{*}{$\begin{array}{l}\text { Approximate } \\
\text { yield, }{ }^{*} \mathrm{kt}\end{array}$} \\
\hline & Total & Serious & & Total & Serious & Nevada & equivalent & \\
\hline 8P2 & 49 & 2 & 1.81 & 27.07 & 1.10 & 8.6 & 4.25 & 38 \\
\hline $6 P 2$ & 20 & 2 & 1.74 & 11.49 & 1.15 & 6.4 & 3.23 & \\
\hline $5 \mathrm{P} 2$ & 14 & 4 & 1.66 & 8.43 & 2.41 & 5.6 & 2.87 & \\
\hline $5 P 3$ & 15 & 1 & 1.78 & 8.43 & 0.562 & 5.6 & 2.87 & \\
\hline $4 \mathrm{P} 2$ & 8 & 0 & $1.75 \dagger$ & 4.57 & 0 & 4.6 & 2.41 & \\
\hline $4 P 3$ & 4 & 1 & 1.48 & 2.70 & 0.676 & 4.6 & 2.41 & \\
\hline $7 \mathrm{G} 7$ & 48 & 2 & 1.72 & 27.91 & 1.16 & 8.4 & 4.32 & 11 \\
\hline $7 \mathrm{G} 8$ & 15 & 2 & 1.75 & 8.57 & 1.14 & 8.4 & 4.32 & \\
\hline $3 \mathrm{G} 8$ & 14 & 0 & 1.82 & 7.69 & 0 & 3.8 & 2.12 & \\
\hline $3 \mathrm{G} 11$ & 36 & 2 & 1.88 & 19.15 & 1.06 & $3.8(8.5)+$ & 4.45 & \\
\hline $3 \mathrm{G} 13$ & 37 & 6 & 1.73 & 21.39 & 3.47 & $3.8(8.5)+$ & 4.45 & \\
\hline Totals & 260 & 22 & 19.12 & 147.40 & 12.728 & & & \\
\hline Av. & 23.6 & 2 & 1.74 & 13.40 & 1.157 & & & \\
\hline
\end{tabular}

* See Table 3.5.

tArea assumed to be that of average for animals noted in Table 3.7.

$\$$ Figures in parentheses show computed reflected pressures, ${ }^{1}$ which crudely can be taken to represent the incident overpressure that would have been required to produce similar missile behavior had the windows in the houses been mounted in the open as was the case with all other glass-missile stations.

TABLE 4.2-PREDICTION OF INTRAPERITONEAL WOUNDS FROM OBSERVED MISSILE DATA AS RELATED TO SEA-LEVEL EQUIVALENT INCIDENT OVERPRESSURE

\begin{tabular}{|c|c|c|c|c|c|c|c|}
\hline $\begin{array}{c}\text { Trap } \\
\text { No. }\end{array}$ & $\begin{array}{l}\text { Trap } \\
\text { area, } \\
\text { sq ft }\end{array}$ & $\begin{array}{c}\text { Total } \\
\text { missiles } \\
\text { recovered }\end{array}$ & $\begin{array}{l}\text { Total } \\
\text { missiles } \\
\text { per sq } \mathrm{ft} \\
\text { of trap }\end{array}$ & $\begin{array}{r}\text { Number } \\
\text { penetrate } \\
\text { Total }\end{array}$ & $\begin{array}{l}\text { dominal } \\
\text { Per } \\
\text { sq ft }\end{array}$ & $\begin{array}{l}\text { ected to } \\
\text { ll of dogs } \\
\text { Per } \\
\text { animal }\end{array}$ & $\begin{array}{c}\text { Incident } \\
\text { overpressure } \\
\text { (sea level), } \\
\text { psi }\end{array}$ \\
\hline 8P2 & 2.754 & 497 & 180.465 & 11.991 & 4.354 & 7.880 & 4.25 \\
\hline $6 \mathrm{P} 2$ & 2.754 & 105 & 38.126 & 0.355 & 0.129 & 0.224 & 3.23 \\
\hline $5 \mathrm{P2}$ & 2.754 & 88 & 31.954 & 0.751 & 0.273 & 0.453 & 2.87 \\
\hline 5P3 & 2.754 & 9 & 3.268 & 0.192 & 0.070 & 0,124 & 2.87 \\
\hline $4 \mathrm{P} 2$ & 2.754 & 48 & 17.429 & 1.258 & 0.457 & 0.799 & 2.41 \\
\hline $4 \mathrm{P3}$ & 2.754 & 1 & 0.363 & 0 & 0 & 0 & 2.41 \\
\hline $7 \mathrm{G} 7$ & 2.754 & 32 & 11.619 & 1.410 & 0.512 & 0.881 & 4.32 \\
\hline $7 \mathrm{G} 8$ & 2.754 & 127 & 46.115 & 6.794 & 2.467 & 4.317 & 4.32 \\
\hline $3 G 8$ & 2.754 & 15 & 5.447 & 0.235 & 0.085 & 0.155 & 2.12 \\
\hline $3 G 11$ & 14.064 & 947 & 67.335 & 27.051 & 1.923 & 3.617 & 4.45 \\
\hline $3 G 13$ & 14.064 & 707 & $\mathbf{5 0} .270$ & 26.761 & 1.903 & 3.292 & 4.45 \\
\hline Totals & 52.914 & 2576 & 452.391 & 76.798 & 12.173 & 21.742 & \\
\hline Av. & & & 41.127 & 6.982 & 1.107 & 1.977 & \\
\hline
\end{tabular}


TABLE 4.3-OBSERVED SERIOUS WOUNDS AND PREDICTED INTRAPERITONEAL WOUNDS PER ANIMAL*

\begin{tabular}{|c|c|c|c|c|c|}
\hline \multirow{2}{*}{$\begin{array}{l}\text { Station } \\
\text { No. }\end{array}$} & \multicolumn{2}{|c|}{$\begin{array}{l}\text { Observed } \\
\text { wounds }\end{array}$} & \multirow{2}{*}{$\begin{array}{c}\text { Predicted } \\
\text { intraperitoneal } \\
\text { wounds }\end{array}$} & \multirow{2}{*}{$\begin{array}{l}\text { Predicted minus } \\
\text { observed wounds }\end{array}$} & \multirow{2}{*}{$\begin{array}{c}\text { Incident } \\
\text { overpressure } \\
\text { (sea level), } \\
\text { psi }\end{array}$} \\
\hline & Total & Serious & & & \\
\hline $8 \mathrm{P} 2$ & 49 & 2 & 7.880 & +5.880 & 4.25 \\
\hline $6 \mathrm{P} 2$ & 20 & 2 & 0.224 & -1.776 & 3.23 \\
\hline $5 \mathrm{P} 2$ & 14 & 4 & 0.453 & -3.547 & 2.87 \\
\hline 5P3 & 15 & 1 & 0.124 & -0.876 & 2.87 \\
\hline $4 \mathrm{P} 2$ & 8 & 0 & 0.799 & +0.799 & 2.41 \\
\hline $4 \mathrm{P3}$ & 4 & 1 & 0 & -1.000 & 2.41 \\
\hline $7 \mathrm{G} 7$ & 48 & 2 & 0.881 & -1.119 & 4.32 \\
\hline $7 \mathrm{G} 8$ & 15 & 2 & 4.317 & +2.317 & 4.32 \\
\hline $3 \mathrm{G} 8$ & 14 & 0 & 0.155 & +0.155 & 2.12 \\
\hline $3 \mathrm{G} 11$ & 36 & 2 & 3.617 & +1.617 & 4.45 \\
\hline $3 \mathrm{G} 13$ & 37 & 6 & 3.292 & -2.708 & 4.45 \\
\hline Total & 260 & 22 & 21.742 & -0.258 & \\
\hline Av. & 23.6 & 2 & 1.977 & -0.023 & \\
\hline
\end{tabular}

$* \chi^{2}=12.945 ; \mathrm{N}=10 ; \mathrm{P}=0.229$. The observed serious wounds do not differ significantly from the predicted intraperitoneal wounds; the observed differences can be explained on the basis of chance alone.

TABLE 4.4-COMPARISON OF OBSERVED SERIOUS WOUNDS WITH PREDICTED INTRAPERITONEAL WOUNDS GROUPED FOR THE LOWER AND HIGHER OVERPRESSURES*

\begin{tabular}{|c|c|c|c|c|c|}
\hline Station No. & $\begin{array}{c}\text { Incident sea-level- } \\
\text { equivalent } \\
\text { overpressure, } \\
\text { psi }\end{array}$ & $\begin{array}{l}\text { Observed } \\
\text { serious }\end{array}$ & $\begin{array}{l}\text { of wounds } \\
\text { Predicted } \\
\text { intra- } \\
\text { peritoneal }\end{array}$ & $\begin{array}{l}\text { Predicted minus } \\
\text { observed wounds }\end{array}$ & $\begin{array}{c}\text { Difference, } \\
\%\end{array}$ \\
\hline \multicolumn{6}{|c|}{ Higher overpressures } \\
\hline $3 G 11$ & 4.45 & 2 & 3.617 & +1.617 & \\
\hline $3 \mathrm{G} 13$ & 4.45 & 6 & 3.292 & -2.708 & \\
\hline $7 \mathrm{G7}$ & 4.32 & 2 & 0.881 & -1.119 & \\
\hline $7 \mathrm{G} 8$ & 4.32 & 2 & 4.317 & +2.317 & \\
\hline $8 \mathrm{P} 2$ & 4.25 & 2 & 7.880 & +5.880 & \\
\hline Totals & & 14 & 19.987 & +5.987 & +42.8 \\
\hline \multicolumn{6}{|c|}{ Lower overpressures } \\
\hline 6P2 & 3.23 & 2 & 0.224 & -1.776 & \\
\hline 5P2 & 2.87 & 4 & 0.453 & -3.547 & \\
\hline $5 \mathrm{P3}$ & 2.87 & 1 & 0.124 & -0.876 & \\
\hline $4 \mathrm{P} 2$ & 2.41 & 0 & 0.799 & +0.799 & \\
\hline 4P3 & 2.41 & 1 & 0 & -1.000 & \\
\hline $3 G 8$ & 2.12 & 0 & 0.155 & +0.155 & \\
\hline Totals & & 8 & 1.755 & -6.245 & -78.1 \\
\hline
\end{tabular}

${ }^{*} \chi^{2}=4.658 ; \mathrm{N}=1 ; \mathrm{P}=0.034$. It is probable that there is a statistically significant difference between the higher and lower overpressures in comparing the observed serious wounds and the predicted intraperitoneal wounds; only 34 times in a thousand would one expect the differences noted on the basis of chance alone. 
TABLE 4.5- OBSERVED AND PREDICTED INTRAPERITONEAL WOUNDS USING WINDOW-GLASS MISSILE DATA TAKEN FROM MISSILE TRAPS LOCATED AT OR VERY NEAR ANIMAL LEVEL

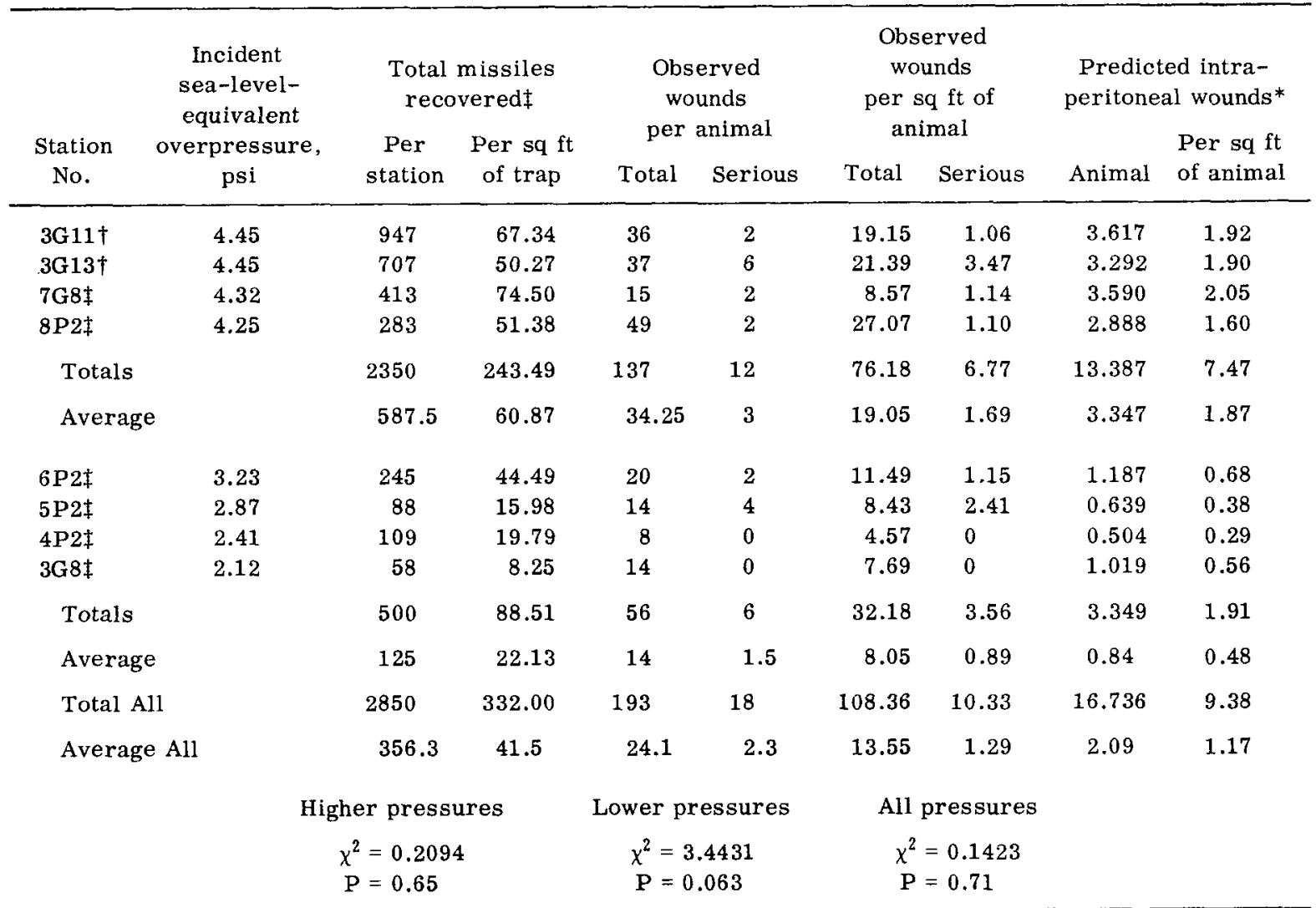

* Arbitrarily termed Series B data (see text).

†Project 33.4 Missile traps (see Tables 3.4 and 4.2)

$\ddagger$ Project 33.2 Missile traps (see Table 3.5).

TABLE 4.6-SUMMARY OF TOTAL AND AVERAGE DATA FOR OBSERVED TOTAL AND SERIOUS WOUNDS AND PREDICTED INTRAPERITONEAL WOUNDS

\begin{tabular}{|c|c|c|c|c|c|c|c|}
\hline & \multicolumn{3}{|c|}{$\begin{array}{l}\text { Observed wounds } \\
\text { in animals }\end{array}$} & \multicolumn{2}{|c|}{$\begin{array}{l}\text { Observed wounds } \\
\text { per sq } \mathrm{ft} \text { of animal }\end{array}$} & \multicolumn{2}{|c|}{$\begin{array}{l}\text { Predicted intra- } \\
\text { peritoneal wounds }\end{array}$} \\
\hline & Total & Serious & Serious & Total & Serious & Animals & animal \\
\hline \multicolumn{8}{|l|}{ Higher pressures } \\
\hline Total & 137 & 12 & 11.4 & 76.18 & 6.77 & 13.39 & 7.47 \\
\hline Average per animal & 34.3 & 3.0 & 11.4 & 19.05 & 1.69 & 3.35 & 1.87 \\
\hline \multicolumn{8}{|l|}{ Lower pressures } \\
\hline Total & 56 & 6 & 9.3 & 32.18 & 3.56 & 3.35 & 1.91 \\
\hline Average per animal & 14.0 & 1.5 & 9.3 & 8.05 & 0.89 & 0.84 & 0.48 \\
\hline \multicolumn{8}{|l|}{ All pressures } \\
\hline Total & 193 & 18 & 10.7 & 108.36 & 10.33 & 16.74 & 9.38 \\
\hline Average per animal & 24.13 & 2.25 & 10.7 & 13.55 & 1.29 & 2.09 & 1.17 \\
\hline
\end{tabular}


TABLE 4.7-COMPARISON OF PREDICTED INTRAPERITONEAL WOUNDS USING DATA FROM MISSILE TRAPS LOCATED ABOVE AND AT

THE SAME LEVELS AS THE ANIMAL TARGETS

\begin{tabular}{|c|c|c|c|c|c|c|c|}
\hline \multirow{3}{*}{$\begin{array}{c}\text { Incident } \\
\text { sea-level } \\
\text { overpressure, } \\
\text { psi }\end{array}$} & \multirow{3}{*}{$\begin{array}{l}\text { Number } \\
\text { serious } \\
\text { wounds } \\
\text { observed }\end{array}$} & \multicolumn{6}{|c|}{ Number predicted intraperitoneal wounds } \\
\hline & & \multicolumn{3}{|c|}{ Traps above animals* } & \multicolumn{3}{|c|}{ Traps at animal level $\dagger$} \\
\hline & & No. & Diff. & $\%$ diff. & No. & Diff. & $\%$ diff. \\
\hline 4.32 & 2 & 4.3 & +2.3 & & 3.6 & +1.6 & \\
\hline 4.25 & 2 & 7.9 & +5.9 & & 2.9 & +0.9 & \\
\hline 3.23 & 2 & 0.2 & -1.8 & & 1.2 & -0.8 & \\
\hline 2.87 & 4 & 0.5 & -3.5 & & 0.6 & -3.4 & \\
\hline 2.41 & 0 & 0.8 & +0.8 & & 0.5 & +0.5 & \\
\hline 2.12 & 0 & 0.2 & +0.2 & & 1.0 & +1.0 & \\
\hline Totals & 10 & 13.9 & +3.9 & +39 & 9.8 & -0.2 & -2.0 \\
\hline
\end{tabular}

* Project 33.4 missile traps.

†Project 33.2 missile traps.

TABLE 4.8 - COMPARISON OF AVERAGE GEOMETRIC MEAN VELOCITIES AND MASSES FOR THE SERIES A \& B MISSILE DATA AS A FUNCTION OF INCIDENT SEA-LEVEL-EQUIVALENT OVERPRESSURE

\begin{tabular}{|c|c|c|c|c|c|}
\hline \multirow{2}{*}{$\begin{array}{l}\text { Station } \\
\text { No. }\end{array}$} & \multirow{2}{*}{$\begin{array}{c}\text { Incident } \\
\text { sea-level } \\
\text { overpressure, } \\
\text { psi }\end{array}$} & \multicolumn{2}{|c|}{$\begin{array}{l}\text { Geometric mean } \\
\text { velocities }\end{array}$} & \multicolumn{2}{|c|}{$\begin{array}{c}\text { Geometric mean } \\
\text { masses }\end{array}$} \\
\hline & & Series A & Series B & Series A & Series B \\
\hline $3 G 11$ & 4.45 & 137 & & 0.303 & \\
\hline 3G13 & 4.45 & 138 & & 0.355 & \\
\hline $7 \mathrm{G} 8$ & 4.32 & 142 & 138 & 0.604 & 0.383 \\
\hline $8 \mathrm{P} 2$ & 4.25 & 145 & 148 & 0.229 & 0.282 \\
\hline $6 \mathrm{P} 2$ & 3.23 & 108 & 126 & 0.651 & 0.507 \\
\hline $5 P 2$ & 2.87 & 104 & 117 & 1.0 & 1.156 \\
\hline 4P2 & 2.41 & 107 & 110 & 1.47 & 0.954 \\
\hline $3 \mathrm{G} 8$ & 2.12 & 96 & 113 & 2.62 & 2.565 \\
\hline
\end{tabular}

TABLE 4.9-PRIMARY BLAST DAMAGE (PRISCILLA AND GALILEO SHOTS)

\begin{tabular}{|c|c|c|c|c|c|c|c|}
\hline \multirow[b]{2}{*}{ Dog No. } & \multicolumn{2}{|c|}{ Overpressure, psi } & \multirow{2}{*}{$\begin{array}{l}\text { Overpressure } \\
\text { duration, } \\
\text { msec }\end{array}$} & \multirow{2}{*}{$\begin{array}{c}\text { Lung } \\
\text { hemorrhage }\end{array}$} & \multicolumn{2}{|c|}{ Eardrums $†$} & \multirow{2}{*}{$\begin{array}{c}\text { Sinus } \\
\text { hemorrhage } \dagger\end{array}$} \\
\hline & Incident & Reflected* & & & Right & Left & \\
\hline 8P2A & 8.6 & 21.6 & 823 & $\begin{array}{c}\text { Bilateral } \\
>\text { Rt Grade I }\end{array}$ & $\mathrm{H}+$ & $\mathbf{H}+$ & - \\
\hline $8 \mathrm{P} 8 \mathrm{~A}$ & 8.6 & 21.6 & 823 & None & $\mathrm{H}$ & $\mathbf{H}$ & - \\
\hline 6P2A & 6.4 & 15.3 & 920 & None & $\mathrm{H}$ & h & - \\
\hline $6 \mathrm{P} 8 \mathrm{~A}$ & 6.4 & 15.3 & 920 & None & $\mathrm{H}$ & $\mathbf{H}$ & - \\
\hline 5P2A & 5.6 (est.) & 13.1 & 964 (est.) & None & $\mathrm{h}$ & h & - \\
\hline 5P3A & 5.6 (est.) & 13.1 & 964 (est.) & None & $\mathrm{H}$ & $\mathbf{H}$ & - \\
\hline $4 \mathrm{P} 2 \mathrm{~A}$ & 4.6 (est.) & 10.5 & 1027 (est.) & None & $\mathrm{H}$ & h & - \\
\hline 4P3A & 4.6 (est.) & 10.5 & 1027 (est.) & None & $\mathrm{H}$ & $\mathbf{H}$ & - \\
\hline 7G3A & 8.4 & 21.2 & 576 & $\begin{array}{c}\text { Bilateral } \\
>\text { Rt Grade II }\end{array}$ & $\mathrm{H}+$ & $\mathrm{H}$ & - \\
\hline 7G7A & 8.4 & 21.2 & 576 & $\begin{array}{c}\text { Bilateral } \\
\text { >Rt Grade I }\end{array}$ & $\mathrm{H}+$ & $\mathrm{H}+$ & $\begin{array}{l}\text { Frontals } \\
\text { Bilateral }\end{array}$ \\
\hline $7 \mathrm{G} 8 \mathrm{~A}$ & 8.4 & 21.2 & 576 & $\begin{array}{c}\text { Bilateral } \\
\text { >Rt Grade I }\end{array}$ & $\mathrm{H}^{+}$ & $\mathrm{H}+$ & - \\
\hline 3G8A & 3.8 & 8.5 & 756 & None & $\mathrm{H}$ & $\mathrm{H}$ & - \\
\hline $3 \mathrm{G} 11 \mathrm{C}$ & 3.8 & 8.5 & 756 & None & - & - & - \\
\hline 3G13C & 3.8 & 8.5 & 756 & None & - & - & - \\
\hline
\end{tabular}

*Reflected overpressures computed after Glasstone. ${ }^{1}$

$\dagger$ The following symbolism is used: + , rupture; $\mathrm{H}$, hemorrhage; $h$, hypermia; - , no pathology 


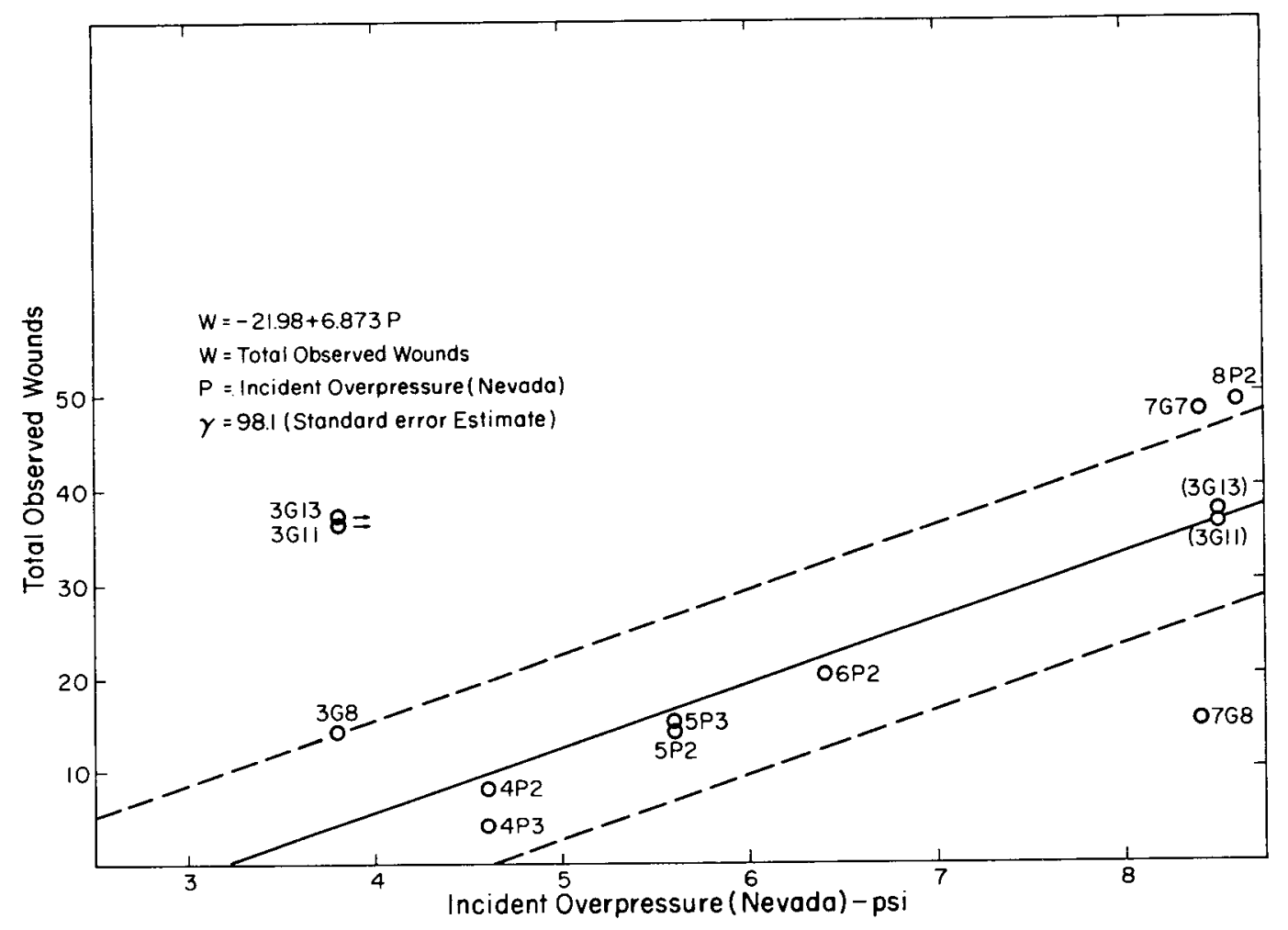

Fig. 4.1 Total wounds observed as a function of Nevada incident overpressure.

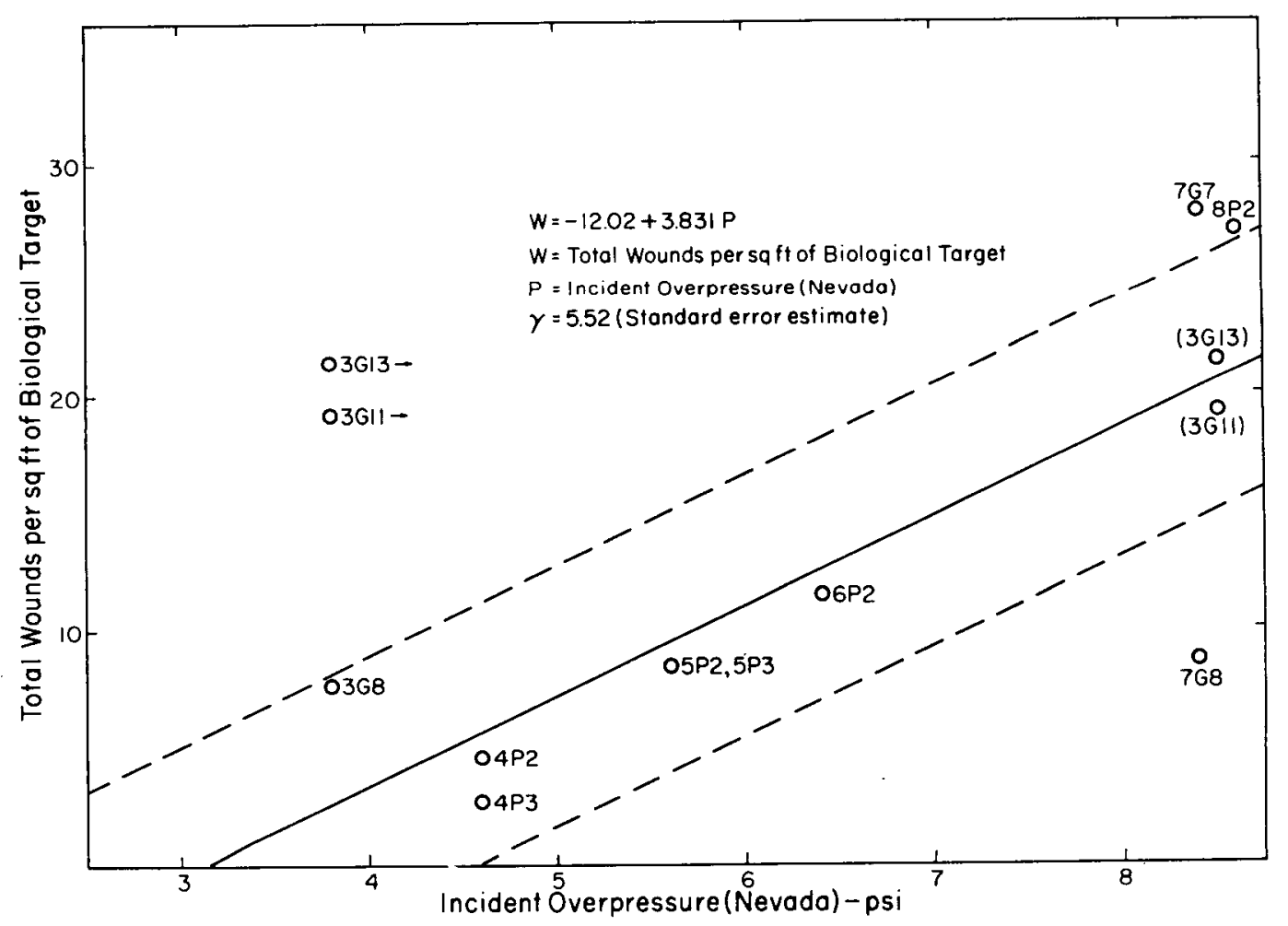

Fig. 4.2 Wounds observed per square foot of biologic target as a function of Nevada incident overpressure. 


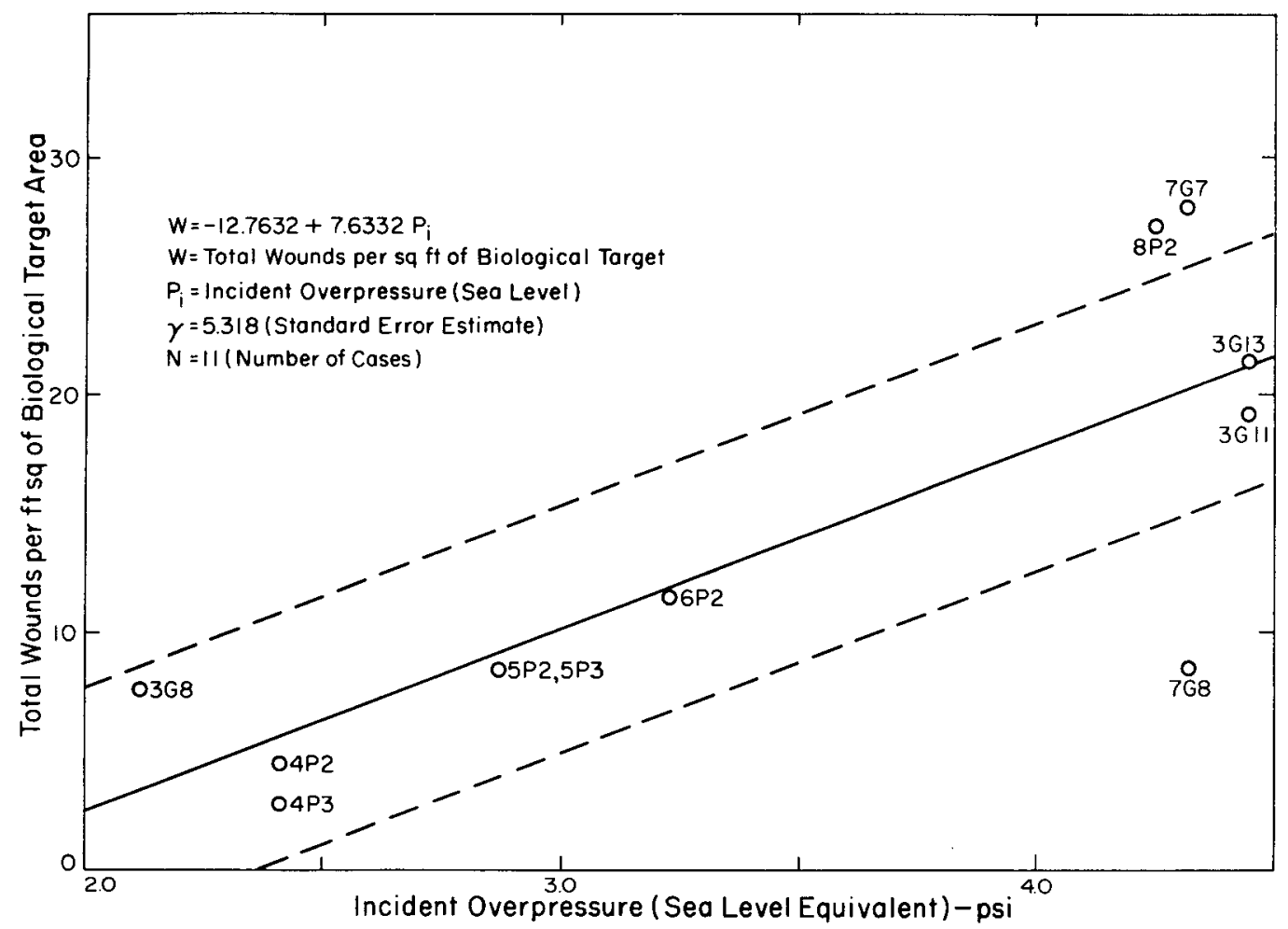

Fig. 4.3 Wounds observed per square foot of biologic target as a function of sea-level-equivalent incident overpressure.

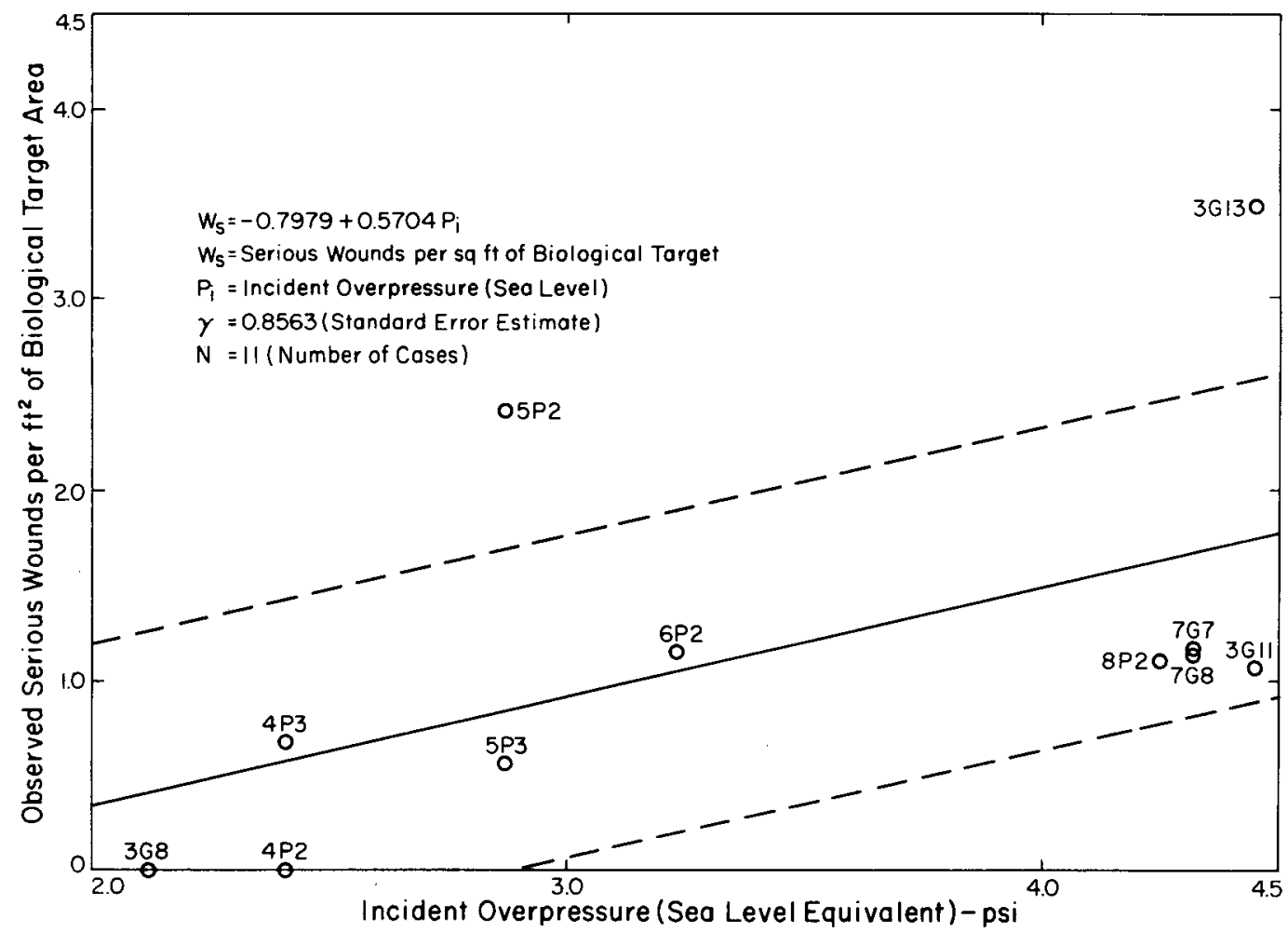

Fig. 4.4 Serious wounds observed per square foot of biologic target as a function of sea-levelequivalent incident overpressure. 


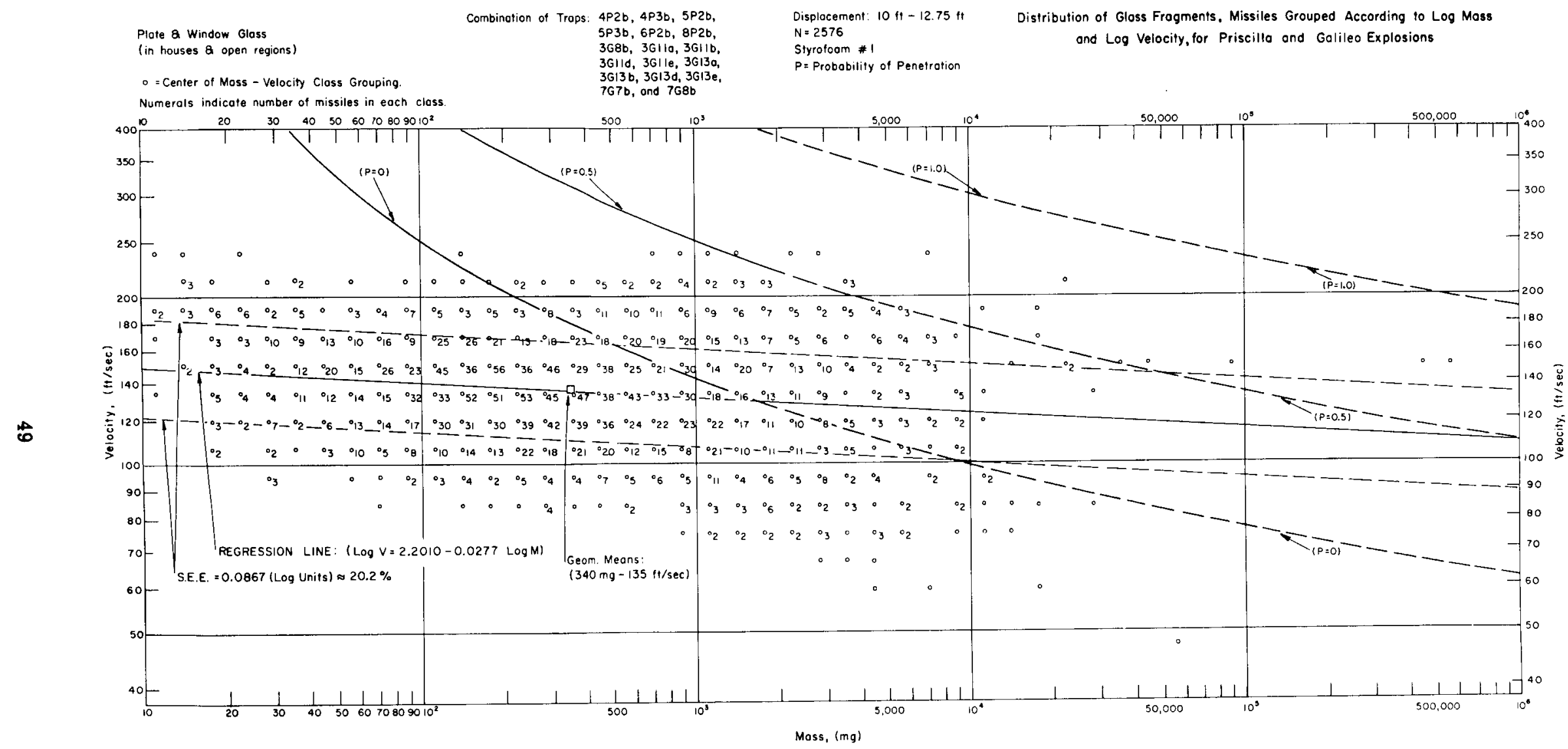

Fig. 4.5 Distribution of glass missiles for Priscilla and Galileo explosions grouped according to log mass and log velocity as these relate to probabilities of penetrating the abdominal wall of dogs. 


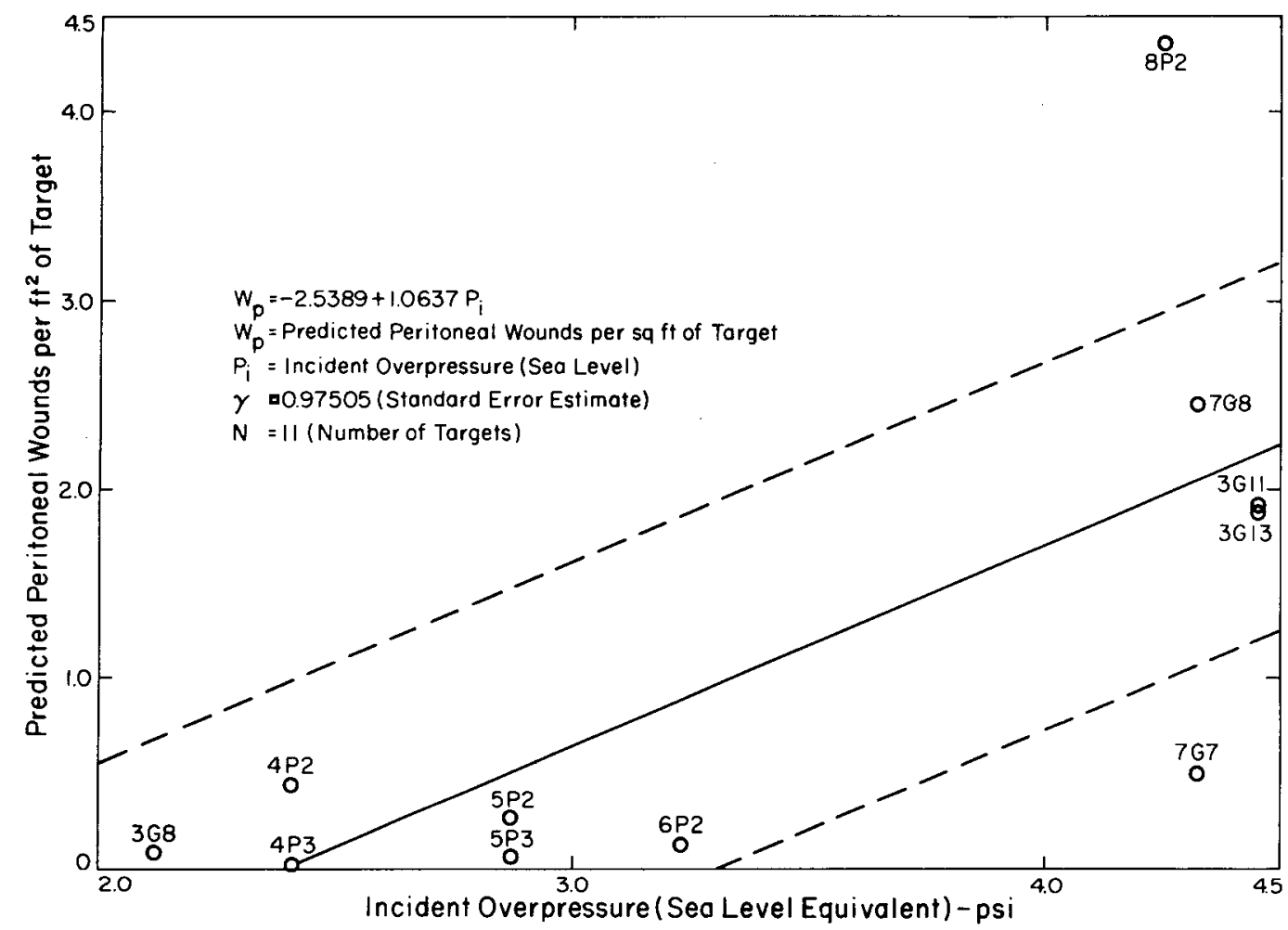

Fig. 4.6 Predicted peritoneal wounds per square foot of biologic target as a function of sea-levelequivalent incident overpressure.

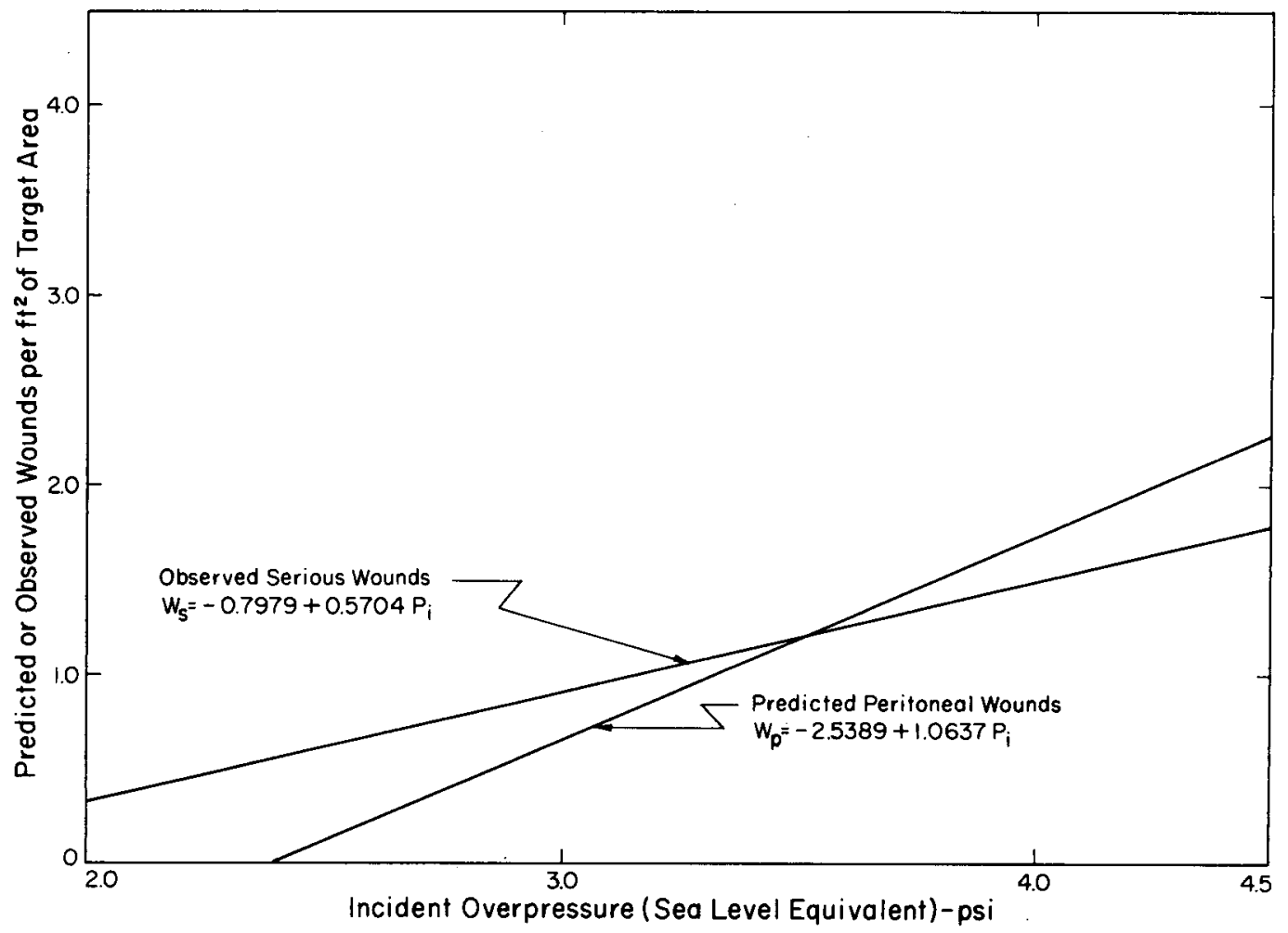

Fig. 4.7 Comparison of regression curves for observed serious wounds and predicted peritoneal wounds. 


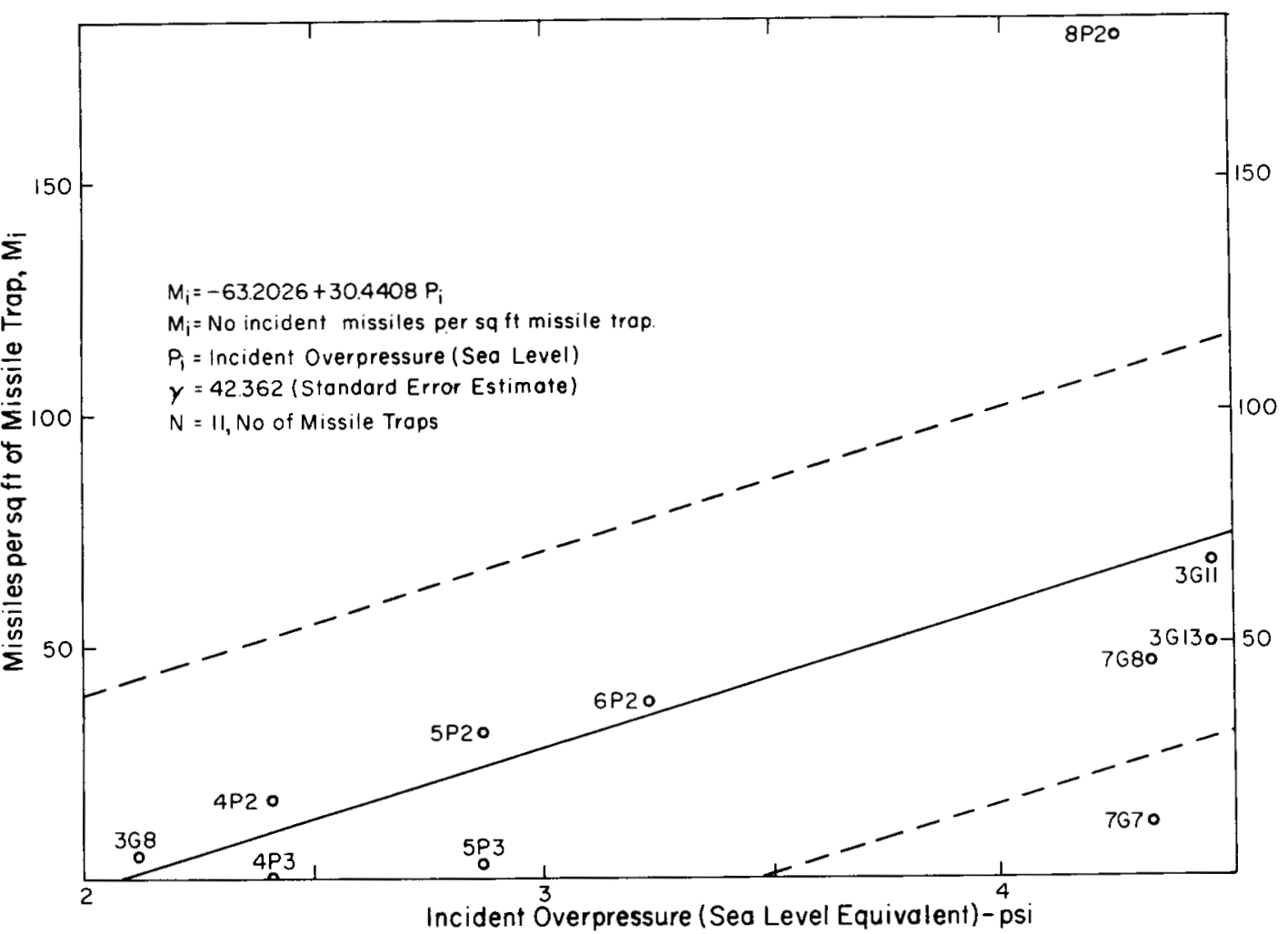

Fig. 4.8 Total observed glass missiles per square foot of missile trap as a function of sea-levelequivalent incident overpressure.

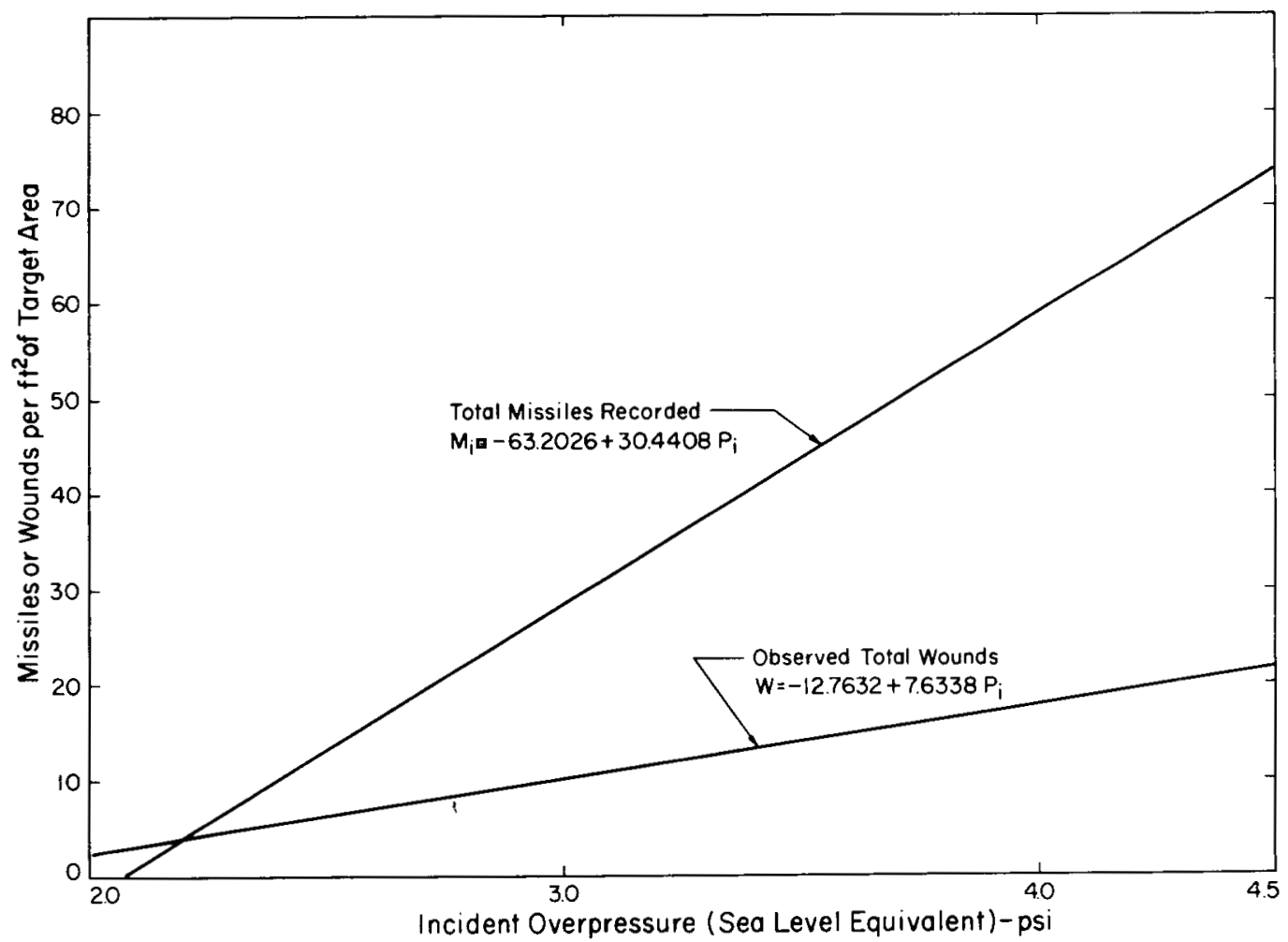

Fig. 4.9 Comparison of regression curves for total missiles recorded and total observed wounds. 


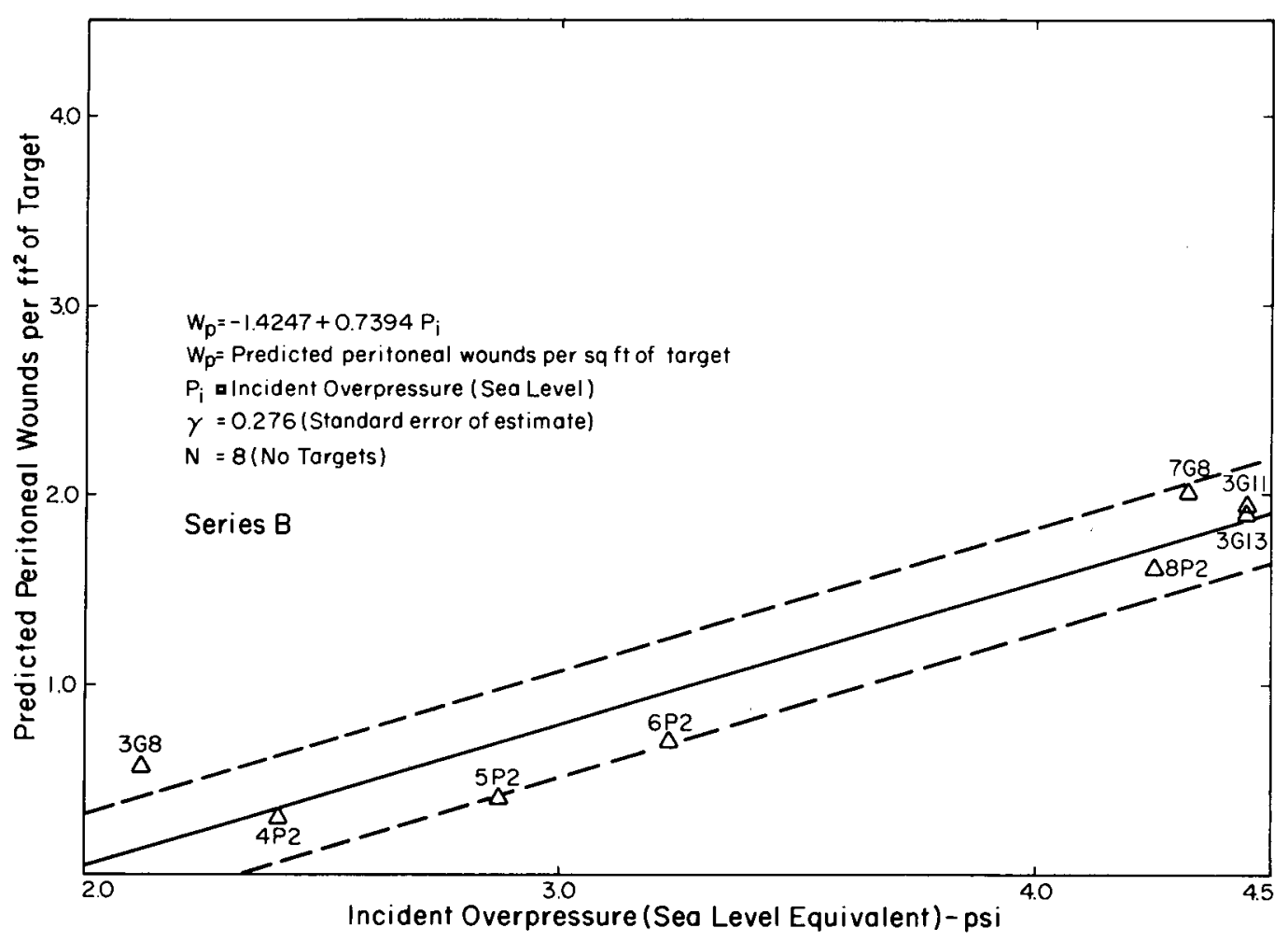

Fig. 4.10 Predicted intraperitoneal wounds using Series B missile data as a function of sea-levelequivalent incident overpressure.

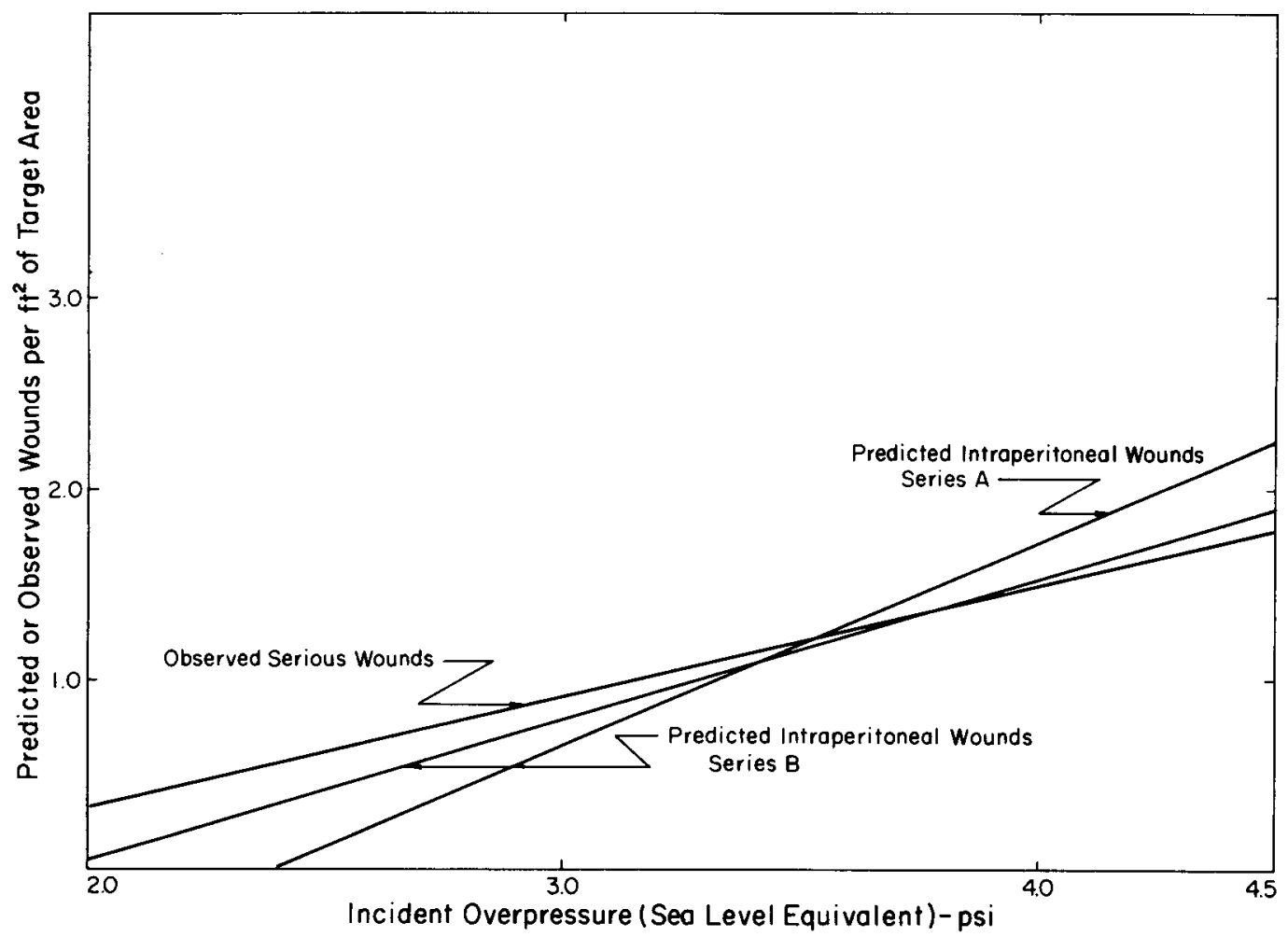

Fig. 4.11 Comparison of regression curves for serious wounds observed and intraperitoneal wounds predicted using Series A and B missile data. 


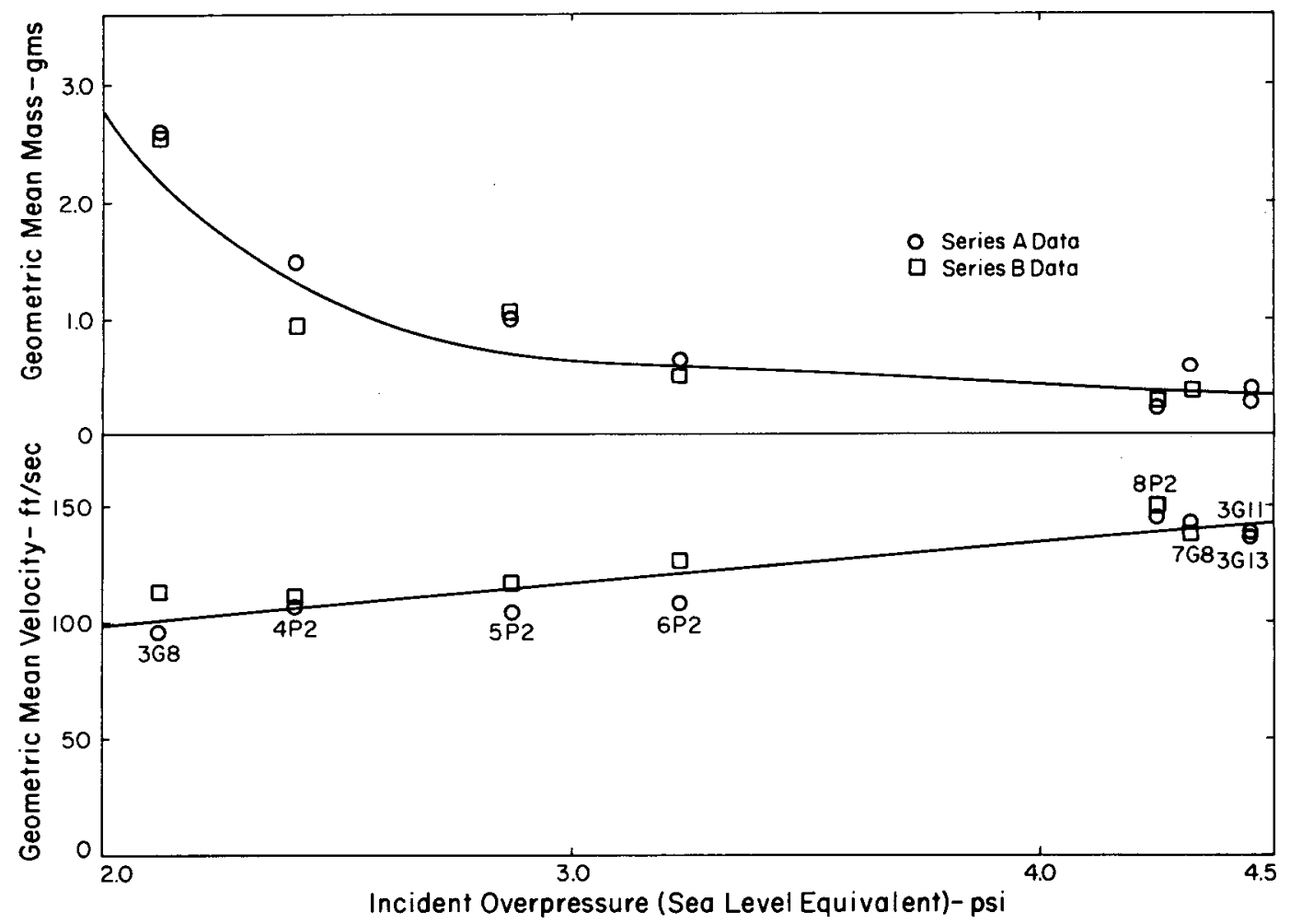

Fig. 4.14 Comparison of geometric mean velocities and missiles for Series A and B missile data as a function of sea-level-equivalent incident overpressure. 


\section{Chapter 5}

\section{DISCUSSION}

\subsection{MISSILES}

There are numerous factors bearing upon the missile-trapping technique used in this study which deserve further mention to aid in realistically appraising the data obtained. Some of the most important factors are:

1. Explosive yield and range from GZ.

2. Other environmental factors, such as the initial ambient pressure, the geometry in which the missile trap is located, and the horizontal and vertical distance of the trap from the missile source.

3. Aerodynamic considerations incorporating missile size, shape, and density; the orientation and behavior of missiles during flight and at impact; the interplay between wind velocity (dynamic pressure), gravity, and the positive and negative lift since these govern missile trajectory; the acceleration coefficient of the missile, which is defined as the presenting area times the drag coefficient divided by the mass; and the possible disturbance of the overpressure and the accompanying winds by the missile trap itself as well as by near-by objects and structures.

4. Details concerning the missile trap, including size and shape; type and characteristics of absorber; calibration data; the threshold for various missiles, which is determined by a complex interplay between missile velocity, mass, shape, and density; and the fate of a given fragile missile at and after impact.

5. The properties of the missile source; e.g., sticks, stones, plate or window glass, size of pane, means of mounting, and many other imponderables related to construction materials and techniques which will influence and govern the debris formed from the interaction of blast phenomena with a given structure.

With regard to the influence of explosive yield and range on glass-missile formation and behavior, relative quantitative data are meager indeed. Yields from about 10 to $40 \mathrm{kt}$ and ranges covering incident overpressures from near 2 to 8 psi have been experienced at NTS. ${ }^{1,2}$ However, for other overpressures and yields under circumstances where the incident pressuretime curves are classical in form, it is possible to predict glass-missile behavior by computational procedures. ${ }^{3}$ The constraints placed upon such predictions by the fact that no experience for very high and low yields exist are not known with certainty; however, some data applicable to conditions wherein pressure-time curves are nonclassical and do not rise to a peak instantaneously are available for the pressures and yields mentioned above for glass-missiles and for stones up to $15 \mathrm{psi}$. Such information is now either undergoing analysis or is in early manuscript form. ${ }^{2}$

In regard to the geometry of exposure, it can be said also that empirical data are limited. Since most weapons' effect data apply to free-field conditions (those referable to flat terrain in the absence of structures) and since, therefore, it is difficult to assess the overpressure 
and wind disturbances that might apply to row on row of houses, apartments, factories, or other structures, glass-missile data should be applied to urban complexes with caution.

It is known, however, that window glass mounted in walls facing the advancing overpressure wave fails as a function of the reflected pressure; whereas, glass mounted over a pit in the ground fails from the incident pressure travelling over the surface. ${ }^{4}$ Although this is not strictly applicable to the finding noted in the present study (that window glass mounted in the wall of a house facing the advancing pressure front responds to the reflected pressure in contrast with glass mounted in the open, which apparently responds to the incident overpressure or perhaps from some slight increase due to reflection), both observations emphasize the need for distinguishing between incident and reflected pressure phenomena as they are related to geometry of exposure and to the computation of range from a detonation. The latter, of course, can be quite different, depending on whether the local static or the reflected overpressure is the parameter of interest.

The present study emphasizes geometric details from another view, namely, the horizontal and vertical distance of a missle-absorbing trap from the missile source. Such factors influence the number, spacial density, masses, and velocities of glass missiles. The variations of these with range, overpressure, and yield are somewhat complex and poorly understood in detail. Thus, it is necessary to caution the reader who is interested in missile data to remember that it takes time for missiles energized by blast phenomena to reach their maximum velocity, which is near that of the existing wind at that moment, and that this time to maximum velocity is associated with a distance of travel before maximum velocity is attained. Beyond this distance and time, the missile slows down; and, under some circumstances, it may actually reverse its direction of travel under the influence of the negative winds associated with the underpressure that usually follows the overpressure. Thus, a given missile trap or target may "see" high and low missile velocities as a consequence of being either too close or too far away from the source or it may "see" maximal velocities because the distance from the source is "ideal" and appropriate to the conditions at hand.

Aerodynamic factors governing missile behavior are also complex and are far from fully understood. For example, once a pane of glass breaks, those pieces which for a time maintain a "flat" orientation nearly parallel with their original plane experience the maximum effect of the wind. Once they rotate slightly or spin, they can develop lift and travel in trajectories either up, down, or from side to side, depending on their orientation to the wind vector. If a rapid spin ensues and the missiles are small, they may, on the average, behave somewhat as an equivalent sphere of the same weight and density.

In view of such possibilities, it is somewhat surprising that a mathematical model describing the behavior of glass missiles has been formulated, but such is the case. ${ }^{3}$ One important facet of the problem concerns the acceleration coefficient mentioned earlier and defined as:

$$
\alpha(\text { acceleration coefficient })=\frac{A \text { (presented area) }}{m \text { (mass) }} C_{D}(\text { drag coefficient })
$$

In the laboratory it has been possible through simple experiments to determine numerical values of $\alpha$ for small irregular objects, spheres, and different species of animals; estimates for anthropometric dummies modeling man also are available. ${ }^{5}$ Such data promise to refine missile-prediction techniques, and they already have been applied to objects the size and shape of man to estimate displacement and velocity histories when exposure to blast phenomena is assumed. ${ }^{6,7}$

The orientations adopted by the missiles in flight are known to influence the missile data in the present study. For example, flat indentations of various sizes, sometimes several square inches in area, were observed on the face of the missile absorber. Usually, no matching missile was found, probably because of fragmentation on, or after, impact with the face of the trap. Thus, missiles do seem to travel from source to trap, maintaining a flat orientation. Other indentations were noted which were irregular and deeper on one side than on another. This indicated a tendency to spin. Many missiles partly embedded on end in the face of the trap were noted, but, in spite of taping and other attempts to keep them in place, they were shaken from their beds in transport from the field. Mostly, this embedding occurred with the 
larger missiles at the greater ranges, and it can be said that as a consequence the missiletrap data are somewhat biased for the lower overpressures because in this area there were more large on-edge and flat missiles than was the case at the higher overpressures.

Some of these factors concern the characteristics of the missile absorber, calibration techniques, and threshold conditions. In this regard it can be stated that for many of the flat indentations calibration procedures, which will be reported subsequently, ${ }^{2}$ were evolved. Briefly, thin, flat pieces of balsa wood, backed by thin metal strips to give the proper weight and density relationships, were used. From measured impact velocities and indentation depth, calibration data for the larger irregular missiles were obtained.

With regard to velocity thresholds of Styrofoam 22 (the missile-absorber employed in the present study), figures for pieces of window glass indicate the thresholds are $93,63,47$, and $40 \mathrm{ft} / \mathrm{sec}$ for particles weighing $0.1,1,10$, and $50 \mathrm{~g}$, respectively, providing they did not hit flat or nearly flat. For irregular pieces of window glass hitting the trap face flat, the thresholds are $82,110,144$, and $157 \mathrm{ft} / \mathrm{sec}$ for masses of $1,10,100$, and $200 \mathrm{~g}$, respectively. Data for pieces of plate glass also hitting flat are about 30 and $70 \mathrm{ft} / \mathrm{sec}$ lower for the 1 and $200 \mathrm{~g}$ missiles, respectively.

One other difficulty noted, particularly with the larger flat missiles, is what might be termed oversaturation of the missile absorber. Apparently small pieces of glass reached the missile traps before larger ones did; frequently a flat piece would be embedded in the Styrofoam, and smaller missiles would be found beneath it. Occasionally, the face of the trap would be peppered by many missiles that entered the absorber and a flat indentation also would be noted. If there was considerable fragmentation of the absorber from the smaller missiles arriving first, it was not possible to evaluate the depression made by the larger flat pieces arriving later. It is known that a few of the larger missiles were not recorded for this reason, giving another reason for believing the missile traps were missing larger fragments that might well have produced serious wounds in the animals.

Whatever may eventually prove to be the future refinements of missile-trapping techniques and the analytical procedures for assessing related data, it can be noted now that information derived from missiles successfully trapped and recovered is fairly valid. For conditions where embedding and recovery of the missiles are uncertain, results may be biased and less reliable; e.g., at the lower overpressures where lower missile velocities and large masses become critical as far as the trapping threshold is concerned.

With regard to the over-all relation of missile velocity and mass to overpressure, it is well to emphasize a few points. First, normalizing the missile data to sea-level-equivalent incident overpressure was undertaken, among other things, to allow application of the missile data obtained in the open in Nevada to houses at sea level; e.g., the sea-level-equivalent overpressure is that overpressure which when incident upon a house at sea level would, by reflection, produce the same missile behavior as observed in the open at Nevada. This, of course, can apply strictly only to a geometry in which the window-containing wall is normal to, and facing, the oncoming pressure pulse. Behavior of windows on the lee side of a house (those in walls parallel to the direction of travel of the shock front and winds, and those at various angles from these two extremes) is not yet well understood. However, some data from the 1955 field test operation do exist, ${ }^{1}$ but they as yet have not been analytically compared with the data of the present study and those of the missile program ${ }^{2}$ in 1957.

Second, the influence of geometry as it contributes to the magnitude and duration of the reflected overpressure and winds must be understood; these factors are important, not only because they are critical in controlling the mass and velocity of missiles, as shown in Fig. 4.14, but also because they establish the numerical value of the overpressure with which a given relationship of missile mass and velocity is associated. Such factors bear also upon the use of selected missile data in predicting and understanding biological response and assessment of a potential hazard.

Finally, it is necessary to emphasize that quantitative missile data apply strictly to cir cumstances under which they were obtained. All contributing parameters must be considered carefully before such data can be applied to other situations or before a synthesis of information can take the form of generalization which is often useful in a variety of circumstances. The present study illustrates this point well because the results demonstrated that missile traps placed above the biologic targets were not sampling the missile environment adequately. 
Also, it was fortuitous that data from other missile traps at ground level were available. Use of this information improved the sampling situation. Even so, it is uncertain whether or not what occurred at about 11 to $13 \mathrm{ft}$ from the glass window panes where the animals were located would have been close to the averages from missile traps closer $(5$ to $8 \mathrm{ft}$ ) and farther (18 to $23 \mathrm{ft}$ ) away. No precise answer is now available, nor will it be until a more refined experiment is performed.

\subsection{BIOLOGICAL FACTORS}

\subsubsection{Secondary Blast Effects (Missiles)}

In spite of the many uncertainties just discussed, the present study established a preliminary correlation between the missile environment as measured and the biologic response in terms of observed total and serious wounds in dogs. There also was verification that an analytical approach to predicting potential abdominal wounds in dogs was feasible and that this approach gave results which, on the average, were quite close to the serious wounds observed. In all probability, this was so because the criteria arbitrarily adopted for the definition of serious wounds involved a depth of penetration of $10 \mathrm{~mm}$ or more. Indeed, this number was chosen because it was believed to represent the average thickness of the abdominal wall of the animals used by Bowen et al. ${ }^{8}$ in formulating the penetration equation defining the probabilities of glass fragments of various masses and velocities reaching the peritoneal cavity. The aver age data obtained in this study, showing close average correspondence between observed serious and predicted peritoneal wounds, support the conclusion that $10 \mathrm{~mm}$ is close to the average thickness of the abdominal wall of the animal species employed.

Even so, for the critical reader it is well to point out two facts. First, the penetration equation of Bowen et al. ${ }^{8}$ was derived from glass fragments varying in mass from about 0.05 to $2.0 \mathrm{~g}$, and verification of this equation for missiles of higher mass has not yet been accomplished. Second, there were many missiles in the present study above $2 \mathrm{~g}$ in weight; and, since the velocity limits for these heavier and larger missiles to penetrate were not empirically established, the analysis assumed that extrapolation of the data was justified. There is at present no information to fully support such an assumption.

Such factors could partially explain why more serious wounds were observed at the lower overpressures than were predicted and why the predicted and observed figures were much more in agreement at the higher overpressures. It seems more probable, however, that the differences noted at the lower overpressures (since they were not statistically significant) reflect a sampling error that often is innate in experiments involving small numbers of animals. Also deserving consideration is the possibility that the threshold for penetration of the dog's abdomen by larger and heavier missiles might involve impact velocities well below the lowest velocities determined by the trapping technique. In this case, the animal would be expected to "see" missiles that the traps did not "record."

In regard to the observed total wounds, it is unfortunate that the lack of an empirical equation defining the glass-missile mass-velocity relationships for simple lacerations of the dog's skin and for skin penetration precluded use of the data obtained to verify the feasibility of predicting wounds of this kind. The study of Bowen et al. ${ }^{8}$ includes some data relevant to penetration of the skin of the dog, but they are too few and cover insufficient velocity ranges to allow formulation of a penetration equation. The absence of such information for glass, plus the unavailability of similar data for the response of the eye to glass missiles, represents a serious gap in data which, until remedied, precludes maximal use of the quantitative missile data that are accumulating. Studies that will assess the protective effects of various types of clothing against glass missiles also are needed.

There is a surprising trend in the data for total wounds observed and total missiles recorded in the region of the lower overpressures. The fact that the regression curves shown in Fig. 4.13 for (a) total Series B missiles recorded and for (b) total observed wounds have intercepts at 1.67 and $1.71 \mathrm{psi}$, respectively, implies, at first glance, a rather startling conclusion. That is, for every missile per square foot recorded by the missile traps in these regions of overpressure, there could be expected, on the average, a corresponding wound observed; i.e., an average 1 to 1 correspondence at the lower overpressures compared with about a 3 to 
1 ratio for the higher overpressures (see Fig. 4.13). In reality, however, it is necessary to take into consideration the relative threshold of the missile traps and animals for low-velocity debris and the fate of the fragments of the large pieces of glass when they shatter against the missile-trap absorber and against the dog. Without photographic coverage there may be no way of resolving this intriguing problem; therefore, there is little point in discussing the matter further here.

Of course, the aim of assessing blast-energized missiles in the environment and the correlation of the data with biologic response has as its ultimate objective an understanding of the human hazard. Thus, the question of similarities between the response of animals and man arises. For high-velocity missiles, such as bullets and mortar fragments, there are many areas of correspondence between animal and human response. ${ }^{9-14}$ For low-velocity relatively light missiles like glass, sticks, and stones, uncertainties arise. Muscle for muscle, a dog, goat, or pig may be quite similar to man ballistically, but this may well be quite different in regard to the skin. Consequently, until appropriate data are available, caution should be observed in applying the data of the present and similar studies to the human case. Currently, there is no empirical evidence for assuming that the response of man, particularly clothed man, can be assessed by extrapolating the meager glass-missile data available from studies of $\operatorname{logs}^{8}$ and pigs. ${ }^{15}$ Neither is there reason for believing that the studies reported by Stewart ${ }^{16}$ of the ballistic response of the rabbit's eye, removed and mounted in gelation, to impact from metal spheres and cubes give very informative data which is applicable in assessing potential damage to the human eye from glass fragments. ${ }^{17}$ However, the reported studies of Stewart ${ }^{16}$ are of great value since they give the only quantitative data known to the authors which empirically set forth the ballistic limit of the eye.

\subsubsection{Primary Blast Effects (Pressure)}

In the 1953 field operation at the NTS, Grade I to III lung hemorrhage was observed in 15 dogs housed inside open underground protective structures when the internal overpressure enduring for about half a second ranged from a maximum of 12 to $20 \mathrm{psi}^{18}$ Also, rupture of the tympanic membrane was noted. There was an initial pulse of pressure which entered and travelled the length of the 50 -ft-long tubular shelters, reflected from the walls of the far ends, and travelled back toward the entry ways. Thus, the animals were exposed to a stepwise increase in pressure. Because of instrumentation constraints it was not possible to say whether or not there was a sharp, almost instantaneous rise in pressure such as occurs with true shock phenomena.

In regard to failure of the tympanic membranes noted in the present study, the rupture of 7 of 28 eardrums in the animals exposed to incident pressures of 3.8 to $8.6 \mathrm{psi}$ is consistent with past experience. Other available data, summarized in several documents (Refs. 7, 18, 21, and 24), show a $P_{50}$ for rupture near 31 psi for the dog eardrum with a threshold near 4 psi.

Several remarks concerning the association between overpressure and lung hemorrhage are indicated. Until the present study was accomplished, the data mentioned above documented the lowest overpressures damaging dogs in full-scale nuclear tests. The findings set forth in Table 4.9 show that in three animals, exposed in a box side-on to an incident overpressure of $8.4 \mathrm{psi}$, which presumably reflected to near $21 \mathrm{psi}$, there was lung damage (Grade $\mathrm{I}$ in two instances and Grade II in the third). Also, one other animal showed Grade I lung hemorrhage at $8.6 \mathrm{psi}$ incident overpressure, with a presumed reflection to near $21.6 \mathrm{psi}$. In all probability the overpressure increased almost instantaneously and each animal experienced the incident and reflected overpressure almost simultaneously.

Since the overpressures at the locations of the dogs were not measured, it cannot be said with certainty what the environmental challenge to the animal actually was. However, the findings do emphasize the care that must be exercised in stating the magnitude and character of a fast-rising overpressure of long duration that represents a near-threshold condition for a biologic target; e.g., does one mean the free-field incident overpressure or the reflected figure? Here, again, geometry of exposure becomes very important, and great caution must be exercised in assessing what is a safe, a threshold, and a mortal pressure-time experience for animals including man.

For those interested in recent shock-tube studies in which single and stepwise fast-rising long-duration pressure pulses were employed to determine mortality curves for mice, rats, 
guinea pigs, and rabbits, the reader is referred to the work of Richmond and Taborelli; ${ }^{19}$ these studies also are reported and discussed more fully elsewhere. ${ }^{7,20,21}$ In this regard, it is well to point out a surprising finding using guinea pigs as an example. For a single, fast-rising long-duration overpressure, the maximal pressure required to fatally wound 50 per cent of the animals $\left(P_{50}\right)$ mounted against the end plate of a shock tube was about $37 \mathrm{psi}$ in contrast with a $P_{50}$ near $58 \mathrm{psi}$ for animals mounted 6 to $12 \mathrm{in.}$ from the end plate. In the latter case, the animal was exposed first to an incident overpressure of about $19 \mathrm{psi}$ and a moment later $(0.6$ to $1.4 \mathrm{msec}$ ) to the reflected pressure of $58 \mathrm{psi}$. Thus, there was a sharp stepwise increase in overpressure in contrast with conditions for the animal against the end-plate that "saw" an incident overpressure of about 12 psi and a reflection up to 37 psi almost simultaneously.

Recent experience ${ }^{22}$ indicates that for exposure against the end plate of a closed shock tube to a sharply rising overpressure of about $400 \mathrm{msec}$ duration, the $P_{50}$ for dogs is between 45 and 50 psi reflected overpressure. Thus, it is possible to say that in an appropriate geometry, somewhat similar to that at the end of long hallways, subway tubes, and tunnels, or against walls, surprisingly low incident overpressures may damage, and prove fatal to, a variety of mammalian species. These effects can probably be extended to include man.

The present study would place the threshold for lung damage in dogs somewhere below 20 psi reflected overpressure; and until further data are available, perhaps a reflected overpressure of 15 psi (or 6 psi incident overpressure in a geometry conducive to reflection) should be taken as the threshold for lung injury to mammals when the pressure rise is practically instantaneous. ${ }^{7,21}$

A further word of caution is necessary in relation to primary blast effects; i.e., the possibility exists that damage and mortality data obtained at NTS, Albuquerque, and other areas having local ambient pressures below those at sea level may not apply to sea level conditions. There are indications that animal and human responses to pressure variations below the ambient are governed by the ratio between the underpressure (gauge) and the ambient pressures expressed in absolute units. ${ }^{18,23}$ Thus, the question of scaling primary blast data obtained at altitude to sea-level conditions arises. For sharply rising overpressures it is the pressure increase, among other things, that damages the animal. Although there is as yet no evidence that response to both underpressure and overpressure concerns the pressure ratio noted above, it is nevertheless obvious that the pressure differential across the chest of an animal is the loading factor of significance. Furthermore this loading factor is determined by the difference between the initial internal alveolar absolute pressure (approximately the local barometric pressure) and the external pressure in absolute units (the overpressure). For the guinea pig ${ }^{24}$ having a $P_{50}$ to sharply rising pressures of $37 \mathrm{psi}$ (gauge) at Albuquerque (near $5000 \mathrm{ft}$ ), the initial pressure is about $12.2 \mathrm{psi}$ absolute and the overpressure is 49.2 psi absolute, giving a pressure ratio of $(49.2-12.2) / 12.2=37 / 12.2=3.0328$. For a similar pressure ratio at sea level, assuming standard conditions (14.7 psi), the arithmetic shows that the equivalent sea-level overpressure would be $14.7 \times 3.033=44.58 \mathrm{psi}$. This compares with 37 psi at $5000 \mathrm{ft}$.

The writers wish to make it quite clear that there is no empirical evidence for assuming that the above or similar ideas are actually involved in scaling primary blast effects in animals. Indeed, let it be said that there are no experimental data "saying" that scaling is necessary. At the same time, we are of the opinion that such a question must be answered one way or the other and that this is one of the significant tasks for future research.

\section{REFERENCES}

1. I. G. Bowen, A. F. Strehler, and M. B. Wetherbe, Distribution and Density of Missiles from Nuclear Explosions, Operation Teapot Report, WT-1168, December 1956.

2. I. G. Bowen et al., Secondary Missiles Generated by Nuclear-produced Blast Waves, Project 33.2, Operation Plumbbob Report, WT-1468 (in preparation).

3. I. G. Bowen et al., A Model Designed to Predict the Motion of Objects Translated by Classical Blast Waves, Lovelace Foundation, Report CEX-58.9 (in preparation).

4. H. Schardin, The Physical Principles of the Effects of a Detonation, in "German Aviation Medicine, World War II," Vol. 2, Chap. 14-A, pp. 1207-1224, Superintendent of Documents, U. S. Government Printing Office, Washington 25, D. C., 1950. 
5. E. R. Fletcher et al., Determination of Aerodynamic Drag Parameters of Small Irregular Objects by Means of Drop Tests, Technical Progress Report, Lovelace Foundation, (in preparation).

6. R. V. Taborelli, I. G. Bowen, and E. R. Fletcher, Tertiary Effects of Blast-Displacement, Operation Plumbbob Report, WT-1469, February 1959.

7. Clayton S. White, Biological Blast Effects, Report TID-5564, September 1959; also published in "Hearings before The Special Subcommittee on Radiation of the Joint Committee on Atomic Energy on The Biological and Environmental Effects of Nuclear War," June 2226, 1959, pp. 313-372, Superintendent of Documents, U. S. Government Printing Office, Washington 25, D. C., 1959.

8. I. G. Bowen et al., Biological Effects of Blast from Bombs. Glass Fragments as Penetrating Missiles and Some of the Biological Implications of Glass Fragmented by Atomic Explosions, Report AECU-3350, Lovelace Foundation, June 18, 1956.

9. E. G. Butler et al., Experiments on Head Wounding by High Velocity Missiles, J. Neurosurg., 2: 358-363 (1945).

10. W. O. Puckett, W. D. McElroy, and E. Newton Harvey, Studies on Wounds of the Abdomen and Thorax Produced by High Velocity Missiles, Military Surgeon, 98: 427-439 (1946).

11. E. Newton Harvey et al., Piezoelectric Crystal Measurements of Pressure Changes in the Abdomen of Deeply Anaesthetized Animals During Passage of a High-velocity Missile, Military Surgeon, 98: 509-528 (1946).

12. E. Newton Harvey et al., Mechanism of Wounding, War Med., 8: 91-104 (1945).

13. E. Newton Harvey et al., Secondary Damage in Wounding Due to Pressure Changes Accompanying the Passage of High Velocity Missiles, Surgery, 21: 218-239 (1947).

14. R. H. Holmes, Wound Ballistics and Body Armor, J. Am. Med. Assoc., 150: 73-78 (1952).

15. Walter Reed Army Institute of Research Project 4.1, Operation Plumbbob Report, WT-1428 (in preparation).

16. G. M. Stewart, The Resistance of Rabbit Eye to Steel Spheres and Cubes, U. S. Army Chemical Warfare Laboratories Technical Report CWLR-2332, Army Chemical Center, Md., January 1960.

17. V. Blocker and T. G. Blocker, The Texas City Disaster-A Survey of 3,000 Casualties, Am. J. Surgery 78: 756-771 (1949).

18. C. S. White et al., Biological Effects of Pressure Phenomena Occurring Inside Protective Shelters Following a Nuclear Detonation, Operation Teapot Report, WT-1179, October 1956.

19. D. R. Richmond and R. V. Taborelli, Some Results of a Shock Tube for Biomedical Investigation, in Proceedings of Second Shock Tube Symposium, pp. 56-69, Report SWR-TM-58-3, Headquarters, Air Force Special Weapons Center, March 5-6, 1958.

20. C. S. White and D. R. Richmond, Blast Biology, Report TID-5764, Lovelace Foundation, Sept. 18, 1959.

21. C. S. White and I. G. Bowen, Comparative Nuclear Effects of Biomedical Interest, Report CEX-58.8 (in preparation).

22. D. R. Richmond, AEC-DASA Project, Lovelace Foundation for Medical Education and Research, Albuquerque, N. Mex., unpublished data.

23. U. C. Luft and R. W. Bancroft, Transthoracic Pressure in Man During Rapid Decompression, J. Aviation Med., 27: 208-220 (1956).

24. D. R. Richmond et al., Blast Biology-A Study of the Primary and Tertiary Effects of Blast in Open Underground Protective Shelters, Operation Plumbbob Report, WT-1467, February 1959. 


\section{Chapter 6}

\section{SUMMARY}

1. Two groups of six and eight dogs (placed behind aluminum foil for thermal protection, housed in stout rectangular boxes with the open side facing GZ, and situated at known distances from panes of window and plate glass, planted gravel, and a concrete-block wall) were exposed to the primary (pressure) and secondary (missile) blast effects associated with the detonation of two nuclear devices having estimated yields of 11 and $38 \mathrm{kt}$, respectively.

2. Eight animals were located downwind of the window glass, two were in houses, and the others were in the open. Three, two, and one were placed on the lee side of plate glass, gravel, and a concrete-block wall, respectively.

3. All survived the immediate effects of the explosions, were recovered successfully, and were subjected to routine necropsy procedures postshot.

4. Ranges from GZ were such that free-field incident overpressures measured near each station varied from 3.8 to $8.6 \mathrm{psi}$.

5. The missile environment near the animals was sampled by missile traps containing calibrated absorbing material that allowed recovery of the missiles and determination of their masses and impact velocities.

6. From missile traps located just above the animals in the open and above and below the animals in the houses, 2898 missiles were recovered, of which 2576, 117, and 205 were glass, planted gravel, and natural stones, respectively.

7. Missile velocities ranged from 45 to $293 \mathrm{ft} / \mathrm{sec}$, with geometric means (the median of the velocity distribution) for individual traps ranging from 47 to $197 \mathrm{ft} / \mathrm{sec}$. The missile weight range was from 0.01 to $596 \mathrm{~g}$, with geometric mean masses for the individual missile traps as low and as high as 0.035 and $151 \mathrm{~g}$, respectively.

8. Since no penetrating wounds were observed in animals from stones and gravel, information referable to the 2576 glass missiles were segregated as the Series A missile data for comparison with Series B missile data (data taken from missile traps of another project including, however, traps in the houses of this project). This gave a total of 2850 Series $B$ window-glass missiles. Except for the traps in the houses, the Series B missile traps were located at similar ranges and at the same level as were the dogs (just above grade), but some missile sources were closer to and some were farther from the traps than the animals were, thus bracketing conditions for the biologic target.

9. The total number of trapped glass missiles, their masses, and their velocities were assessed as a function of the incident sea-level-equivalent overpressure. The latter was defined as that overpressure at sea level which, if incident upon a house, would produce by virtue of the reflected overpressure and associated winds, the same missile behavior as was observed at NTS altitude. Normalizing the data to sea-level conditions also allowed equitable comparison of data from the two explosions, which occurred at different ambient pressures.

10. In general, there were more Series A than Series B missiles at the higher overpressures, but fewer Series A than Series B missiles at the lower overpressures. The velocities of the Series B missiles were, on the average, slightly greater than those noted in the Series 
A data; whereas, the Series B results showed missiles slightly less in weight than those for Series A.

11. In general, missile velocity for both series increased linearly with increasing overpressure, but the missile mass increased exponentially with decreasing overpressures.

12. Biologically, primary (pressure) blast pathology was noted in 12 of the 14 exposed animals. Three had Grade I and one had Grade II lung hemorrhage. Seven eardrums were ruptured, 13 other tympanic membranes were hemorrhagic, and 4 additional ones were hyperaemic. A hemorrhagic sinus was noted in one animal. Thermal singeing of hair was recorded in four instances; and in two cases hot stones and debris peppered the lower extremities causing small black singed areas.

13. Secondary (missile) damage was observed in 12 of the 14 animals. This was from glass that either had nicked or penetrated the skin or had reached deeper tissues. Rarely did nonpenetrating missiles cause bruising.

14. In the 12 injured animals, 270 wounds were observed, of which 22 were judged serious using the arbitrary criteria that any penetration in tissue to, or in excess of, $10 \mathrm{~mm}$ or to bone constituted a serious wound. Thus, on the average, for every 12 wounds there was one serious injury.

15. Some of the more notable injuries included the laceration of a scrotum and evisceration of a testicle, a circumrectal incision exposing the rectal sphincter, four small fractures of bone including a fracture of a canine tooth, a perforation of the face into the nasal cavity, a severing of the anterior group of extensor tendons of the foreleg in one animal, and a through and through penetration of a leg $(38 \mathrm{~mm})$.

16. Observed total and serious wounds were assessed as a function of the incident overpressure as measured at NTS. The data concerning the dogs located in the houses at $3.8 \mathrm{psi}$ appeared to be inconsistent with all other observations but became consistent when it was as sumed that the computed reflected overpressure and associated winds were responsible for missile formation and behavior.

17. Total and serious wounds per square foot of biologic target were presented as a function of the incident overpressure normalized to sea-level conditions assuming reflection as might occur at the wall of a house facing the source of detonation. Regression equations with standard error of the estimates were presented and compared with similar data showing recovered missiles per square foot of missile-absorber.

18. Expected intraperitoneal wounds per square foot of biologic target and per animal were predicted from laboratory information available from other studies defining the probability of glass missiles penetrating the abdominal wall of dogs to reach the peritoneal cavity in terms of missile mass and impact velocity combined with data from the present study relevant to the presenting area of the animals and also giving the mass and velocity of each individual missile.

19. A total of 21.7 intraperitoneal wounds were predicted compared with a total of 22 observed serious wounds, indicating that the criterion for observed serious wounds was near that required for intraperitoneal wounds.

20. Because the predicted and observed data showed rather large variations in the 11 individual cases available, further analysis was undertaken which revealed that the predictions from the Series A data were about 43 and 78 per cent too high and too low for the higher and the lower overpressures, respectively. These discrepancies suggest that the missile traps above the animals were not sampling the missile environment adequately.

21. A similar analysis employing Series B data (that from traps located, as were the dogs, just above grade) improved the prediction potential considerably. The predicted figures were only 11 per cent above the observed at the higher overpressures and 44.2 per cent below the observed at the lower overpressures. These differences were not significant statistically.

22. Comparison of Series A and B predictions for six comparable window-glass missile stations located in the open showed the increased reliability of the Series B missile information: the Series A data were 39 per cent too high, and Series B figures were 2 per cent too low. Thus the Series B data demonstrate the feasibility of using missile trapping and related analytical techniques for assessing biologic hazard.

23. The relation of the observed primary blast effects involving damage to the lung, middle ear, and sinuses to the measured pressure-time variations was set forth, and the fact that 
an incident overpressure between 8 and 9 psi was associated with significant lung hemorrhage in a geometry where reflection to between 21 and 22 psi probably took place was noted as the lowest free-field incident overpressure known to damage the lung in full-scale nuclear tests.

24. Many factors regarding the reliability of the missile-trapping technique and the association of the environmental data so obtained with biologic hazard in animals and man were discussed along with a number of relevant findings in the literature bearing upon both the primary and secondary facets of modern blast biology. 